\author{
UNIVERSIDADE DE SÃO PAULO \\ INSTITUTO DE FÍSICA DE SÃO CARLOS \\ INSTITUTO DE QUÍMICA DE SÃO CARLOS \\ ESCOLA DE ENGENHARIA DE SÃO CARLOS
}

RAFAELA CRISTINA SANFELICE

SÍNTESE E FABRICAÇÃO DE FILMES FINOS DE COPOLÍMEROS
CONTENDO AZOBENZENOS PARA SUPERFÍCIES HIDROFÓBICAS

SÃO CARLOS

2010 

RAFAELA CRISTINA SANFELICE

\section{SÍNTESE E FABRICAÇÃO DE FILMES FINOS DE COPOLÍMEROS CONTENDO AZOBENZENOS PARA SUPERFÍCIES HIDROFÓBICAS}

Dissertação apresentada ao Programa de PósGraduação Interunidades em Ciência e Engenharia de Materiais, da Universidade de São Paulo, para obtenção do título de Mestre em Ciência e Engenharia de Materiais.

Área de Concentração: Desenvolvimento, Caracterização e Aplicação dos Materiais.

Orientador: Prof. Dr. Osvaldo Novais de Oliveira Jr.

São Carlos 
AUTORIZO A REPRODUÇÃO E DIVULGAÇÃO TOTAL OU PARCIAL DESTE TRABALHO, POR QUALQUER MEIO CONVENCIONAL OU ELETRÔNICO, PARA FINS DE ESTUDO E PESQUISA, DESDE QUE CITADA A FONTE.

Sanfelice, Rafaela Cristina

Síntese e fabricação de filmes finos de copolimeros contendo azobenzenos para superficies hidrofóbicas/ Rafaela Cristina Sanfelice; orientador Osvaldo Novais de Oliveira Junior - São Carlos, 2010.

$106 \mathrm{p}$.

Dissertação (Mestrado - Programa de Pós-Graduação Interunidades em Ciência e Engenharia de Materiais. Área de Concentração: Desenvolvimento, Caracterização e Aplicação de Materiais) - Escola de Engenharia de São Carlos, Instituto de Física de São Carlos, Instituto de Química de São Carlos da Universidade de São Paulo.

1. Azopolímeros. 2. Filmes de Langmuir-Blodgett (LB). 3. Superficies superhidrofóbicas. I. Título. 


\section{FOLHA DE APROVAÇĀO}

Rafaeia Cristina Sanfelice

Dissertaçlo apresentada ao Programa de Pós-Graduaço em Ciéncia e Engenharia de Materiais da Universidada de Sso Paulo para obtençào do bitulo de Mestre em Cxencia e Engenharia de Materiais. Area de Concentracac Desenvolvimento, Caracterizasab e Aplcacbo de Materiais.

Aprowado(a) em 07.07 .2010

Comissto Julgadora

Prof(a). Dr(a): Osvaldo Nowais de Olhweira Junior Inatituicho: IFSCrUSP Assinatura

Prof(a), Dr(a) Antonio Aprigio da Silva Curvelo insticuiplo: IOSCrUSP Assinatura

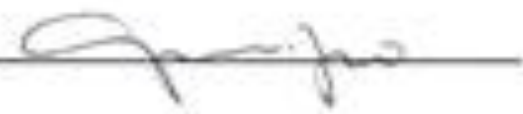
Prof(a). Dr(a). Antonio Carlos Bender Burtoloso
instituigbo: iQScrusp Assinatura 

DEDICATÓRIA

Dedico esse trabalko aos meus pais Pedro e Vera, e aos meus irmãos Mariana e Jiago. 



\section{AGRADECIMENTOS}

Agradeço primeiramente a Deus pela minha vida e por tudo o que Ele tem me proporcionado.

Á Fapesp pelo apoio financeiro.

Ao meu orientador Chu, agradeço por todos esses anos de orientação, dedicação e confiança.

Á Débora e ao Felippe, pela paciência, dedicação e todos os ensinamentos que tanto contribuíram para o meu crescimento.

Ao Marcos e ao Cleber pela colaboração e paciência nesse trabalho.

Aos meus queridos pais Pedro e Vera por serem os meus exemplos de vida, e minha fonte inesgotável de amor, carinho e compreensão.

Á minha irmã Mariana pelos cuidados e preocupação, e por sempre estar ao meu lado.

Ao meu irmão Tiago por ser meu eterno companheiro, com quem eu posso sempre contar.

Á Lara e ao Guilherme por serem mais que primos, uma junção de irmãos e amigos, sendo sempre as minhas "estrelinhas".

Aos meus avós Arquimedes e Assunta que, onde quer que estejam, sempre estarão em minha memória e em meu coração.

Á minha avó Julia, pelo carinho, amor e bolinhos de fubá.

A todas as pessoas da minha família, padrinhos, tios e primos, que sempre me apoiaram.

Ao meu namorado Renan pelo amor, carinho, companheirismo e por me ajudar e me apoiar na realização desse trabalho.

Á minhas amigas de longa data Ladi e Gabi, que mesmo estando longe, sempre se fazem presente, e cuja presença é de grande importância em minha vida.

Aos meus amigos Leandro, Luiza e Natália pelo carinho e pelo "clubinho" que proporciona muitas horinhas de boa conversa. Ao Viet pela amizade "muito Loka", e á Tati por compartilhar as dificuldades das disciplinas.

Ao Rafa por ser um grande amigo e estar sempre muito presente em minha vida.

Á Vanessa por esses anos de companheiros dentro e fora do trabalho, pela amizade e por todo carinho e preocupação.

Á Thatyane pela amizade, carinho, conselhos e todos os cuidados concedidos.

Ao Rafa pela colaboração, carinho e amizade. 
Á Adriana e ao Guido pelo carinho e paciência.

Ao Níbio pela "mãozinha" no laboratório, carinho e conselhos que muito me ajudaram.

Aos amigos do grupo de Polímeros Bernhard Gross, em especial aos amigos da minha sala Ângelo, Josi, Júnior, Marcos e Thiers pelo convívio e distrações.

Aos técnicos Ademir e Bertho, e as secretárias Rosângela e Simone por todo o apoio. 


\section{RESUMO}

SANFELICE, R. C. Síntese e fabricação de filmes finos de copolímeros contendo azobenzenos para superfícies hidrofóbicas. 2010. 106p. Dissertação (Mestrado em Ciência e Engenharia de Materiais) - Instituto de Física de São Carlos, Instituto de Química de São Carlos, Escola de Engenharia de São Carlos, Universidade de São Paulo, São Paulo, 2010.

A funcionalização de materiais poliméricos para a produção de superfícies superhidrofóbicas é importante para uma série de aplicações, principalmente as associadas com superfícies autolimpantes e anti-aderentes. Uma abordagem para obter superhidrofobicidade é combinar polímeros hidrofóbicos com outros materiais passíveis de ser microestruturados. Neste estudo, copolímeros hidrofóbicos foram sintetizados através de polimerização radicalar convencional usando os monômeros 2,2,3,3,4,4,5,5 octafluorpentil metacrilato (OFPMA) ou 2,2,2 trifluoretil metacrilato (TFEMA) copolimerizado com o azo monômero 4'-[N-etil-N-(2metacriloxi-etil)]amino-4-nitro-azobenzeno (DR13-MA) em proporções distintas. A polimerização foi bem sucedida, apresentando massas molares acima de $10.000 \mathrm{~g} / \mathrm{mol}$, com uma polidispersividade relativamente baixa. Os copolímeros e homopolímeros, derivados de OFPMA e TFEMA - usados para comparação - tiveram sua estrutura confirmada através de espectroscopia no infravermelho (FTIR) e ressonância magnética nuclear (RMN). A proporção de azo monômero incorporada foi estimada por RMN e espectroscopia no UV-vis e foram condizentes com a relação utilizada, ou seja, 10, 20 e 30\% em massa. Foram formados filmes de Langmuir estáveis dos copolímeros na interface ar / água, cuja isoterma de pressão superficial apresentou transição de fase provavelmente atribuída a um rearranjo molecular. O potencial de superfície dos filmes dos copolímeros foi negativo, o que indica que os átomos de flúor estavam direcionados para o ar. Esta organização molecular foi mantida após a transferência de filmes sobre substratos sólidos na forma de filmes Langmuir-Blodgett (LB), formando superfícies hidrofóbicas com ângulos de contato próximos de $90^{\circ}$ para todos os copolímeros, independentemente do número de camadas depositadas. A natureza organizada dos filmes LB não contribuiu para a hidrofobicidade, pois o ângulo de contacto é semelhante ao obtido com filmes cast. Grades de relevo foram inscritas nos filmes cast, mas o ângulo de contato não foi afetado significativamente. Portanto, uma otimização na inscrição de nanoestruturas será necessária para se alcançar a superhidrofobicidade.

Palavras-chave: Azopolímeros. Filmes de Langmuir-Blodgett(LB). Superfície hidrofóbica. 



\begin{abstract}
SANFELICE, R. C. Synthesis and fabrication of thin films of copolymer contains azobenzene for hydrophobic surface. 2010. 106 p. Dissertação (Mestrado em Ciência e Engenharia de Materiais) - Instituto de Física de São Carlos, Instituto de Química de São Carlos, Escola de Engenharia de São Carlos, Universidade de São Paulo, São Paulo, 2010.

The functionalization of polymer materials to produce superhydrophobic surfaces is an important goal for a number of applications, especially those associated with self-cleaning and anti-adherent surfaces. A possible approach to achieve superhydrophobicity is to combine hydrophobic polymers with other materials amenable to be microstructured. In this study, hydrophobic copolymers were synthesized through conventional radicalar polymerization using the monomers 2,2,3,3,4,4,5,5 octafluorpenthyl methacrylate (OFPMA) or 2,2,2 trifluorethyl methacrylate (TFEMA) copolymerized with the azomonomer 4'-[N-ethyl-N(2methacryloxy-ethyl)]amine-4-nitrobenzene methacrylate (DR-13MA) in distinct proportions. Polymerization was successful leading to molar masses above 10,000 g/mol, with a relatively low polydispersity. The copolymers and the homopolymers from OFPMA and TFEMA - used for comparison - had their structure confirmed with Fourier transform infrared (FTIR) spectroscopy and nuclear magnetic resonance (NMR) measurements. The proportion of azomonomer incorporated estimated via NMR was consistent with that determined with UV-vis. spectroscopy for the relative concentrations used, namely 10, 20 and $30 \%$ in mass. The copolymers formed stable Langmuir films at the air/water interface, whose surface pressure isotherms featured a phase transition probably associated with molecular rearrangement. The surface potential of the condensed copolymer Langmuir films was negative, which indicates that the fluorine atoms were directed toward the air. This molecular organization was maintained upon film transfer onto solid substrates in the form of LangmuirBlodgett (LB) films, leading to hydrophobic surfaces with contact angles close to $90^{\circ}$ for both copolymers, which did not depend on the number of layers deposited. The organized nature of the LB films did not contribute to the hydrophobicity, however, as similar contact angles were measured for the cast films made with the copolymers. Surface-relief gratings could be inscribed on the cast films, but the contact angle was not affected significantly. Therefore, an optimization in the inscription of such nanostructures will be required for achieving superhydrophobicity.
\end{abstract}

Keywords: Azopolymers. Langmuir-Blodgett(LB) films. Hydrophobic surface. 



\section{LISTA DE FIGURAS}

Figura 1-Fotoisomerização trans-cis-trans do azobenzeno

Figura 2-Ilustração da inscrição de grades de relevo em uma superfície. Retirada da referência

14.

Figura 3-Imagem de uma superfície autolimpante

Figura 4-Imagens de uma gota em uma superfície lisa (à esquerda) e em uma superfície rugosa (à direita). Retirada da referência 17.

Figura 5-Ilustração dos possíveis tipos de copolímeros com os monômeros "A" e "B".

Figura 6-Ilustração da interação entre moléculas na superfície e no interior do líquido

Figura 7-Esquema geral da cuba de Langmuir, que contém uma cuba de Teflon, com barreiras moveis. Medidores de pressão e potencial de superfície e um dipper para emersão e retirada do substrato.

Figura 8-Isoterma de pressão de superfície para o ácido esteárico, e ilustração da estruturação das moléculas no filme durante a compressão. $(\bullet)$ cabeça hidrofóbica e $(\mid)$ cauda hidrofóbica.

Figura 9-Modelo de Demchak e Fort tratando-se o filme como um capacitor de 3 camadas. 35

Figura 10-Tipos de filme LB que podem ser depositados. 36

Figura 11-Ilustração das tensões envolvidas na medida do ângulo de contato entre uma gota de um líquido e uma superfície sólida.

Figura 12-Estrutura química do monômero azo DR13MA (1), dos monômeros fluorados (OFPMA)(2) e (TFEMA)(3) utilizados na síntese dos copolímeros contendo como grupo azobenzênico o corante DR13 (4 e 5).

Figura 13-Esquema simplificado do aparato experimental para a formação de grades de Relevo (14)

Figura 14-Espectros UV-Vis dos monômeros com concentração conhecida .46

Figura 15-Curva de calibração obtida a partir dos espectros de UV-Vis dos monômeros com concentração conhecida 
Figura 16-Espectros UV-Vis dos copolímeros TFEMA-co-DR13MA.................................................48

Figura 17-Espectros UV-Vis dos copolímeros OFPMA-co-DR13MA ….........................................48

Figura 18-Curva de distribuição de Massa Molecular mostrando os quatro valores médios

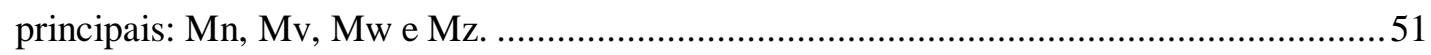

Figura 19-Distribuição de massas molares dos polímeros com o mero TFEMA, obtida por SEC........52

Figura 20-Distribuição de massas molares dos polímeros contendo o mero OFPMA, obtidas por SEC.

Figura 21-Espectro de Infravermelho do homopolímero HPTFEMA e dos copolímeros

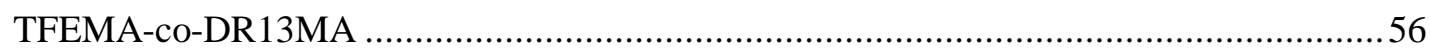

Figura 22-Espectro de FTIR do monômero DR13MA …….............................................................58

Figura 23-Espectros de Infravermelho do homopolímero HPOFPM e dos copolímeros OFPMAco-DR13MA 59

Figura 24-Estrutura dos polímeros TFEMA-co-DR13MA ….......................................................61

Figura 25-Espectro de RMN $\mathrm{H}^{-1}$ dos polímeros TFEMA-co-DR13MA..............................................61

Figura 26-Estrutura dos polímeros OFPMA-co-DR13MA .........................................................63

Figura 27-Espectro de RMN $\mathrm{H}^{-1}$ dos polímeros OFPMA-co-DR13MA.............................................63

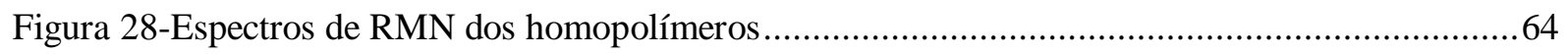

Figura 29-Curvas de DTG e TGA dos copolímeros TFEMA-co-DR13MA e dos homopolímeros

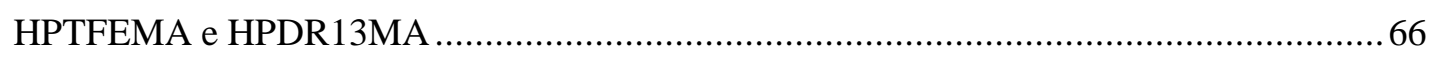

Figura 30-Curvas de DTG e TGA dos copolímeros OFPMA-co-DR13MA e dos homopolímeros HPOFPMA e HPDR13MA 68

Figura 31-Curvas de DSC dos copolímeros TFEMA-co-DR13MA(10\%), TFEMA-coDR13MA(20\%), TFEMA-co-DR13MA(30\%), e dos homopolímeros HPTFEMA e HPDR13MA.

Figura 32- Curvas de DSC dos copolímeros TFEMA-co-DR13MA(10\%), TFEMA-coDR13MA(20\%), TFEMA-co-DR13MA(30\%), e dos homopolímeros HPTFEMA e HPDR13MA

Figura 33-Fotos dos filmes cast dos copolímeros. 
Figura 34-Espectros de UV-vis dos filmes cast.

Figura 35-Filmes cast com grades de relevo

Figura 36-Isoterma de pressão vs. Área por molécula do homopolímero HPDR13MA .74

Figura 37-Fotos da superfície do filme de Langmuir do HPDR13 com o microscópio no ângulo de Brewster 75

Figura 38-Isoterma de pressão vs. área por mero do homopolímero HPTFEMA 76

Figura 39-Fotos da superfície do filme de Langmuir do HPTFEMA com o microscópio no ângulo de Brewster .78

Figura 40-Isoterma de pressão vs. área por molécula do homopolímero HPOFPMA .79

Figura 41-Fotos da superfície do filme de Langmuir do HPOFPMA com o microscópio no ângulo de Brewster

Figura 42-Isoterma de pressão vs. área por molécula do copolímero TFEMA-coDR13MA(10\%)

Figura 43-Isoterma de pressão vs. Área por molécula do copolímero TFEMA-coDR13MA(20\%) .82

Figura 44-Fotos da superfície do filme de Langmuir com microscópio no ângulo de Brewster 83

Figura 45-Espectro de Infravermelho por transmissão dos filmes LB do copolímero TFEMA-co$\operatorname{DR} 13 \mathrm{MA}(20 \%)$

Figura 46-Espectro de Infravermelho por reflexão dos filmes LB do copolímero TFEMA-coDR13MA(20\%) .86

Figura 47-Esquema do tipo de deposição realizada nos copolímeros .87

Figura 48-Espectros de UV-Vis dos filmes LB e suas respectivas curvas de absorbância por número de camada do copolímero TEMDR13(20\%)

Figura 49-Dependência linear do ângulo de contato com o número de camadas .90

Figura 50-Isoterma de pressão vs. área por molécula do copolímero TFEMA-coDR13MA(30\%)

Figura 51-Isoterma de pressão vs. área por molécula do copolímero OFPMA-coDR13MA(10\%) 
Figura 52-Isoterma de pressão vs. área por molécula do copolímero OFPMA-co-

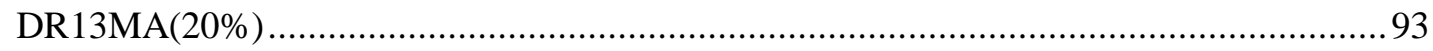

Figura 53-Fotos da superfície do filme de Langmuir do TFEMA-co-DR13MA(20\%) com o microscópio no ângulo de Brewster

Figura 54-Espectro de Infravermelho por transmissão dos filmes LB do copolímero OFPMAco-DR13MA(20\%)

Figura 55-Espectros de Infravermelho no modo de reflexão dos filmes LB, depositados em ouro, do copolímero OFPMA-co-DR13MA(20\%)

Figura 56-Espectros de UV-Vis dos Filmes LB e suas respectivas curvas de absorbância por número de camada do copolímero OFPMA-co-DR13MA(20\%)

Figura 57-Isoterma de pressão vs. área por molécula do copolímero OFPMA-coDR13MA(30\%) 


\section{LISTA DE TABELAS}

Tabela 1-Condições reacionais das polimerizações

Tabela 2-Proporção de azo monômero incorporado na molécula, determinada por UV-Vis

Tabela 3-Valores de massas molares e polidispersividades dos copolímeros contendo o mero

TFEMA.

Tabela 4-Valores de massas molares e polidispersividade dos polímeros contendo o mero OFPMA

Tabela 5-Atribuições das principais bandas de FTIR .57

Tabela 6-Atribuições das principais bandas de FTIR

Tabela 7-Proporção em massa de azo monômero incorporado na molécula determinado por RMN H ${ }^{-1}$

Tabela 8-Proporção em massa de azo monômero incorporado na molécula determinado por $\mathrm{RMN} \mathrm{H}^{-1}$

Tabela 9-Valores de temperatura e \% de resíduo final obtidos por TGA dos homopolímeros HPTFEMA e HPDR13MA e dos copolímeros TFEMA-co-DR13MA.

Tabela 10-Valores de temperatura e \% de resíduo final obtidos por TGA dos homopolímeros HPOFPMA e HPDR13MA e dos copolímeros OFPMA-co-DR13MA.

Tabela 11-Ângulo de contato dos filmes cast dos copolímeros

Tabela 12-Relação dos filmes LB para o composto TFEMA-co-DR13MA(20\%). .84

Tabela 13-Ângulos de contato dos filmes LB em vidro do copolímero TFEMA-coDR13MA(20\%)

Tabela 14-Ângulos de contato dos filmes LB em vidro do copolímero OFPMA-coDR13MA(20\%) 



\section{SUMÁRIO}

Apresentação

Objetivos

1 Introdução.

1.1 Polímeros Fluorados.

1.2 Azopolímeros 23

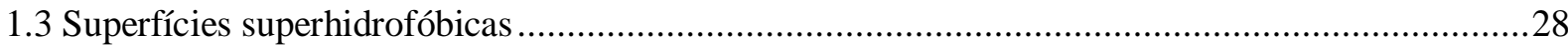

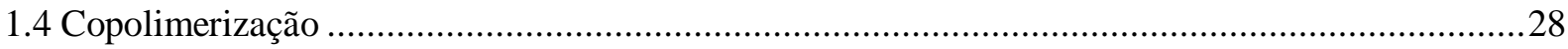

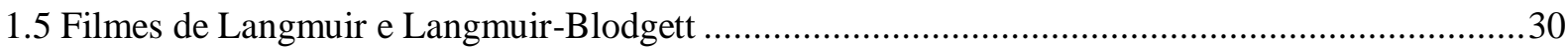

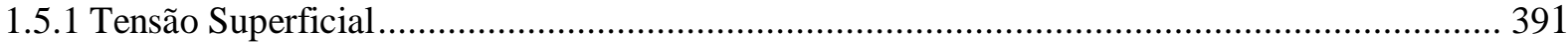

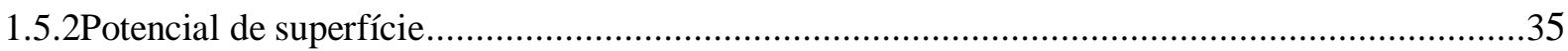

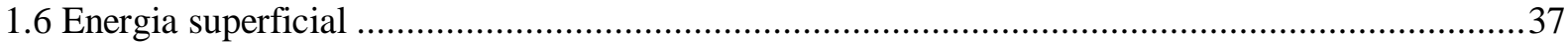

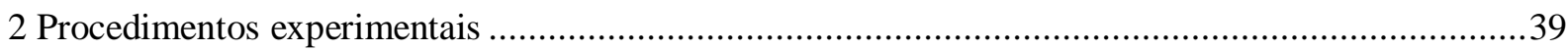

2.1 Síntese e caracterização dos homopolímeros e copolímeros ..........................................................39

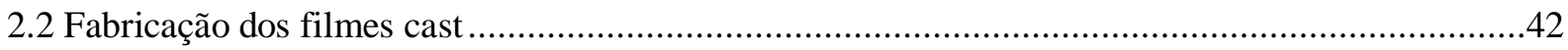

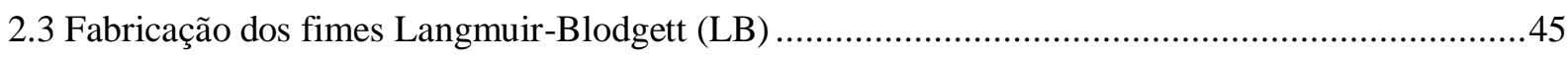

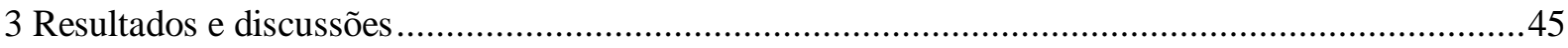

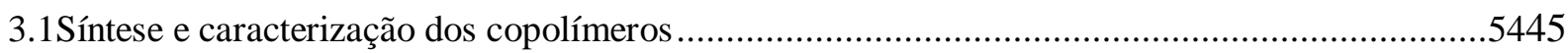

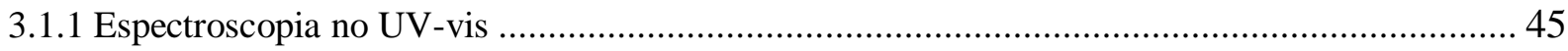

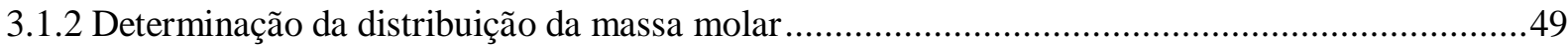

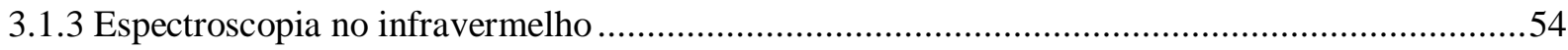

3.1.4 Espectrometria de ressonância magnética de hidrgênio ..............................................................60

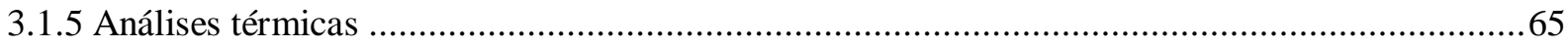




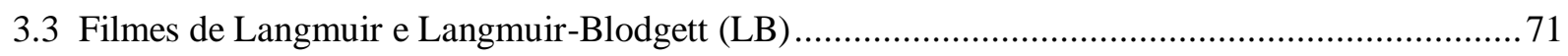

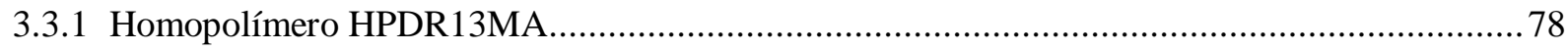

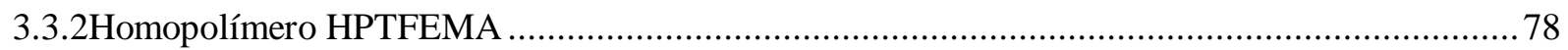

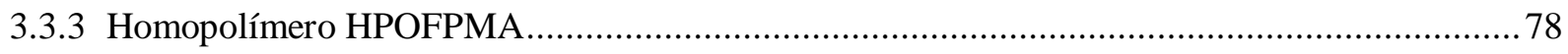

3.3.4 Copolímero TFEMA-co-DR13MA(10\%) .......................................................... 81

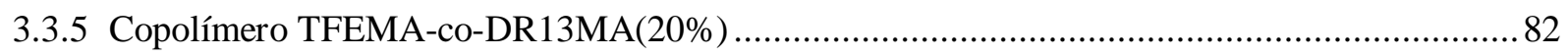

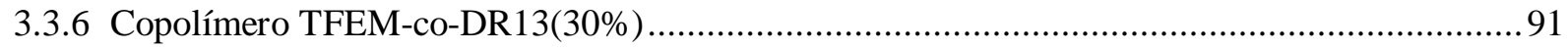

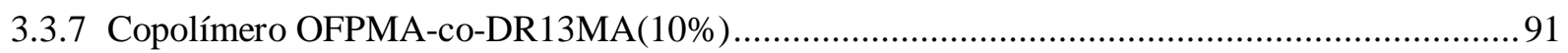

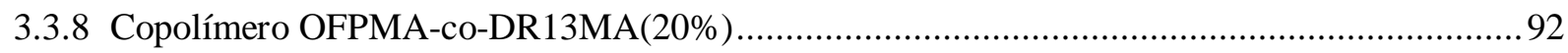

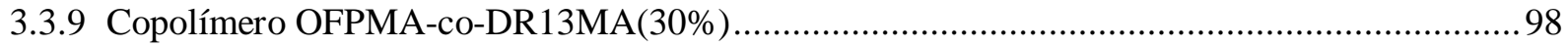

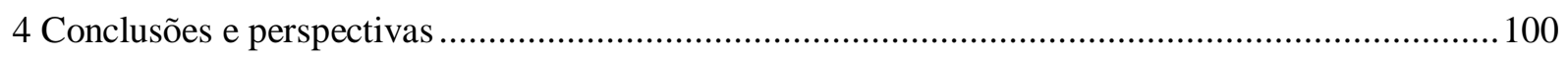

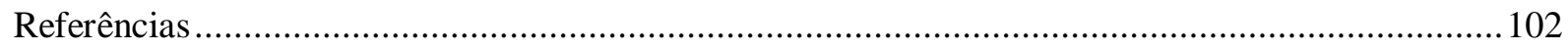




\section{Apresentação}

A superfície sempre limpa das flores de lótus inspirou cientistas na busca de materiais que possibilitassem obter superfícies similares, autolimpantes e naturalmente repelentes à água. Observou-se que a hidrofobicidade das pétalas das flores era conferida por microestruturas que dificultam a fixação das moléculas de água, que deslizam pela superfície das pétalas arrastando impurezas ali presentes. Este trabalho focalizou a síntese de polímeros com potencial para obter superfícies superhidrofóbicas, com características parecidas com as das flores de lótus. Para isso utilizaram-se copolímeros contendo monômeros azobenzênicos e fluorados. Os polímeros fluorados já são usados em superfícies hidrofóbicas, como o Teflon, enquanto os azocompostos têm caráter hidrofílico, mas podem ter sua superfície microestruturada. A copolimerização desses dois tipos de monômeros visou então à união de materiais com características hidrofóbicas e que permitissem microestruturação em filmes finos.

Esta dissertação foi dividida em 4 capítulos. O primeiro é introdutório, em que são discutidos os principais tópicos para o desenvolvimento do trabalho, incluindo as características dos compostos usados e os conceitos de técnicas para fabricar e analisar materiais. O capítulo 2 mostra os detalhes experimentais das sínteses e descreve os aparatos experimentais para formar e caracterizar os filmes finos. No capítulo 3 estão descritos os resultados das sínteses, com a caracterização dos materiais, e a formação dos filmes e sua aplicação em superfícies microestruturadas. As conclusões e perspectivas para trabalhos futuros são apresentadas no Capítulo 4. 


\section{Objetivos}

O objetivo deste trabalho de mestrado foi sintetizar copolímeros com unidades fluoradas e outras contendo grupos azobenzênicos para obter superfícies hidrofóbicas e que possam vir a se tornar superhidrofóbicas.

\section{Introdução}

\subsection{Polímeros fluorados}

Polímeros fluorados apresentam ligações C-F substituindo ligações C-H de hidrocarbonetos, tendo como principais características a alta estabilidade térmica, hidrofobicidade, lipofobicidade, alta resistência química e baixa força de atração intermolecular, em comparação com os hidrocarbonetos similares. Grande parte dessas características é devida aos átomos de flúor, dentre elas o alto potencial de ionização, conferindo caráter iônico à ligação carbono-flúor, maior força de ligação e estabilidade térmica, alta eletronegatividade e baixa polarizabilidade. $\mathrm{O}$ alto potencial de ionização, combinado com a baixa polarizabilidade, leva a interações intermoleculares fracas, com energia superficial e índice de refração baixos. Por isso, os per fluorados podem ser usados em superfícies antiaderentes e não molháveis com baixa energia superficial ${ }^{(1)}$, como é o caso do Teflon, muito empregado em recipientes repelentes à água.

\subsection{Azopolímeros}

Azo compostos são organo-nitrogenados com uma dupla ligação R-N=N-R', em que R e R' podem ser grupos alifáticos ou aromáticos. A dupla ligação afeta a estereoquímica da 
molécula, proporcionando mais rigidez e restrição no número de formas possíveis. É também responsável pela coplanaridade dos átomos adjacentes à ligação dupla e dos átomos de nitrogênio ${ }^{(2)}$. Os azocompostos aromáticos apresentam cores vivas, especialmente vermelha, alaranjada e amarela, sendo chamados de azo corantes e usados como pigmentos na indústria química. Essa pigmentação é conseqüência da deslocalização do orbital $\Pi$ da dupla ligação entre os nitrogênios e os anéis aromáticos e seus substituintes. Os compostos azoaromáticos, incluindo o usado neste trabalho (Corante vermelho disperso 13, Disperse Red 13 (DR13)), são geralmente estáveis. Quando expostos à luz, têm o momento de dipolo alterado devido à isomerização da forma trans (E), mais estável em condições ambientes de temperatura e iluminação, para a forma cis $(\mathrm{Z})$, de mais alta energia ${ }^{(3)}$. Esse processo pode ocorrer com conversão cis-trans e trans-cis fotoquímicas e a cis-trans térmica ${ }^{(4)}$.

Sob incidência de luz visível e ultravioleta, ocorrem duas transições eletrônicas principais nos azo corantes. Para o azobenzeno, mostrado na figura 1, essas transições eletrônicas são: i) $n \rightarrow \pi^{*}$ em $450 \mathrm{~nm}$, e ii) dos elétrons $\pi$ conjugados da molécula para orbitais $\pi$ antiligantes $\pi \rightarrow \pi^{*}$, em $330 \mathrm{~nm}$. A fotoisomerização nos azobenzenos, que pode ocorrer pelos mecanismos de rotação ou inversão, se dá quando a luz incidida apresenta comprimento de onda ressonante com a banda de absorção. Por rotação, a isomerização envolve a transição dos elétrons $\pi$ conjugados da molécula para o orbital antiligante $\pi^{*}$. Isso possibilita que os anéis benzênicos troquem suas posições relativas, uma vez que, com essa transição eletrônica, a ligação entre os nitrogênios passa a ser simples. Na isomerização por inversão, os elétrons não ligantes (n) são excitados para o orbital $\pi$ antiligante, permitindo uma re-hibridização do orbital $\mathrm{sp}^{2}$ do nitrogênio, variando o ângulo entre as ligações azo e N-C, e possibilitando a troca das posições dos anéis ${ }^{(5,6)}$. 


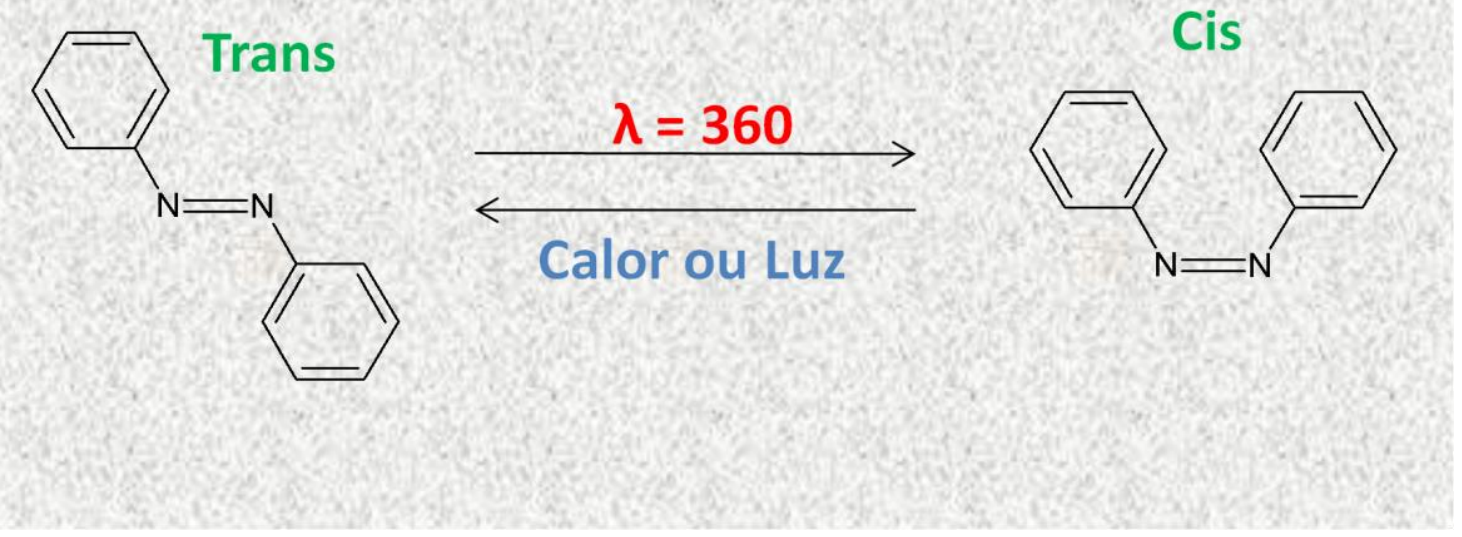

Figura 1-Fotoisomerização trans-cis-trans do azobenzeno

Essa capacidade de fotoisomerização possibilita a escrita de grades de relevo na superfície do material. A formação dessas grades foi primeiramente observada em 1992 e publicada em 1995 por Kim et al., ${ }^{(7)}$ e hoje é amplamente usada, não somente em materiais amorfos, mas também em materiais líquido-cristalinos, em que se estuda a sua formação em filmes cast, spin-coated, Langmuir-Blodgett (LB) ${ }^{(8)}$ e automontados (layer-by-layer, LbL) ${ }^{(9-}$ 11). Em compostos contendo azocromóforos é utilizado o mecanismo de transporte de massa fotoinduzido para a inscrição das grades de relevo na superfície, sendo pré-requisito a fotoisomerização trans-cis-trans ${ }^{(12)}$. Em outros corantes que também se isomerizam, não foi possível inscrever grades por esse método, pois o movimento molecular causado pela fotoisomerização não é tão eficiente quanto o apresentado pelos azocromóforos ${ }^{(13)}$.

Na figura 2 é mostrada imagem de microscopia de força atômica de uma grade de relevo na superfície de um material contendo grupos azo benzênicos ${ }^{(14)}$. As partes mais altas da figura representam regiões não iluminadas, porque ocorre um transporte de massa dos cromóforos e cadeias do polímero para essas regiões. Esse processo é altamente dependente da polarização do laser de escrita, sendo que a força responsável pelo movimento tem a direção dada pelo produto escalar do gradiente do campo elétrico (da iluminação pelo laser) com o campo elétrico. Portanto, nos vales observa-se um excesso de moléculas com cromóforos perpendicularmente orientados em relação à direção de polarização do campo elétrico. Nos picos das grades, os cromóforos devem ser orientados preferencialmente ao longo da direção de polarização ${ }^{(14)}$. 


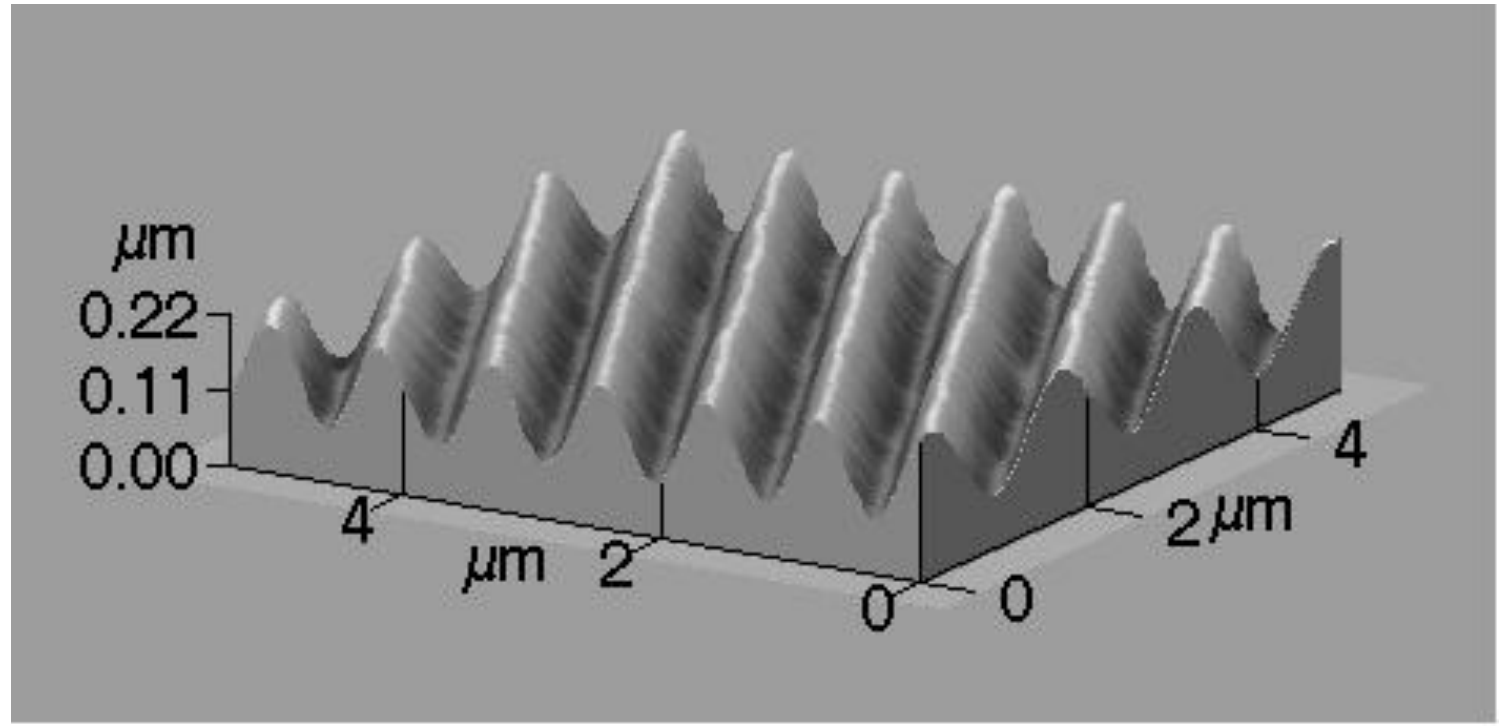

Figura 2-Ilustração da inscrição de grades de relevo em uma superfície. Retirada da referência 14.

\subsection{Superfícies superhidrofóbicas}

É crescente o interesse em superfícies superhidrofóbicas, que podem se tornar autolimpantes e mais resistentes à corrosão, já que esta é facilitada pela presença de água. A busca por superhidrofobicidade é inspirada nas flores de Lótus, cujas superfícies ficam sempre limpas por serem naturalmente repelentes à água, como mostra a figura 3. As gotas escorrem pelas folhas e carregam consigo os grãos de poeira que possam ali estar. Essa característica se deve à microestrutura dos nódulos das folhas das plantas, que não oferecem superfície suficiente para a água se espalhar, fazendo com que ela se contraia em gotas e role sobre a superfície ${ }^{(15)}$. Para uma superfície ser considerada superhidrofóbica, o ângulo de contato com uma gota de água tem que ser maior que 150 graus ${ }^{(16)}$. 


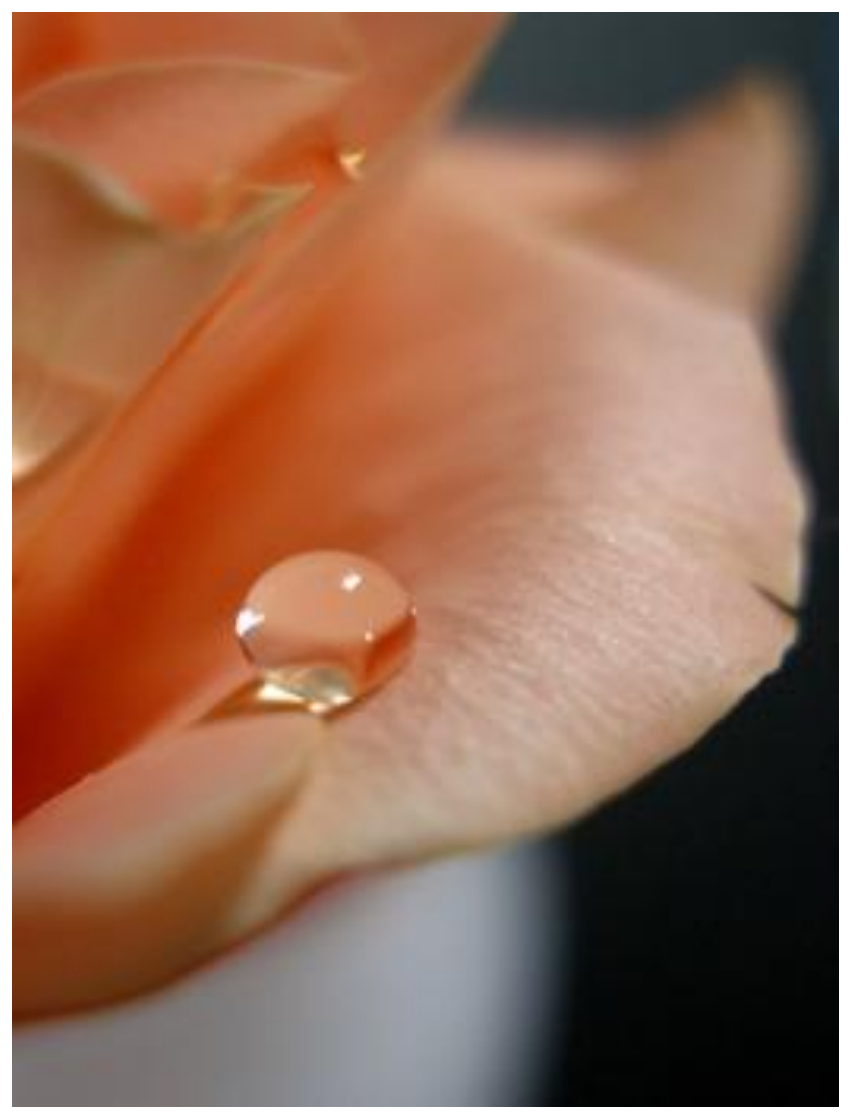

Figura 3-Imagem de uma superfície autolimpante

Superfícies superhidrofóbicas podem ser produzidas em duas etapas, que consistem em criar uma estrutura hidrofóbica (com ângulo de contato superior a 90) e então modificar a superfície, por exemplo criando rugosidades ou microestruturas como as grades de relevo. Para se obter superfície superhidrofóbica é necessário que a distância entre os picos da microestrutura seja tal que faça com que a gota de água não consiga se apoiar na superfície, facilitando o seu escoamento, arrastando eventuais sujeiras. A figura 4 mostra duas imagens de ângulos de contato $(\mathrm{AC})$ de uma superfície com a água. Na fotografia à esquerda tem-se uma superfície lisa (AC de aproximadamente $111^{\circ}$ ), e na direita uma superfície rugosa (AC de aproximadamente $\left.162^{\circ}\right)^{(17)}$. 


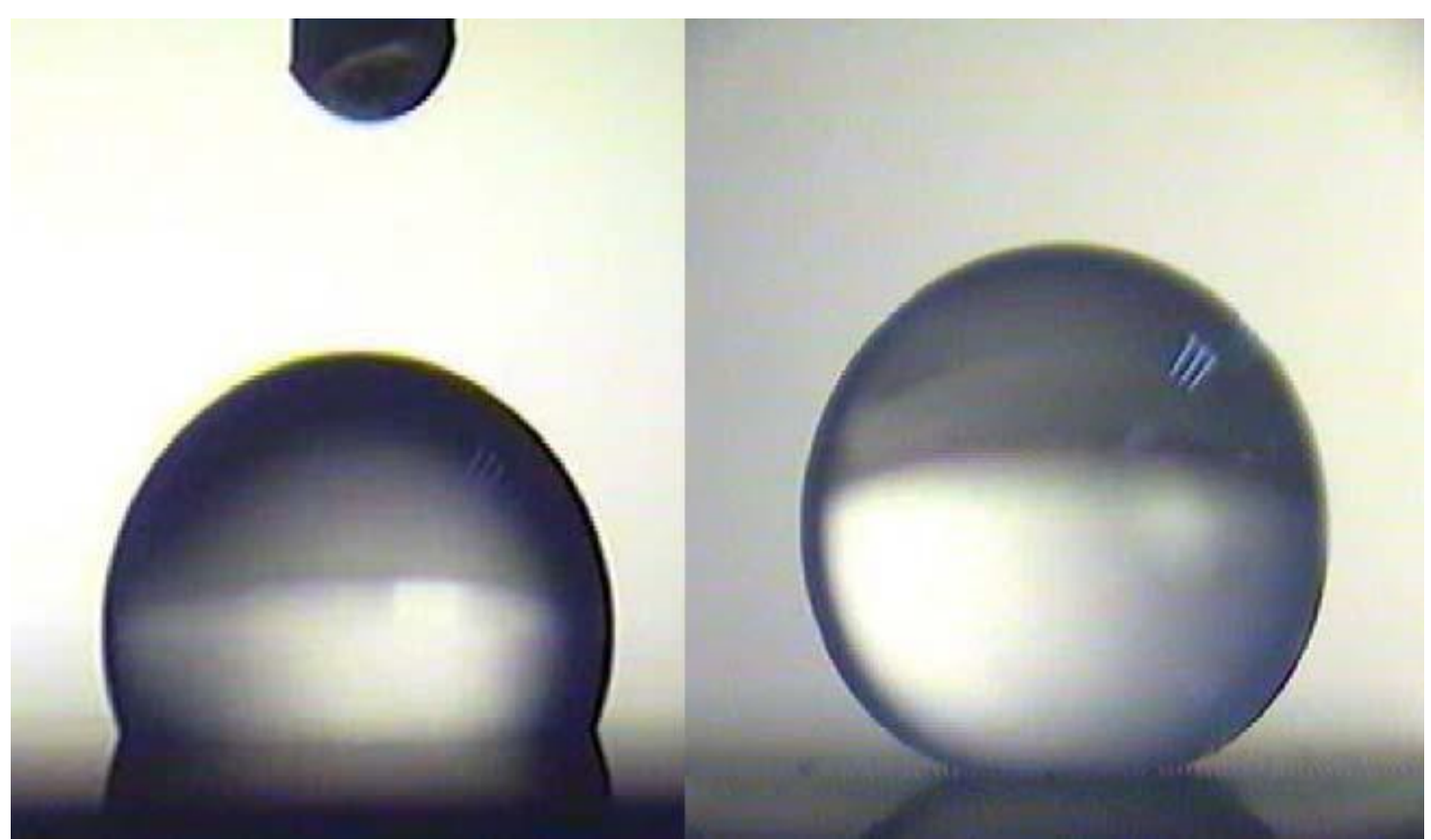

Figura 4-Imagens de uma gota em uma superfície lisa (à esquerda) e em uma superfície rugosa (à direita). Retirada da referência 17.

\subsection{Copolimerização}

Copolímeros têm mais de um mero diferente na cadeia polimérica e a reação de polimerização que dá origem a eles é chamada de copolimerização ${ }^{(18)}$. Podem ser classificados em função do modo de distribuição dos meros na cadeia polimérica, em quatro tipos, mostrados na figura 5:1) alternados, onde os diferentes meros se dispõem de maneira alternada; 2) aleatórios em que não há sequência definida dos meros; 3) em bloco onde se formam grandes sequências (blocos) de um dado mero alternando-se com grandes sequências de outro mero; e 4) enxertados em que sobre a cadeia de um homopolímero ocorre a ligação de outra cadeia polimérica ${ }^{(19)}$. 


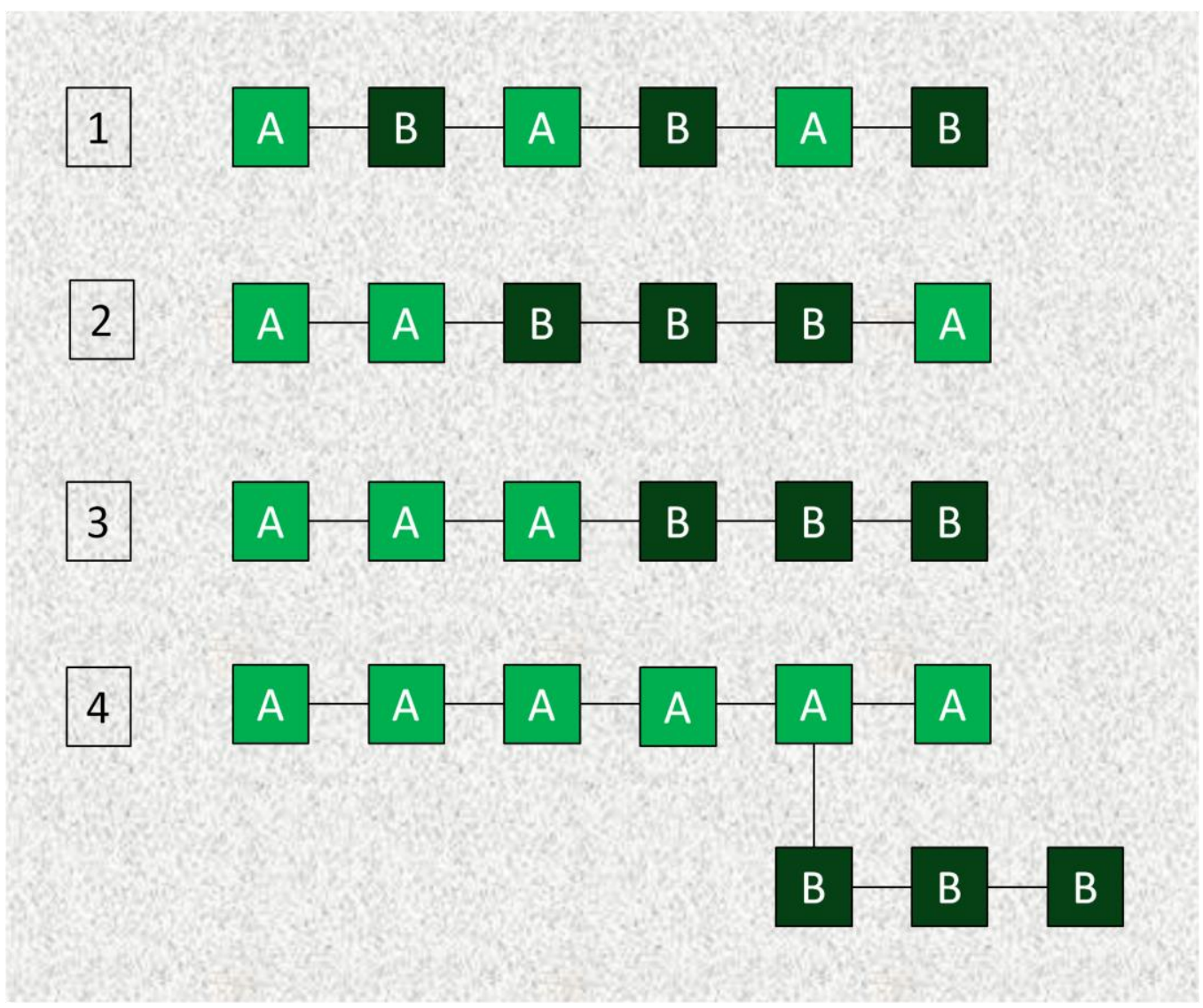

Figura 5-Ilustração dos possíveis tipos de copolímeros com os monômeros "A" e "B".

Neste trabalho empregamos um tipo comum de polimerização, a polimerização em cadeia via radical livre, que ocorre em três etapas: iniciação, propagação e término (ou terminação). $\mathrm{Na}$ iniciação são usados iniciadores termicamente instáveis, que são decompostos em dois centros ativos:

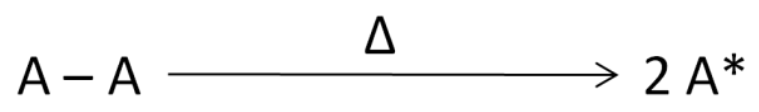

Imediatamente o radical ativo $\left(\mathrm{A}^{*}\right)$ ataca a dupla ligação do monômero e transfere o centro ativo para o mesmo, iniciando a polimerização.

$$
\mathrm{A}^{*}+\mathrm{H}_{2} \mathrm{C}=\mathrm{CHR} \longrightarrow \mathrm{A}-\mathrm{H}_{2} \mathrm{C}-\mathrm{CHR} *
$$

A etapa de propagação consiste na transferência do centro ativo de monômero para monômero, com o crescimento da cadeia a uma alta velocidade e baixa energia de ativação. 


$$
\begin{gathered}
\text { A - } \mathrm{H}_{2} \mathrm{C}-\mathrm{CHR} *+\mathrm{H}_{2} \mathrm{C}=\mathrm{CHR} \longrightarrow \mathrm{A}-\mathrm{H}_{2} \mathrm{C}-\mathrm{CHR}-\mathrm{H}_{2} \mathrm{C}-\mathrm{CHR}^{*} \\
\mathrm{~A}-\mathrm{H}_{2} \mathrm{C}-\mathrm{CHR}-\mathrm{H}_{2} \mathrm{C}-\mathrm{CHR}^{*}+\mathrm{H}_{2} \mathrm{C}=\mathrm{CHR} \longrightarrow \sim \sim \sim \sim \sim \sim \sim \sim \\
-\mathrm{H}_{2} \mathrm{C}-\mathrm{CHR}^{*}
\end{gathered}
$$

Por fim, na etapa de término, o crescimento da cadeia cessa com o desaparecimento do centro ativo, que pode ser por combinação de dois macro-radicais, por transferência intermolecular de hidrogênio do carbono-cauda de uma ponta da cadeia para um carbonocabeça localizado na ponta da outra cadeia, ou através da transferência do centro ativo para outras cadeias ${ }^{(20)}$

\subsection{Filmes de Langmuir e Langmuir-Blodgett}

Irving Langmuir foi o primeiro a realizar estudos sistemáticos de monocamadas sobre a água no final da década de 1910 e início de 1920. As contribuições científicas desses estudos levaram-no ao prêmio Nobel. Em 1920 ele relatou a transferência de moléculas de ácidos graxos da superfície da água para suportes sólidos. No entanto, a primeira descrição detalhada da transferência de monocamada seqüencial foi dada anos mais tarde por Katherine Blodgett

${ }^{(21)}$. Por esse motivo, o filme obtido pela deposição das monocamadas em substratos sólidos é chamado filme Langmuir-Blodgett (LB).

Após esse trabalho pioneiro de Langmuir e Blodgett, passou-se quase meio século antes que cientistas começassem a perceber as possibilidades da técnica. A primeira conferência internacional sobre filmes LB foi realizada em 1979, e desde então o uso desta técnica aumentou em vários campos de pesquisa. Para descrever a aplicação dessa técnica na fabricação de filmes finos, primeiramente é necessário entender alguns conceitos básicos de tensão superficial e potencial de superfície.

\subsubsection{Tensão superficial}


As moléculas em um líquido atraem-se entre si, como mostra a figura 6, de uma maneira dependente das propriedades da substância. No interior do líquido, existem forças igualmente atrativas em todas as direções. Porém, há na superfície um desequilíbrio de forças, ou seja, uma molécula na interface ar/água tem maior atração para a fase líquida do que para o ar ou a fase gasosa. Portanto, haverá uma força resultante atrativa voltada para o líquido, e a interface ar/água tende, espontaneamente, a minimizar sua área de contato. $\mathrm{O}$ efeito é o aparecimento de energia livre na superfície.

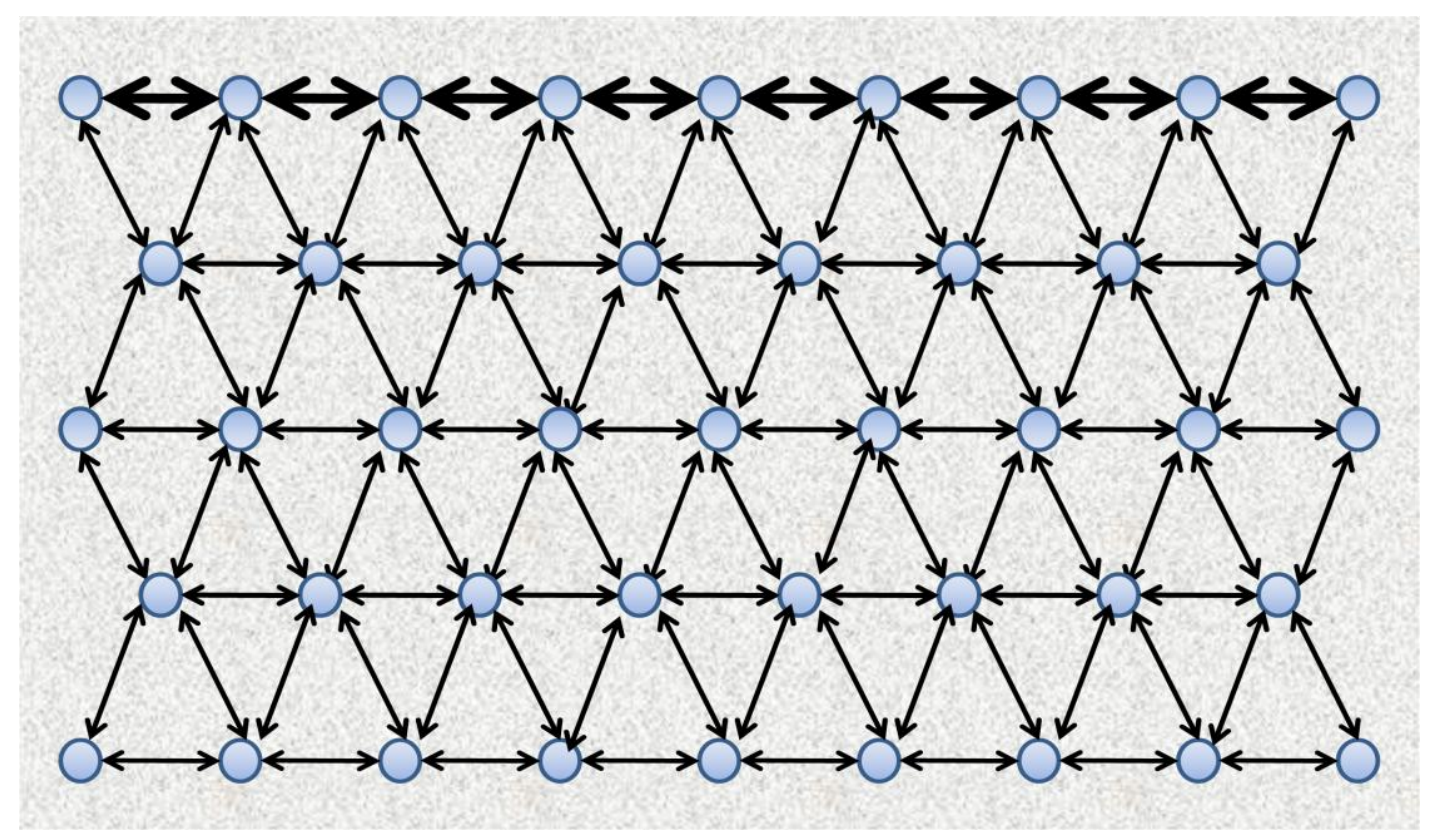

Figura 6-Ilustração da interação entre moléculas na superfície e no interior do líquido

A força que age sobre as moléculas da superfície é chamada tensão superficial $(\gamma)$. Em equilíbrio termodinâmico, a tensão superficial de uma interface plana pode ser determinada pelas derivadas parciais da função de energia livre.

onde F é energia livre de Helmholtz, G a energia livre de Gibbs e A a área superficial. T, V, P e ni são, respectivamente, temperatura, volume, pressão e número de partículas. Para um líquido puro, em equilíbrio, com saturação de vapor na superfície planar, a tensão superficial é igual à energia livre de Helmholtz por unidade de área (A). 
onde $\mathrm{F}^{\mathrm{S}}$ refere-se à superfície com excesso de energia livre.

Em estudos envolvendo monocamadas obtêm-se medidas de pressão de superfície, que é igual à redução da tensão superficial do líquido puro. Essa pressão, portanto, pode ser expressa como:

$$
\Pi=\gamma_{0}-\gamma
$$

onde $\Pi$ é a pressão de superfície, $\gamma_{0}$ é a tensão superficial da água pura e $\gamma$ é a tensão superficial na presença da monocamada ${ }^{(22)}$.

Líquidos polares, como a água, têm fortes interações intermoleculares e por isso, elevadas tensões superficiais. Substâncias surfactantes, compostas de moléculas anfifílicas (que possuem uma parte hidrofóbica e outra hidrofílica), diminuem essas tensões, assim como elevadas temperaturas. Existe grande variedade de lipídios, polímeros e outras moléculas orgânicas com natureza anfifílica, que abaixam drasticamente a tensão superficial da água. Muitas destas substâncias anfifílicas insolúveis em água podem, com a ajuda de um solvente volátil e imiscível em água, facilmente se espalhar em uma superfície para formar uma monocamada insolúvel na interface ar/água. Estas monocamadas são chamadas filmes de Langmuir. A natureza anfifílica das moléculas dita a sua orientação na interface de modo que, em geral, o grupo polar fica imerso na água e a cadeia longa de hidrocarbonetos aponta para o ar.

A cadeia de hidrocarbonetos da substância usada nos filmes de Langmuir tem que ser longa o suficiente para se formar uma camada insolúvel. Se a cadeia é pequena, embora ainda insolúvel em água, a parte apolar na superfície da água tende a formar micelas. Estas micelas são solúveis em água, o que impede a formação de uma monocamada na interface. Por outro lado, se a cadeia for muito longa, a camada apolar tende a cristalizar na superfície da água e, consequentemente, não forma uma monocamada. É difícil determinar o tamanho ideal para a cadeia de hidrocarbonetos, porque sua capacidade de formação de filme depende também da parte polar ${ }^{(23,24)}$.

Para a deposição dos filmes LB, é preciso inicialmente estudar os filmes de Langmuir. No preparo destes filmes, um pequeno volume de solução do composto em solvente volátil e, de preferência imiscível com a água, é espalhado sobre a superfície da subfase, em geral água 
ultrapura, contida na cuba de Langmuir, confeccionada de material inerte, geralmente Teflon. A figura 7 mostra um esquema de uma cuba de Langmuir ${ }^{(25,26)}$.

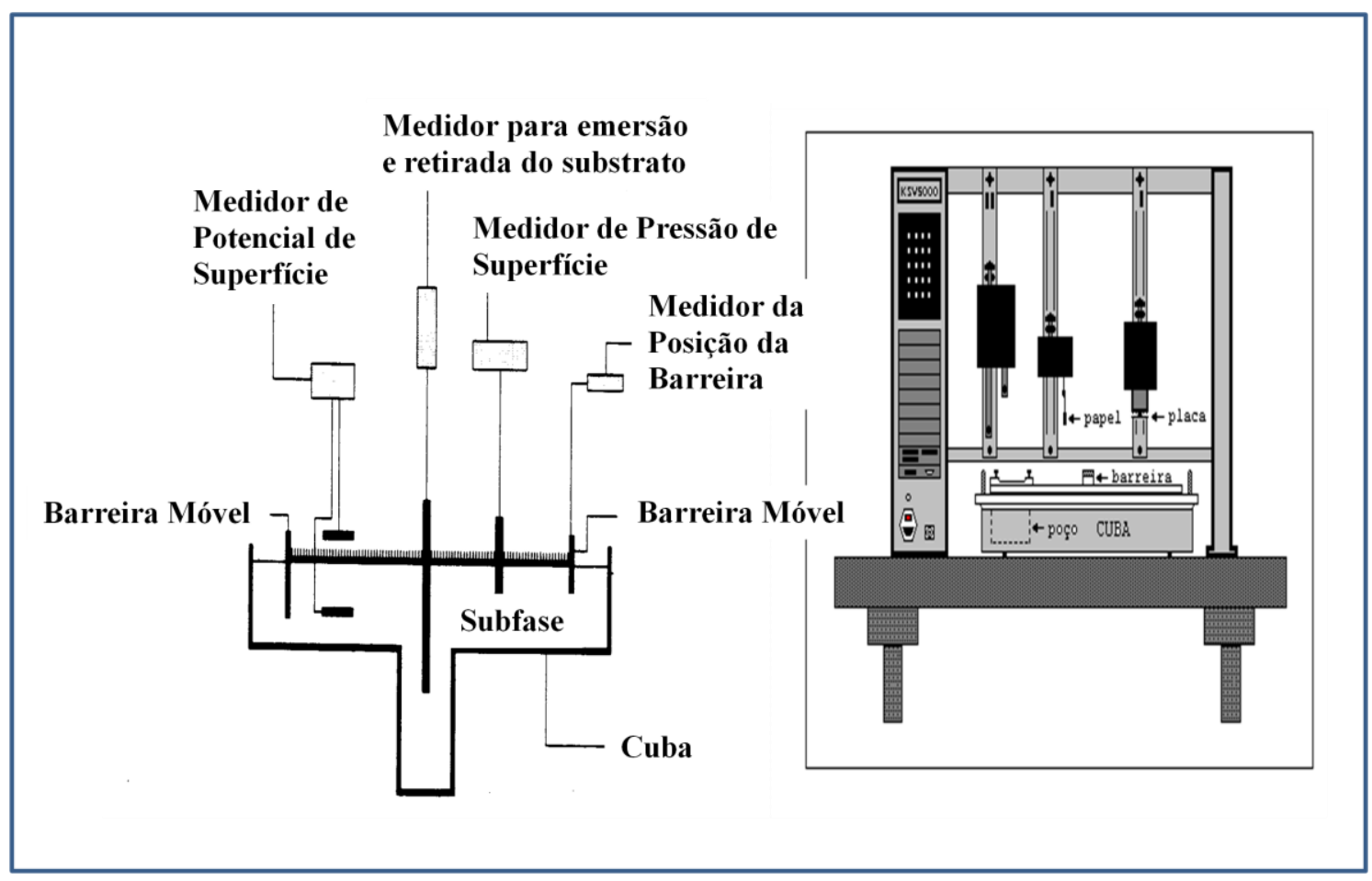

Figura 7-Esquema geral da cuba de Langmuir, que contém uma cuba de Teflon, com barreiras moveis. Medidores de pressão e potencial de superfície e um dipper para emersão e retirada do substrato.

Os filmes de Langmuir são normalmente caracterizados por medidas de pressão e de potencial de superfície. A pressão de superfície é a diferença da tensão superficial entre uma subfase com água pura $\left(\gamma_{0}\right)$ e uma subfase com água + filme $(\gamma)$. O valor de pressão mínimo é zero, e o valor máximo pode se aproximar da tensão superficial da água pura, em torno de 73 $\mathrm{mN} / \mathrm{m}$ para a temperatura ambiente ${ }^{(21)}$. A figura 8 mostra a isoterma de pressão do ácido esteárico. Inicialmente as moléculas estão dispersas como em fase gasosa, em que não ocorre interação entre elas. Com a compressão da barreira, a área ocupada pelo filme diminui e as moléculas começam a interagir, atingindo-se a fase líquido-expandida. Com o aumento dessa interação, tem-se a formação de arranjos regulares no filme resultando em uma fase condensada. 


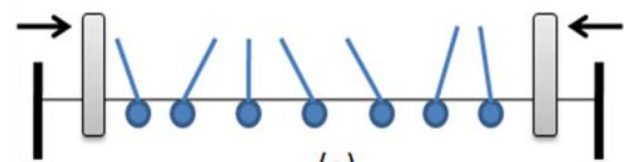

(a)

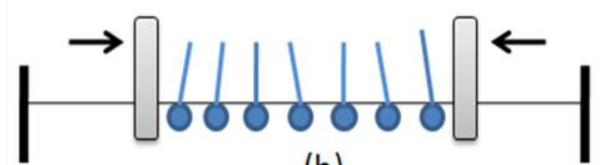

(b)

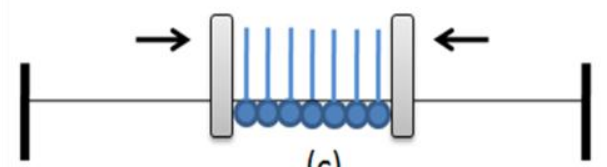

(c)

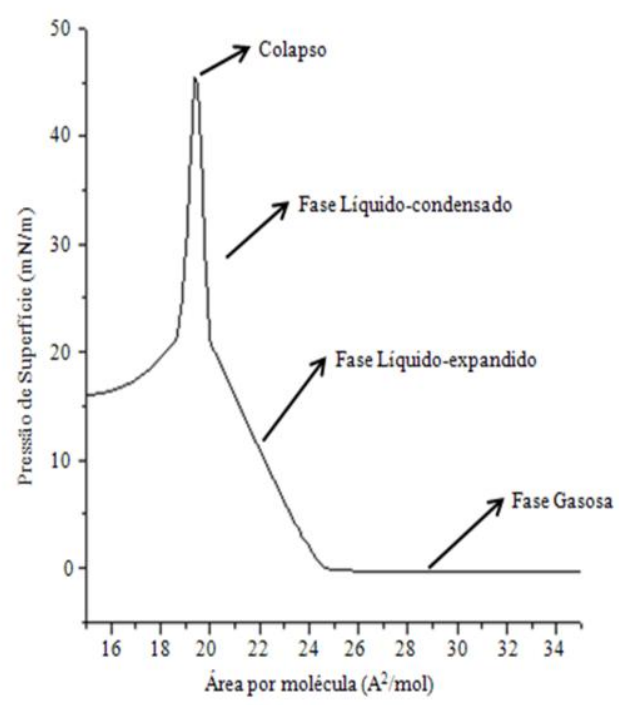

Figura 8-Isoterma de pressão de superfície para o ácido esteárico, e ilustração da estruturação das moléculas no filme durante a compressão. $(\bullet)$ cabeça hidrofóbica e $(\mid)$ cauda hidrofóbica.

\subsubsection{Potencial de superfície}

O potencial de superfície é definido como a diferença de potencial entre uma superfície aquosa com filme e sem filme, e é medido por uma prova de Kelvin (de capacitor vibrante), em que uma das placas do capacitor vibra acima da superfície da água e a outra é a própria superfície da água. A presença de dipolos permanentes no filme, ou a dupla camada formada na interface filme-água, gera uma diferença de potencial $(\Delta V)$. Os potenciais medidos podem ser relacionados com os momentos de dipolo das moléculas do filme ${ }^{(27)}$, através de modelos teóricos. Um dos mais usados é o modelo de Demchak e Fort ${ }^{(28)}$ em que trata-se o filme como um capacitor de 3 camadas com um momento de dipolo efetivo cada uma e uma constante dielétrica local, como representado na figura 9. 


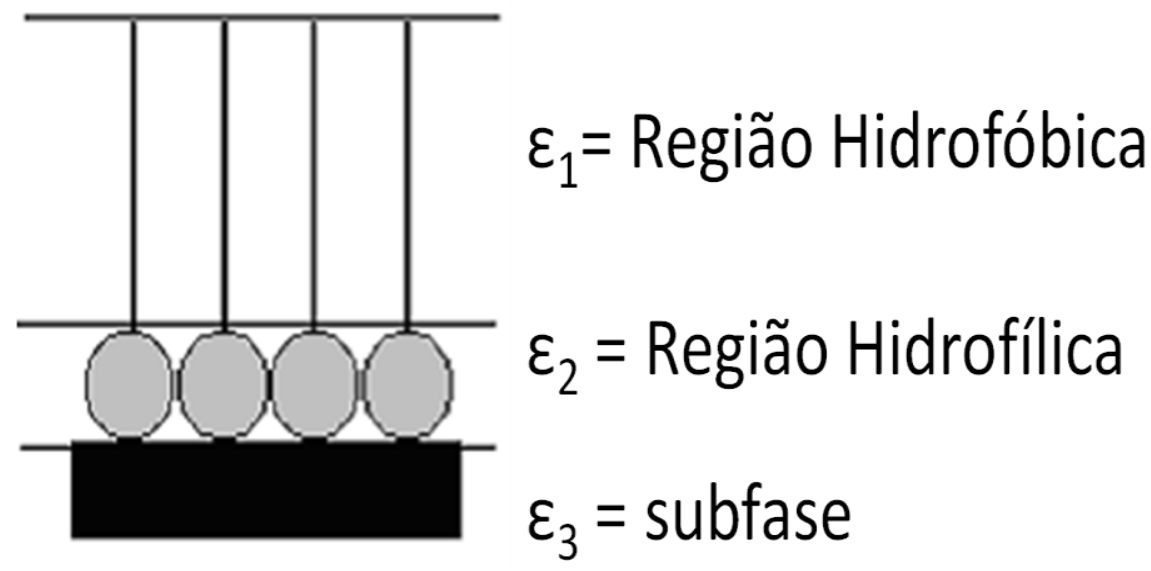

Figura 9-Modelo de Demchak e Fort tratando-se o filme como um capacitor de 3 camadas.

Por analogia com um capacitor de placas paralelas e lembrando que a polarização pode ser definida como o momento de dipolo por unidade de volume, tem-se que $\mathrm{P}_{\mathrm{n}}$ é dada por:

$$
P_{n}=\varepsilon \varepsilon_{0} \Delta V / d=\mu_{n} / A d
$$

onde $\varepsilon$ é a permissividade relativa do filme, $\boldsymbol{\varepsilon}_{\boldsymbol{o}}$ é a permissividade do vácuo, $\boldsymbol{d}$ é a espessura do filme, A é a área média ocupada pela molécula e $\boldsymbol{\mu}_{\boldsymbol{n}}$ é o componente do momento de dipolo molecular normal ao plano da monocamada, que pode ser dado pela seguinte equação: ${ }^{(29),(30)}$.

$$
\mu_{n}=\left(\mu_{1} / \varepsilon_{1}\right)+\left(\mu_{2} / \varepsilon_{2}\right)+\left(\mu_{3} / \varepsilon_{3}\right)=\varepsilon_{0} \mathbf{A} \Delta V
$$

Na equação (5) os momentos de dipolo e as constantes dielétricas locais são numerados de acordo com a localização no modelo de 3 camadas da Figura 9. Em termos adimensionais, a constate dielétrica do material $\varepsilon_{r}$ é dada por:

$$
\varepsilon_{r}=\varepsilon / \varepsilon_{o}
$$

Outra abordagem proposta por Vogel e Mobius ${ }^{(31)}$ trata a monocamada como sendo um capacitor de duas camadas sendo uma composta pela interface ar/monocamada e a outra pela interface monocamada/água.

Para grandes áreas por molécula num filme de Langmuir, as interações intermoleculares são relativamente fracas a ponto de não ser possível detectá-las no potencial da subfase líquida. Quando o filme começa a ser comprimido, a área por molécula diminui, ocorrendo aumento muitas vezes abrupto do potencial. As medidas de potencial de superfície são mais 
sensíveis à organização do filme da Langmuir, com um potencial não nulo sendo detectado mesmo num estágio de compressão em que a pressão de superfície ainda é nula. A caracterização do filme de Langmuir por potencial de superfície não pode ser analisada quantitativamente para moléculas muito grandes como os polímeros, pois não se pode saber a orientação precisa dos grupos que contribuem para a componente vertical do momento de dipolo. Para esses compostos, utiliza-se o potencial para comparação entre materiais diferentes ou entre o mesmo material em condições diferentes ${ }^{(32)}$.

Os filmes LB são produzidos através de imersões e retiradas sucessivas do substrato na subfase, após o filme de Langmuir ser comprimido e mantido a certa pressão de superfície. Os filmes são caracterizados pela estrutura em multicamadas, onde em uma molécula ideal, cada camada possui espessura de uma única molécula. O tipo da deposição pode variar, sendo formados filmes do tipo $\mathrm{X}, \mathrm{Y}$ e $\mathrm{Z}$, dependendo da natureza da superfície do substrato (hidrofílica ou hidrofóbica), e do tipo de material do filme de Langmuir. A figura 10 mostra esquematicamente as arquiteturas dos filmes do tipo $\mathrm{X}, \mathrm{Y}$ e $\mathrm{Z}$ para uma molécula anfifílica ideal.
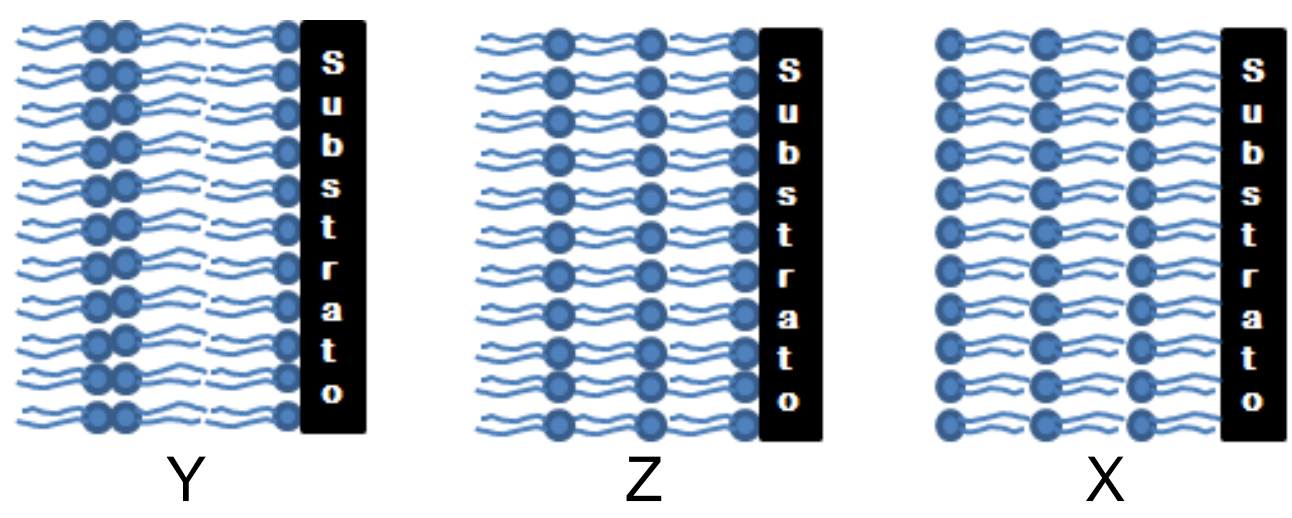

Figura 10-Tipos de filme LB que podem ser depositados.

Os filmes podem ser caracterizados pela taxa de transferência das camadas dos filmes de Langmuir, definida como:

onde AL é a diminuição da área ocupada pelo filme de Langmuir sobre a subfase e As é a área do substrato sólido imerso na subfase. Para TR próxima de 1, pode-se dizer que o filme é homogêneo. Na prática, os valores de TR só podem ser usados como caracterizadores da 
homogeneidade de filmes se o filme de Langmuir for estável na pressão de superfície escolhida para a deposição do filme LB. Ou seja, se a área ocupada pelo filme, mantido à pressão escolhida, não variar em função do tempo.

\subsection{Energia superficial}

Uma forma de estudar a energia de superfície de materiais sólidos é por medidas de ângulo de contato, que resulta entre uma gota de um líquido depositada sobre a superfície. $\mathrm{Na}$ figura 11 é mostrada uma representação desse sistema, do ângulo de contato entre os dois materiais e das energias de superfície e interface envolvidas ${ }^{(25)}$

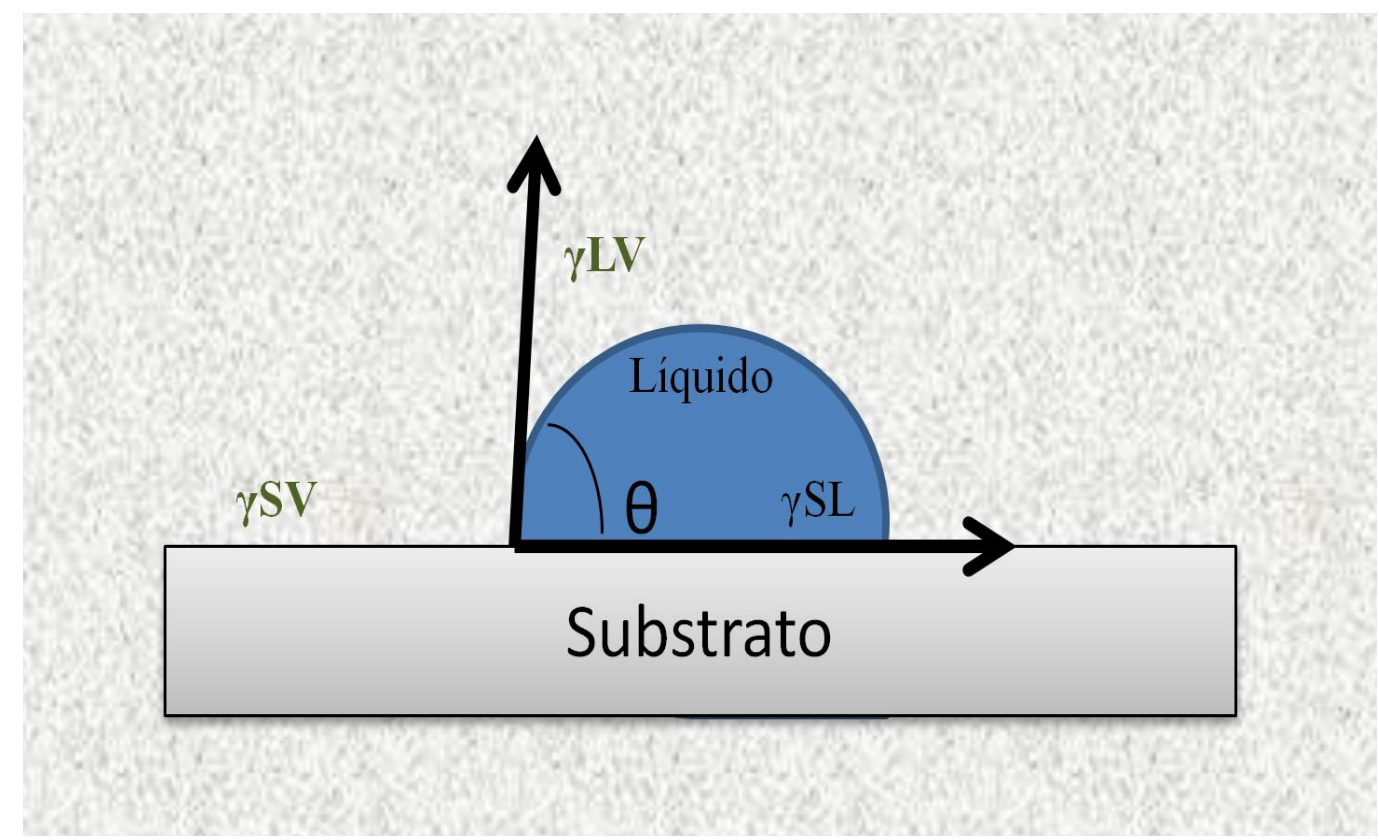

Figura 11-Ilustração das tensões envolvidas na medida do ângulo de contato entre uma gota de um líquido e uma superfície sólida.

Para a situação de equilíbrio da gota na superfície, a equação de Young pode ser usada para determinar o ângulo de contato a partir das energias de superfície/interface. O contrário também pode ser feito; por exemplo, se duas das energias interfaciais são conhecidas, uma terceira pode ser determinada pela medida de ângulo de contato ${ }^{(26)}$. A equação de Young é: 


$$
\gamma_{\mathrm{sv}}-\gamma_{\mathrm{sl}}=\gamma_{\mathrm{lv}} \cos \theta
$$

onde $\gamma$ é a tensão interfacial entre as fases, e $\mathbf{s}, \mathbf{l}$ e $\mathbf{v}$ referem-se a sólido, liquido e vapor, respectivamente. A tensão superficial é geralmente expressa em dinas/cm ou $\mathrm{mN} / \mathrm{m}$. Um exemplo de um líquido com alta energia de superfície, ou seja, com alta tensão superficial é a água, que possui $\gamma=73 \mathrm{mN} / \mathrm{m}$ a $20^{\circ} \mathrm{C}$. Nas medidas em que se usa água, o ângulo de contato $\theta$ será tanto maior quanto mais hidrofóbica for a superfície do material sólido. A denominação hidrofílica (afinidade por água) e hidrofóbica (repulsão por água) surge dessa interação, e significa que determinado material tem, respectivamente, maior ou menor energia de superfície. Para algumas aplicações, pode-se desejar que uma superfície tenha caráter mais hidrofílico ou hidrofóbico. Por exemplo, materiais para a adesão de células necessitam ter alta energia de superfície, enquanto superfícies autolimpantes e que não molham facilmente devem ter baixa energia de superfície ${ }^{(33)}$. 


\section{Procedimentos experimentais}

\subsection{Síntese e caracterização dos homopolímeros e copolímeros}

Os copolímeros com o azo monômero metacrílico 4'-[N-etil-N-(2-metacriloxietil)]amino-4-nitro-azobenzeno (DR13-MA) e um monômero hidrofóbico metacrílico (metacrilato de 2,2,3,3,4,4,5,5 octafluoropentila) (OFPMA) ou metacrilato de 2,2,2 trifluoroetila (TFEMA), mostrados na figura 12, foram sintetizados por polimerização radicalar convencional. Todos os monômeros foram obtidos comercialmente e usados sem purificação prévia. As reações foram feitas em solução de $4 \mathrm{~mL}$ dos solventes metil-etilcetona (MEK) e dimetilformamida (DMF) (3:1, v/v), empregando 0,015 g de AIBN como iniciador térmico e razões de 10, 20, 30 e 50\% em massa do azomonômero em relação a cada um dos monômeros fluorados. A temperatura nas sínteses foi de $70^{\circ} \mathrm{C}$. 


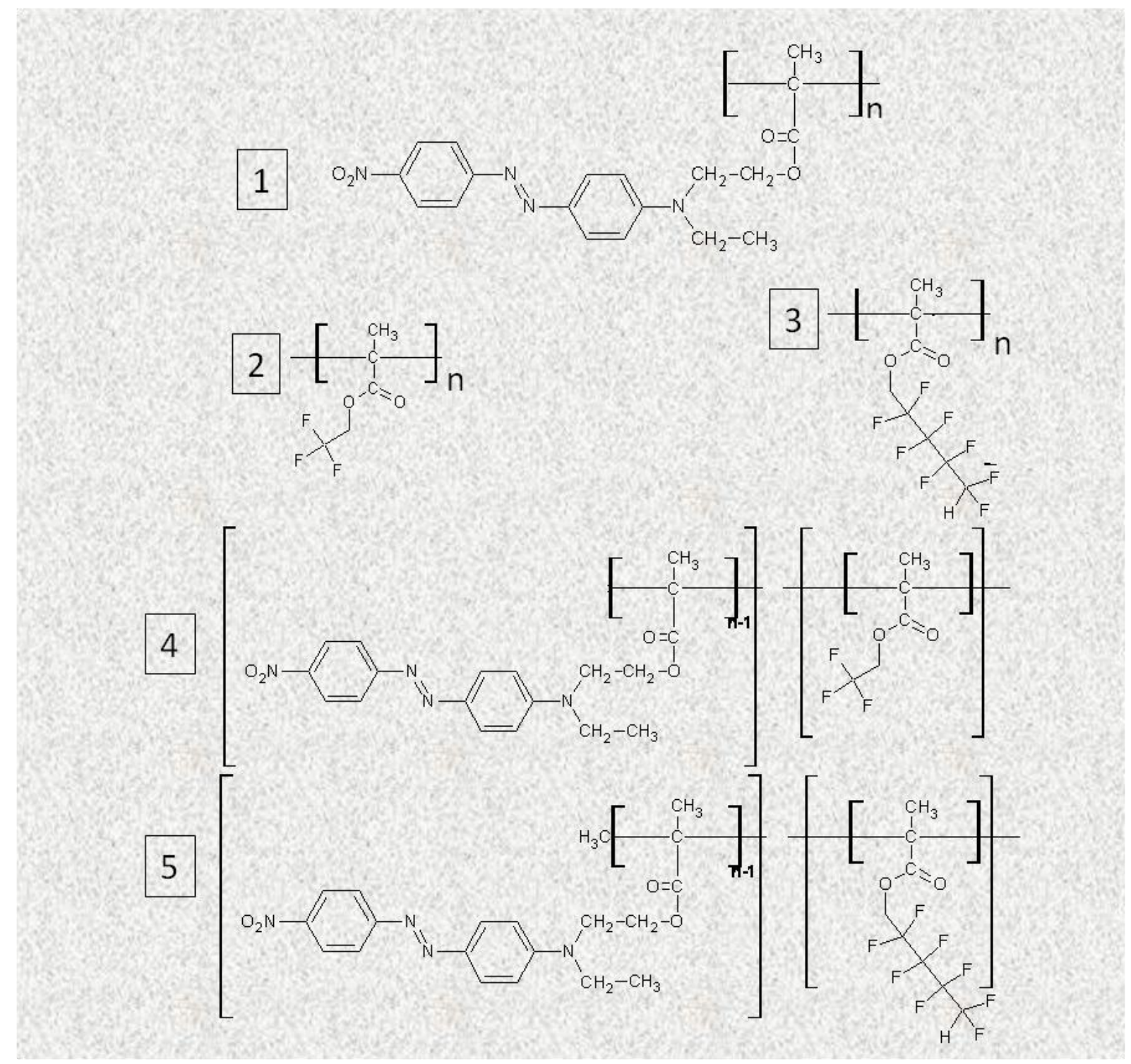

\section{Rafaela}

Figura 12-Estrutura química do monômero azo DR13MA (1), dos monômeros fluorados (OFPMA)(2) e (TFEMA)(3) utilizados na síntese dos copolímeros contendo como grupo azobenzênico o corante DR13 (4 e 5).

A quantidade de monômero hidrofóbico foi sempre a mesma, $560 \mu \mathrm{L}$, variando-se a quantidade de monômero azo em 10, 20, 30 e 50\% em massa, como mostra a tabela 1 . O tempo de reação foi de 72 horas. Os copolímeros com proporção de 30 e $50 \%$ em massa de azomonômero foram sintetizados novamente nas mesmas condições, porém sob agitação, pois sem agitação constante não foi possível obter rendimento satisfatório da reação. 
Tabela 1-Condições reacionais das polimerizações

\begin{tabular}{cc}
\hline Copolímeros & Monômero Azo \\
\hline TFEMA-co-DR13MA 10\% & $0,08 \mathrm{~g} \mathrm{(10 \% )}$ \\
TFEMA-co-DR13MA 20\% & $0,16 \mathrm{~g}(20 \%)$ \\
TFEMA-co-DR13MA 30\% & $0,20 \mathrm{~g} \mathrm{(30 \% )}$ \\
TFEMA-co-DR13MA 50\% & $0,30 \mathrm{~g} \mathrm{(50 \% )}$ \\
TFPMA-co-DR13MA 10\% & $0,08 \mathrm{~g}(10 \%)$ \\
OFPMA-co-DR13MA 20\% & $0,16 \mathrm{~g} \mathrm{(20 \% )}$ \\
OFPMA-co-DR13MA 30\% & $0,20 \mathrm{~g} \mathrm{(30 \% )}$ \\
OFPMA-co-DR13MA 50\% & $0,30 \mathrm{~g} \mathrm{(50 \% )}$ \\
\hline
\end{tabular}

Todos os azo-copolímeros foram purificados por re-precipitação em etanol 90\%. A ausência de azo monômero residual foi comprovada por cromatografia de camada delgada (TLC) em sílica gel e solvente diclorometano/n-hexano 7/3 v/v. Os homopolímeros HPTFEMA e HPOFPMA foram sintetizados da mesma forma que os copolímeros, usando a mesma proporção de monômero/iniciador e a mesmas condições reacionais. Esses compostos foram sintetizados a fim de comparar seus comportamentos com os dos copolímeros correspondentes, assim como será feito com o homopolímero HPDR13, sintetizado em trabalhos anteriores.

Os polímeros foram caracterizados quanto à estrutura química por ressonância magnética nuclear de hidrogênio ${ }^{1}\left(\mathrm{RMN}^{-} \mathrm{H}^{1}\right)$, espectroscopia na região do infravermelho (FTIR) e do ultravioleta-visível (UV-Vis.). A distribuição de massas molares foi obtida por cromatografia de exclusão de tamanho de alta performance (HPSEC). Para as análises por RMN-H ${ }^{1}$, preparou-se soluções dos polímeros em clorofórmio deuterado com aproximadamente $10 \%$ em massa, e utilizou-se um equipamento Bruker operando em 400 $\mathrm{MHz}$, tendo o tetrametilsilano como padrão. Os espectros de FTIR foram registrados em um espectrofotômetro Thermo Nicolet Nexus 470 no modo transmissão com sinal processado por transformada de Fourier. Os filmes foram obtidos por derramamento de soluções dos polímeros em clorofórmio sobre janela de monocristal de cloreto de sódio $(\mathrm{NaCl})$, e posterior evaporação do solvente, ou então pela técnica de Langmuir-Blodgett (LB) (como discutido 
depois). As medidas foram realizadas sob fluxo de gás nitrogênio. As análises de UV-vis foram realizadas em espectrofotômetro Hitachi U2001 operando no modo transmissão, cubeta de vidro óptico com $1 \mathrm{~cm}$ de espessura (para os polímeros em solução) e temperatura ambiente de aproximadamente $25^{\circ} \mathrm{C}$.

A massa molar dos compostos foi determinada por cromatografia por exclusão de tamanho de alta performance, em um sistema cromatográfico Agilent 1100 com duas colunas PLgel mixed-B e mixed-C e detector de índice de refração, tetraidrofurano (THF) como solvente, fluxo de $1 \mathrm{~mL} / \mathrm{min}$ a $35{ }^{\circ} \mathrm{C}$, padrões de poliestireno (12 padrões com Mw entre 162 $\mathrm{g} / \mathrm{mol}$ e $6.035 .000 \mathrm{~g} / \mathrm{mol}$ ), volume de injeção de $50 \mu \mathrm{L}$ e concentração de aproximadamente $2 \mathrm{mg} / \mathrm{mL}$. As medidas de temperatura de transição vítrea foram feitas por Calorimetria Exploratória Diferencial (DSC) e análises termogravimétricas (TG). Para o DSC, as medidas foram realizadas em equipamentos da marca TA modelo QS100 em atmosfera inerte de nitrogênio com fluxo de $50 \mathrm{~mL} / \mathrm{min}$. Cadinhos de alumínio foram usados como suporte para as amostras, e um outro de mesma massa de alumínio para servir como referência com uma taxa de aquecimento de $20^{\circ} \mathrm{C} / \mathrm{min}$ sob atmosfera de nitrogênio. As medidas de TG foram realizadas em um equipamento da marca TA, modelo Q50, utilizando-se cadinho de platina, no intervalo de temperatura ambiente $\left(25^{\circ} \mathrm{C}\right)$ até $800^{\circ} \mathrm{C}$ com uma taxa de aquecimento de $20^{\circ} \mathrm{C} / \mathrm{min}$ sob atmosfera de nitrogênio com fluxo de $40 \mathrm{~mL} / \mathrm{min}$.

\subsection{Fabricação dos filmes cast}

Para a deposição dos filmes cast dos copolímeros foram feitas soluções de concentração $5 \mathrm{mg} / \mathrm{mL}$ em clorofórmio. O substrato foi vidro limpo com água e detergente, e seco com jatos de nitrogênio. As soluções foram depositadas em estufa, com temperatura interna de 40 ${ }^{\circ} \mathrm{C}$ sem vácuo, até completa evaporação do solvente.

As grades de relevo foram inscritas com o aparato experimental descrito na literatura (34),(35) e representado na figura 13. Essa etapa do trabalho foi realizada em colaboração do Grupo de Fotônica do Instituto de Física de São Carlos da Universidade de São Paulo, com o Prof. Cleber Renato Mendonça e o Especialista em Laboratório Marcos Roberto Cardoso. Foi utilizado laser de argônio com potência de chegada de $85 \mathrm{~mW} / \mathrm{cm}^{2}$ por 20 minutos tanto na direção $X$ quanto na direção $Y$, produzindo um padrão de interferência com uma periodicidade de $2 \mu \mathrm{m}$. 


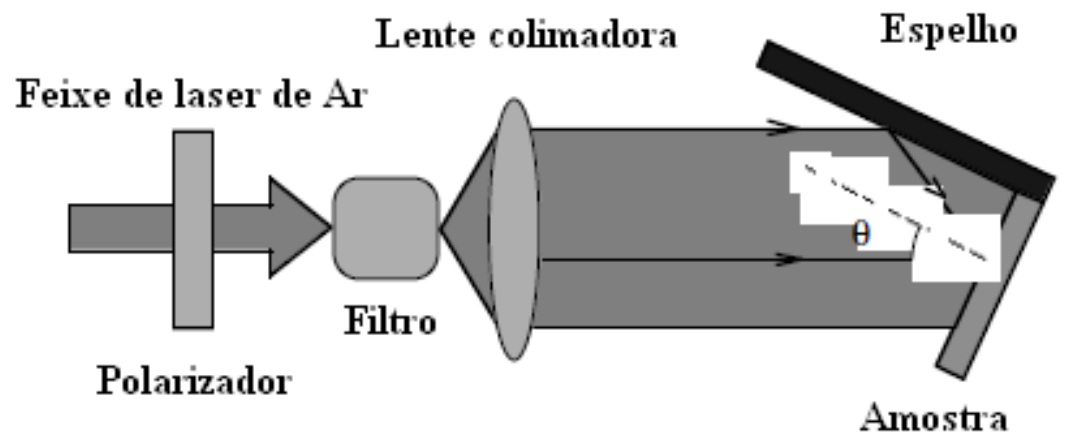

Figura 13-Esquema simplificado do aparato experimental para a formação de grades de Relevo ${ }^{(14)}$

\subsection{Fabricação dos filmes Langmuir-Blodgett (LB)}

Os filmes LB dos polímeros foram fabricados em uma cuba KSV 5000 em sala limpa classe 10.000 com temperatura interna constante de $22^{\circ} \mathrm{C}$. Em todos os casos a concentração das soluções foi de $0.5 \mathrm{mg} / \mathrm{mL}$. Os filmes foram depositados em lâminas de vidro hidrofóbico, ouro e silício. O vidro foi hidrofilizado com hidróxido de potássio $2 \%$ dissolvido em uma mistura de $90 \%$ de etanol e $10 \%$ de água, onde as lâminas permaneceram em solução por 10 minutos em ultrasson. Após esse tempo lavou-se com água Milli-Q e secou-se com aquecimento com álcool isopropílico e depois fluxo de nitrogênio. As lâminas hidrofilizadas foram em seguida deixadas em atmosfera de 1,1,1,3,3,3 - hexametil disilazano, 99,9\% (HMDS), por cerca de 48 horas, para torná-las hidrofóbicas. 


\section{Resultados e discussão}

\subsection{Síntese e caracterização dos copolímeros}

Os copolímeros sintetizados, e os homopolímeros obtidos para comparação, foram caracterizados por técnicas usuais para esses materiais, com o intuito de verificar se a estrutura pretendida foi alcançada, principalmente a incorporação dos dois meros nos copolímeros.

\subsubsection{Espectroscopia no UV-vis.}

A absorção molecular na região do ultravioleta e do visível depende da estrutura eletrônica da molécula. A absorção de energia é quantizada e conduz à passagem dos elétrons de orbitais do estado fundamental para orbitais de maior energia em um estado excitado. Para muitas das estruturas eletrônicas, essa absorção ocorre em uma porção pouco acessível do ultravioleta. A absorção de energia no ultravioleta produz modificações da energia eletrônica da molécula em consequiência de transições dos elétrons de valência. Estas transições implicam a excitação de um elétron de orbital molecular ocupado ao primeiro orbital de energia superior. A energia absorvida depende da diferença de energia entre o estado fundamental e o estado excitado. Quanto menor for a diferença, maior será o comprimento de onda de absorção. $\mathrm{O}$ excesso de energia acumulada no estado excitado pode resultar em dissociação ou ionização da molécula, ou ser reemitido na forma de calor ou de luz. As características principais de uma banda de absorção são a sua posição e a sua intensidade, sendo que a posição de absorção corresponde ao comprimento de onda da radiação cuja energia é igual à necessária para que ocorra a transição eletrônica. Já a intensidade de absorção depende de dois fatores: a probabilidade de interação entre a energia radiante e o sistema eletrônico, e a diferença entre o estado fundamental e excitado ${ }^{(36)}$.

Neste trabalho, além de determinar a banda de absorção dos compostos, os espectros de UV-Vis foram usados para determinar a porcentagem de meros contendo grupos 
azobenzênicos nos copolímeros. Primeiramente construiu-se uma curva de calibração com soluções de concentrações conhecidas do azomonômero puro em clorofórmio, solvente que dissolve por completo tanto o monômero quanto os copolímeros. Os monômeros fluorados, assim como os meros fluorados dos copolímeros, não absorvem nessa região do espectro. As curvas das diferentes concentrações de monômero estão representadas na figura 14.

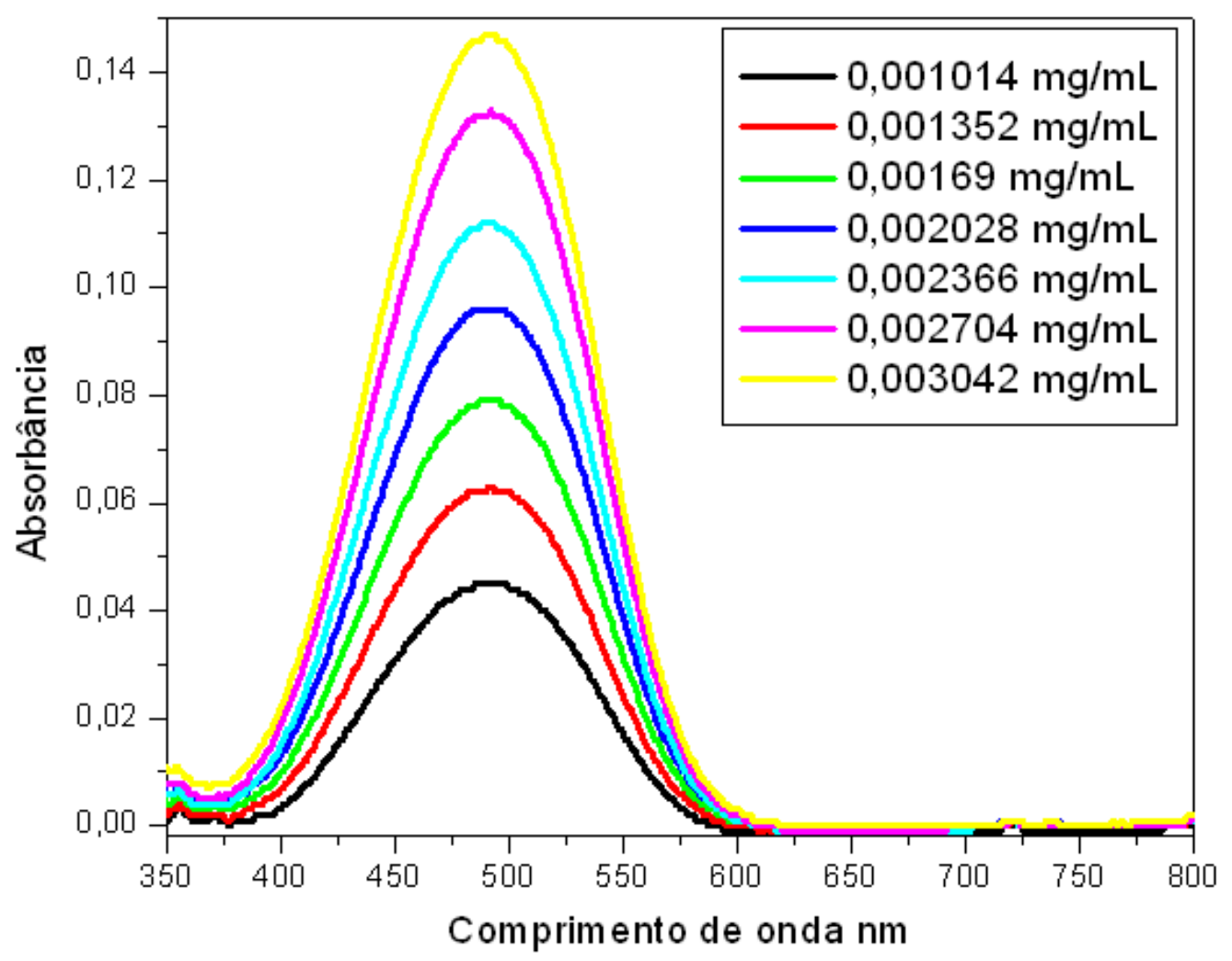

Figura 14-Espectros UV-Vis dos monômeros com concentração conhecida

A absorbância máxima ocorre no comprimento de onda $\lambda=490 \mathrm{~nm}$. Utilizando-se os valores de absorção neste comprimento de onda para as soluções de diferentes concentrações, juntamente com os valores de concentração, construiu-se a curva de calibração da Figura 15, representada pela equação de reta: $\mathrm{ABS}=-0,00228+49,21105 *$ Conc. 


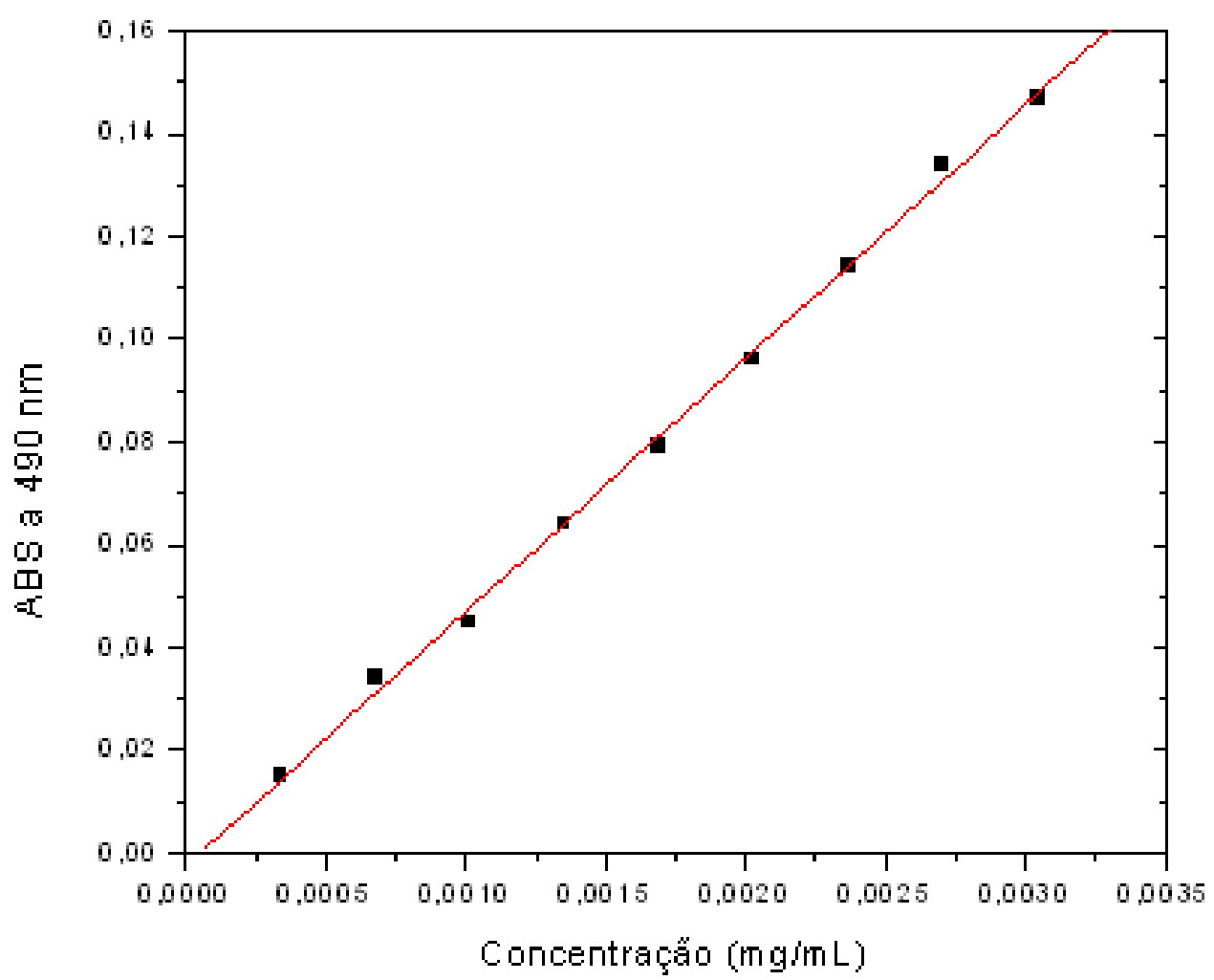

Figura 15-Curva de calibração obtida a partir dos espectros de UV-Vis dos monômeros com concentração conhecida

Foram medidos também os espectros de soluções dos polímeros com concentração de 0,025 $\mathrm{mg} / \mathrm{mL}$ para o TFEMA-co-DR13MA(10\%), 0,0072 $\mathrm{mg} / \mathrm{mL}$ para o TFEMA-coDR13MA(20\%), 0,0068 mg/mL para o TFEMA-co-DR13MA(30\%) e 0,011 mg/mL para o TFEMA-co-DR13MA(50\%), $0,0054 \mathrm{mg} / \mathrm{mL}$ para o OFPMA-co-DR13MA(10\%), 0,0045 $\mathrm{mg} / \mathrm{mL}$ para o OFPMA-co-DR13MA(20\%), $0,007 \mathrm{mg} / \mathrm{mL}$ para o OFPMA-coDR13MA(30\%) e 0,009 mg/mL para o OFPMA-co-DR13MA(50\%). Essas concentrações foram obtidas através de diluição de soluções estoque, para obter valores que se adequassem ao intervalo da curva de calibração. Os espectros de absorção dos copolímeros estão nas figuras 16 e 17. 


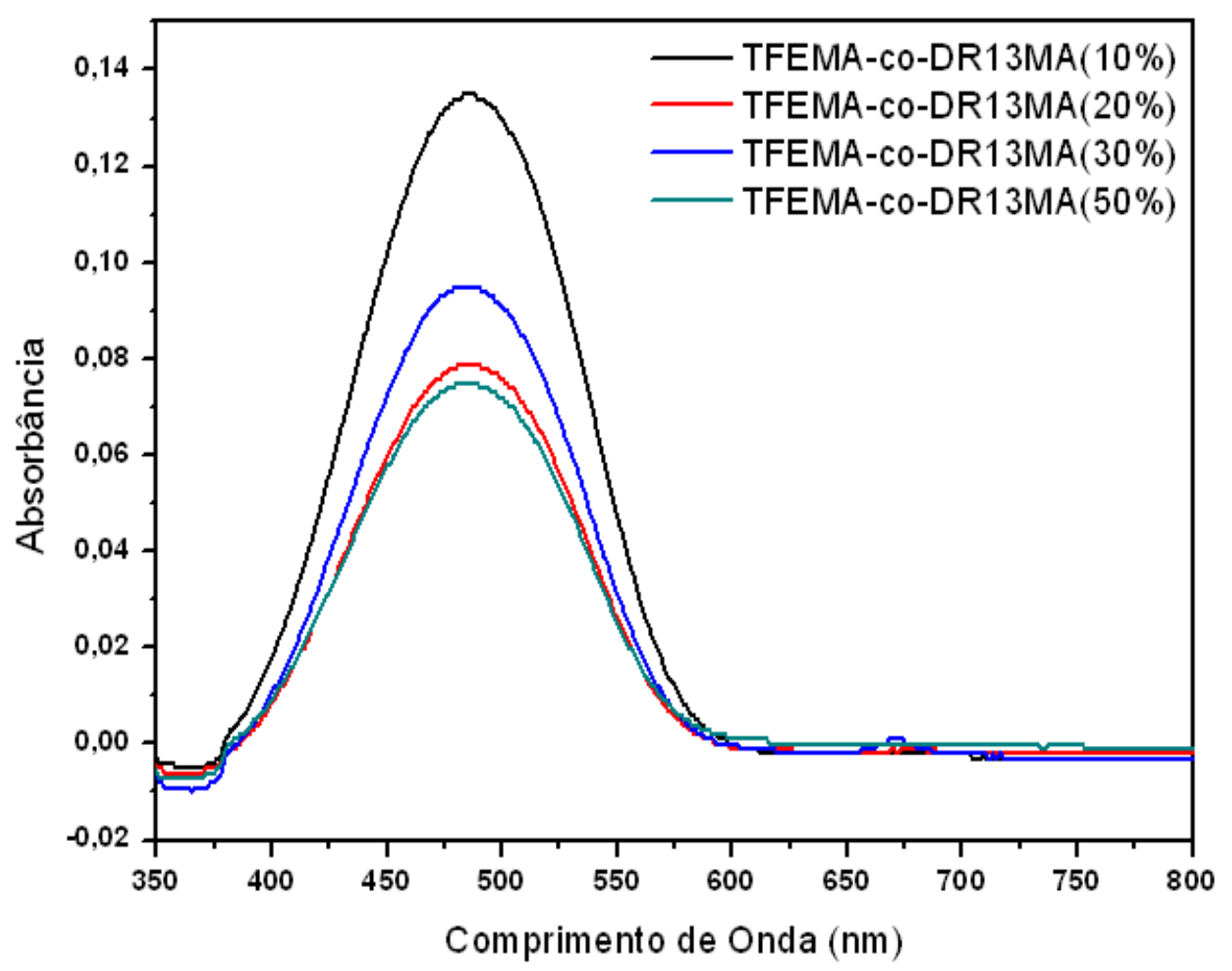

Figura 16-Espectros UV-Vis dos copolímeros TFEMA-co-DR13MA

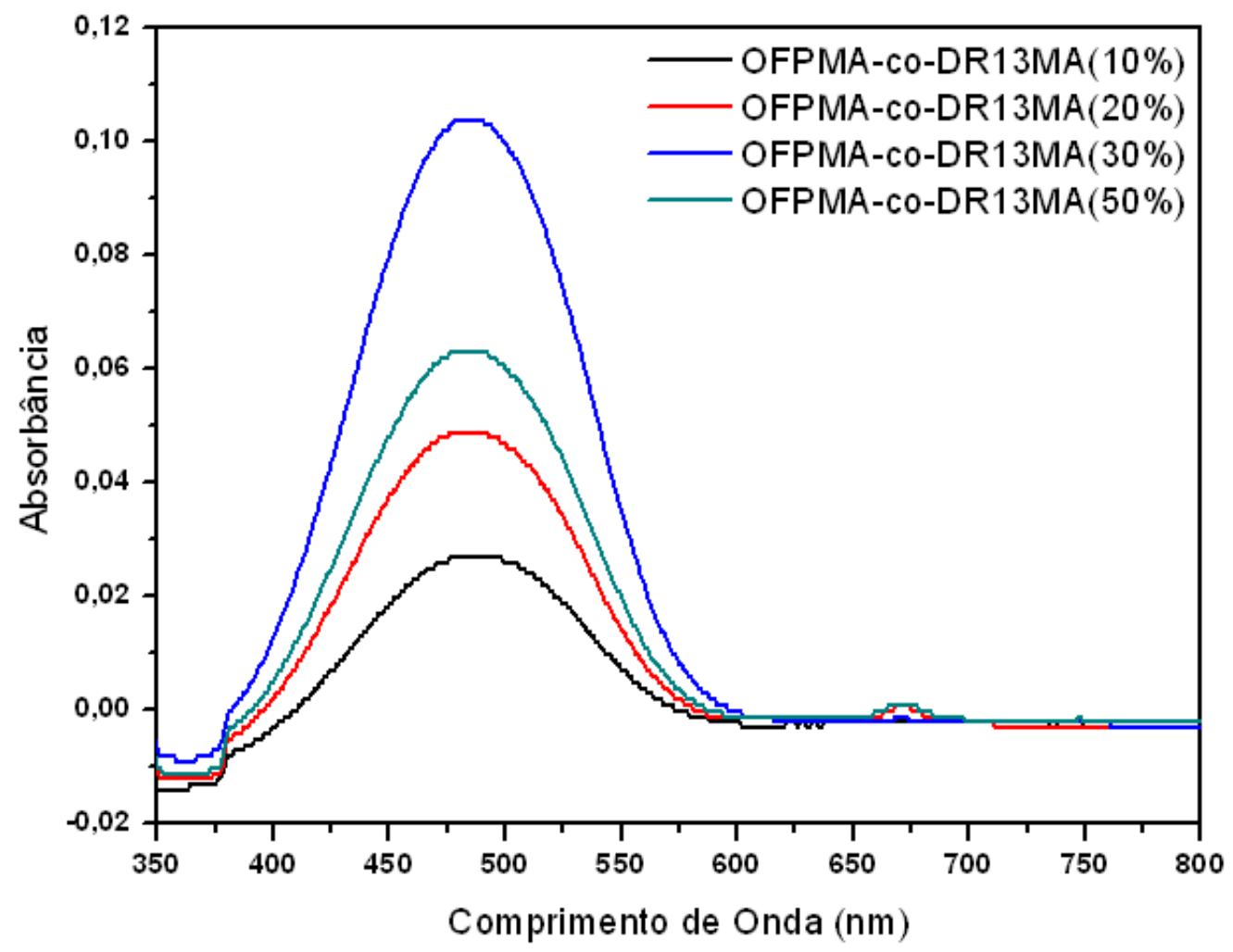

Figura 17-Espectros UV-Vis dos copolímeros OFPMA-co-DR13MA 
A partir da equação de calibração, e com os valores de absorção para cada polímero e a concentração das soluções dos polímeros, determinou-se a proporção em massa do mero azo em cada composto. Esses valores aparecem na tabela 2, e mostram ter sido possível sintetizar copolímeros com proporções de azo monômero desejadas. Porém não se obteve uma maior quantidade de DR13MA, pois uma maior quantidade no meio reacional dificulta a síntese, já que o azomonômero apresenta significativo impedimento estérico. Esse fato foi comprovado nas tentativas de se produzir copolímeros com proporção 1:1 de monômeros fluorados e DR13MA, em que a incorporação de azomonômero foi de menos de $20 \%$.

Tabela 2-Proporção de azo monômero incorporado na molécula, determinada por UV-Vis

\begin{tabular}{ccc}
\hline Polímero & Absorbância máxima & \% de azo calculado \\
\hline TFEMA-co-DR13MA(10\%) & 0,134 & 10 \\
TFEMA-co-DR13MA(20\%) & 0,079 & 23 \\
TFEMA-co-DR13MA(30\%) & 0,095 & 29 \\
TFEMA-co-DR13MA(50\%) & 0,075 & 14 \\
OFPMA-co-DR13MA(10\%) & 0,027 & 11 \\
OFPMA-co-DR13MA(20\%) & 0,049 & 21 \\
OFPMA-co-DR13MA(30\%) & 0,104 & 31 \\
OFPMA-co-DR13MA(50\%) & 0,063 & 15 \\
\hline
\end{tabular}

\subsubsection{Determinação da distribuição de massas molares}

O crescimento das cadeias poliméricas na reação de polimerização se dá de forma diferenciada para cada molécula, o que produz cadeias poliméricas com comprimentos diferentes e gerando uma distribuição de massa molar (DMM). Assim, o cálculo de massa molar dos polímeros deve ser estatístico, podendo ser definidos diferentes tipos de massas molares médias, tais como ${ }^{(36)}$ :

Massa Molar Média Numérica (Mn): definida como a massa molar de todas as cadeias dividida pelo número total de cadeias. Privilegia o número de cadeias. 
Massa Molar Média Ponderal (Mw): Nesse método, o mais importante é a massa das cadeias poliméricas, em que a massa molecular de cada fração contribui de maneira ponderada para o cálculo da média.

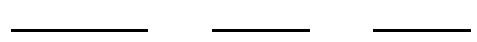

Onde wi é a massa da fração e w é a massa total.

Massa Molar Viscosimétrica (Mv): método que considera a viscosidade de uma solução diluída.

Mark e Houwink relacionaram a viscosidade intrínseca de um polímero em solução com a sua massa média:

em que (a mesma usada anteriormente) e K são constantes dependentes do polímero, solvente e temperatura.

Massa Molecular Z - média (Mz): usada quando há interesse maior na massa molecular de cada fração.

Em uma curva de distribuição de massa molecular estão contidos todos os valores de massa médios. Um exemplo dessa curva é dado na figura 18. 


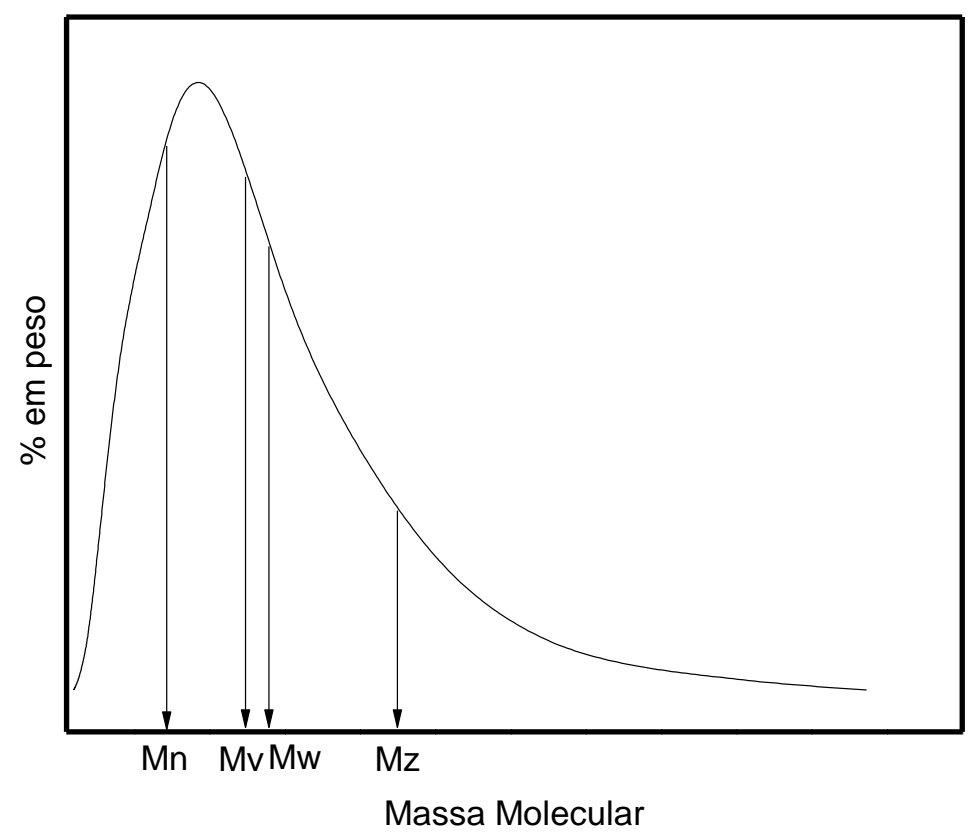

Figura 18-Curva de distribuição de Massa Molecular mostrando os quatro valores médios principais: Mn, Mv, Mw e Mz.

As curvas de distribuição podem ser largas, dependendo da polidispersividade ou polidispersão (PDI), definida pela relação $\mathrm{Mw} / \mathrm{Mn}$. Esse valor pode ser maior ou igual a 1 . Quanto mais próximo de 1, menor é a polidispersão, ou seja, mais estreita é a curva, o que indica uma menor diferença de tamanho entre as cadeias poliméricas ${ }^{(36)}$.

Neste trabalho foi usada a técnica de cromatografia de exclusão por tamanho (size exclusion chromatography - SEC) para a determinação da massa molecular dos polímeros. Esse método consiste na eluição de uma solução diluída, contendo o composto a ser analisado, por uma coluna cromatográfica com gel poroso. Os poros têm dimensões que permitem penetração de cadeias poliméricas de menor massa molar, percorrendo um caminho maior, e excluem as cadeias maiores que, então, percorrem o caminho de contorno entre as partículas, que é menor. Assim, as moléculas a saírem primeiro possuem massa molar maior, e as que saem por último apresentam massa molar menor. Por ser um método relativo, a SEC precisa de calibração com padrões conhecidos, obtendo-se previamente uma curva de calibração ${ }^{(36)}$.

Todos os polímeros sintetizados neste trabalho tiveram crescimento satisfatório, confirmado pelo grau de polimerização (GP), que indica o número de unidades estruturais 
repetidas numa macromolécula, mostrados na tabela 3. A figura 19 mostra as distribuições de massas molares dos polímeros com o mero TFEMA. O copolímero TFEMA-coDR13MA(30\%) apresentou distribuição de massa molecular deslocada para valores maiores, comparando com os demais copolímeros, porque a reação foi realizada com agitação constante, enquanto que nos outros dois casos a agitação se manteve somente durante a mistura dos reagentes. O homopolímero HPTFEMA mostrou crescimento mais acentuado das cadeias. Houve maior dificuldade de polimerizar copolímeros, por conterem o azomonômero, que é um monômero volumoso e com impedimento estérico. Isso resultou em cadeias com massas molares médias menores. A polidispersividade dos compostos foi relativamente baixa para polimerizações radicalares convencionais.

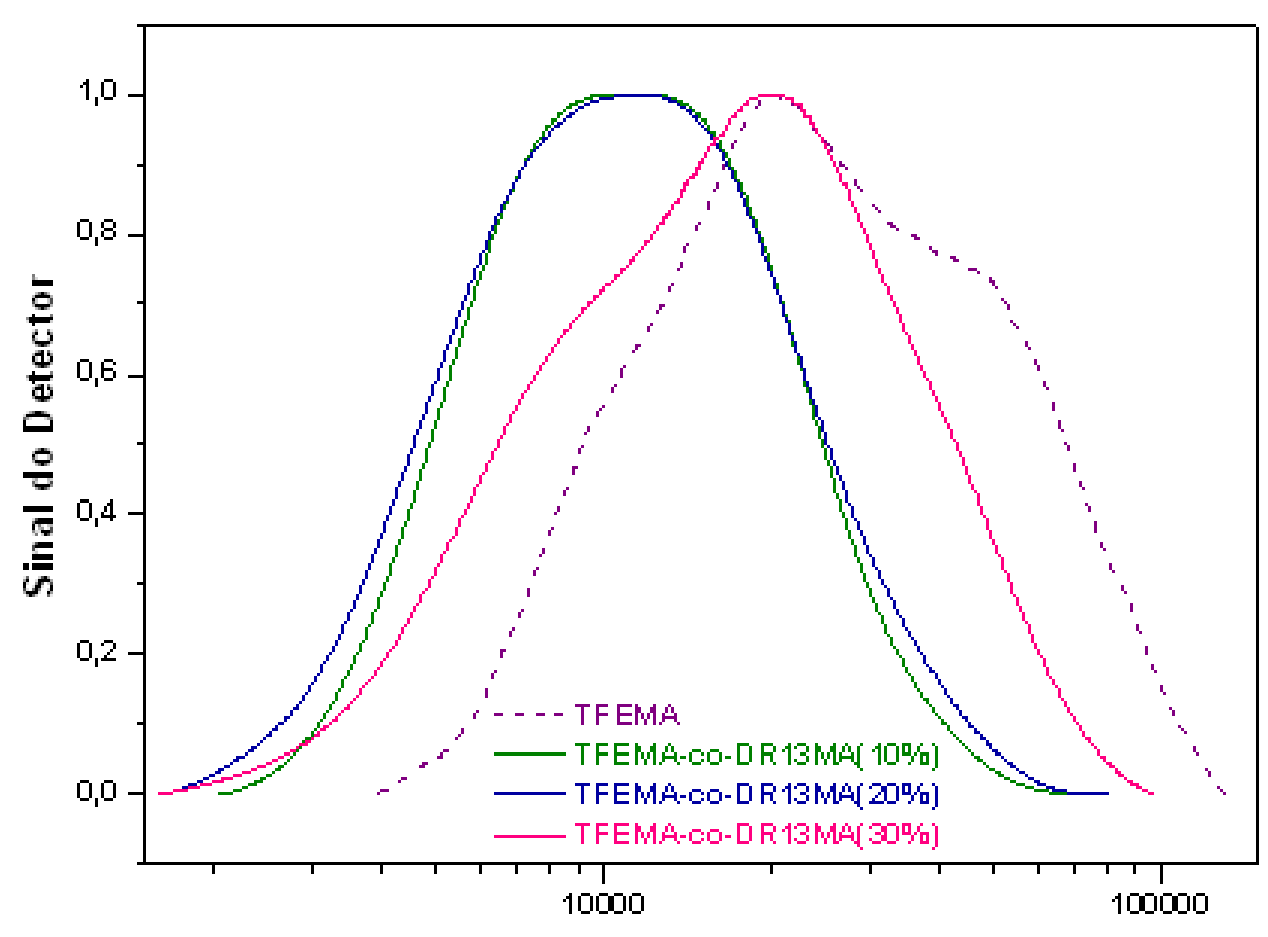

Massa Molecular $(\mathrm{g} / \mathrm{mol}$

Figura 19-Distribuição de massas molares dos polímeros com o mero TFEMA, obtida por SEC. 
Tabela 3-Valores de massas molares e polidispersividades dos copolímeros contendo o mero TFEMA.

\begin{tabular}{ccccc}
\hline Polímero & $\begin{array}{c}\text { Mn } \\
(\mathbf{g} / \mathbf{m o l})\end{array}$ & $\begin{array}{c}\text { Mw } \\
(\mathbf{g} / \mathbf{m o l})\end{array}$ & PDI & GP \\
\hline HPTFEMA & $2,0 \times 10^{4}$ & $3,0 \times 10^{4}$ & 1,6 & 119 \\
TFEMA-co-DR13MA(10\%) & $9,3 \times 10^{3}$ & $1,3 \times 10^{3}$ & 1,4 & 48 \\
TFEMA-co-DR13MA(20\%) & $8,8 \times 10^{3}$ & $1,3 \times 10^{3}$ & 1,5 & 41 \\
TFEMA-co-DR13MA(30\%) & $1,2 \times 10^{4}$ & $2,1 \times 10^{4}$ & 1,7 & 84 \\
\hline
\end{tabular}

A figura 20 mostra as distribuições de massas molares dos polímeros de OFPMA, enquanto a tabela 4 apresenta os respectivos valores de Mn, Mw e PDI e GP. Neste caso também nota-se que um dos copolímeros, o OFPMA-co-DR13MA(20\%), apresentou distribuição de massa molecular deslocada para valores maiores, pelo mesmo motivo apresentado para o TFEMA-co-DR13MA(30\%). O homopolímero HPTFEMA também apresentou crescimento mais acentuado das cadeias poliméricas, assim como o HPOFPMA. A polidispersividade dos compostos foi novamente relativamente baixa para polimerizações radicalares convencionais. 


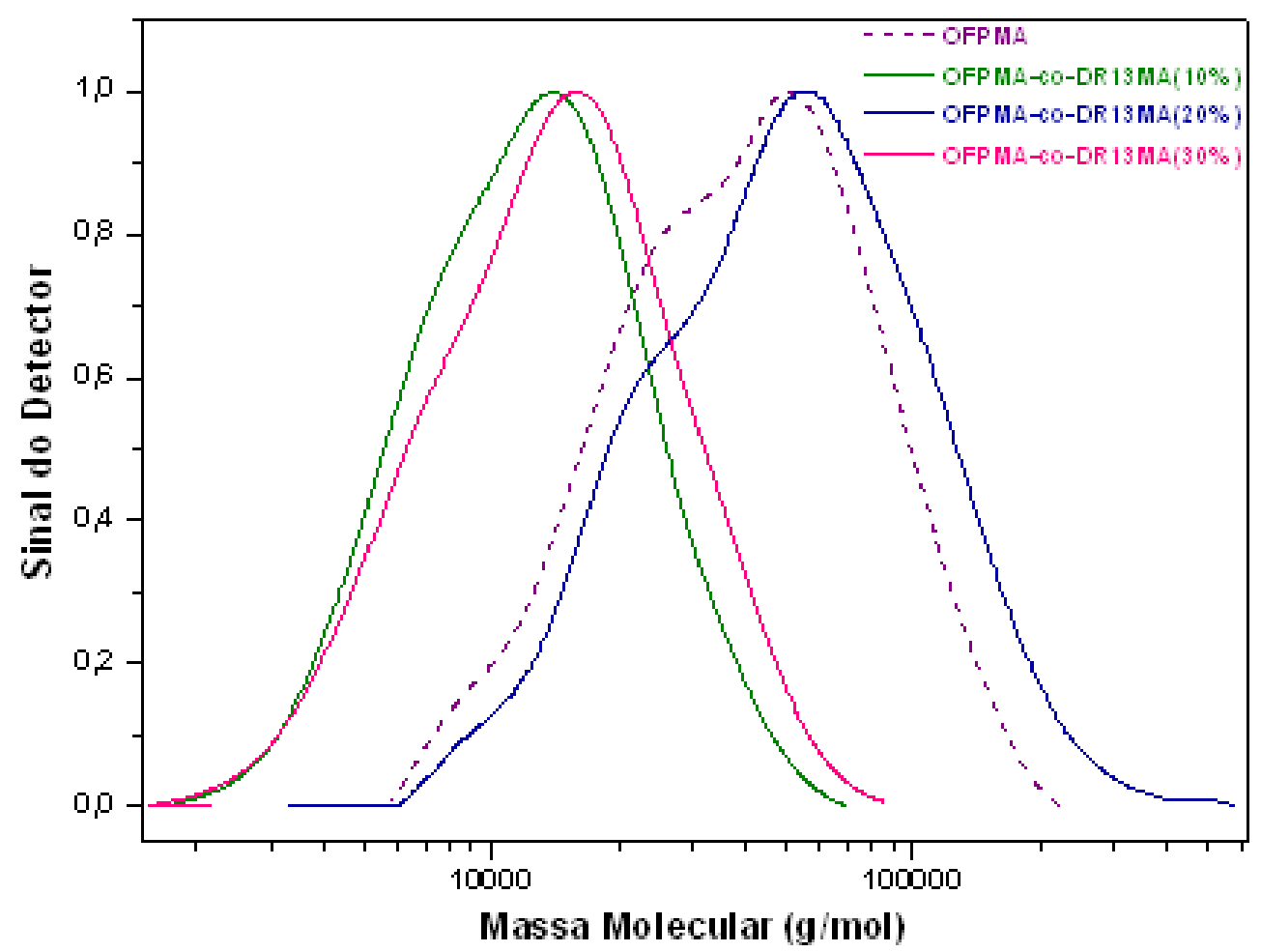

Figura 20-Distribuição de massas molares dos polímeros contendo o mero OFPMA, obtidas por SEC.

Tabela 4-Valores de massas molares e polidispersividade dos polímeros contendo o mero OFPMA.

\begin{tabular}{ccccc}
\hline Polímero & $\begin{array}{c}\text { Mn } \\
(\mathrm{g} / \mathbf{m o l})\end{array}$ & $\begin{array}{c}\text { Mw } \\
(\mathrm{g} / \mathbf{m o l})\end{array}$ & PDI & GP \\
\hline HPOFPMA & $3,0 \times 10^{4}$ & $5,0 \times 10^{4}$ & 1,7 & 100 \\
OFPMA-co-DR13MA(10\%) & $1,0 \times 10^{4}$ & $1,5 \times 10^{4}$ & 1,4 & 32 \\
OFPMA-co-DR13MA(20\%) & $3,7 \times 10^{4}$ & $6,7 \times 10^{4}$ & 1,8 & 114 \\
OFPMA-co-DR13MA(30\%) & $1,1 \times 10^{4}$ & $1,7 \times 10^{4}$ & 1,5 & 33 \\
\hline
\end{tabular}

\subsubsection{Espectroscopia no infravermelho}

A radiação infravermelha corresponde à parte do espectro entre o visível e as microondas. Essa radiação, quando em freqüências menores do que $100 \mathrm{~cm}^{-1}$, pode ser 
absorvida por uma molécula orgânica e convertida em rotação molecular, e quando a faixa da radiação está entre 10000 a $100 \mathrm{~cm}^{-1}$ a energia absorvida é convertida em energia de vibração molecular. Há dois tipos de vibrações moleculares: as deformações axiais, movimentos rítmicos ao longo do eixo da ligação, de forma que a distância interatômica varie, e as deformações angulares que correspondem a variações de ângulos de ligação. Somente as vibrações que resultam em alteração no momento de dipolo molecular são observadas no infravermelho convencional, pois o campo elétrico alternado, produzido pela mudança de distribuição de carga que acompanha a vibração, acopla a vibração molecular com o campo oscilante da radiação eletromagnética, o que resulta em absorção de energia radiante ${ }^{(37)}$.

Os polímeros, por apresentarem grupos funcionais com vibrações no infravermelho, puderam ser analisados por essa técnica. A figura 21 mostra os espectros dos copolímeros contendo os meros TFEMA e DR13MA, e também do homopolímero HPTFEMA. As principais bandas estão marcadas na figura e suas atribuições se encontram na tabela 5. 


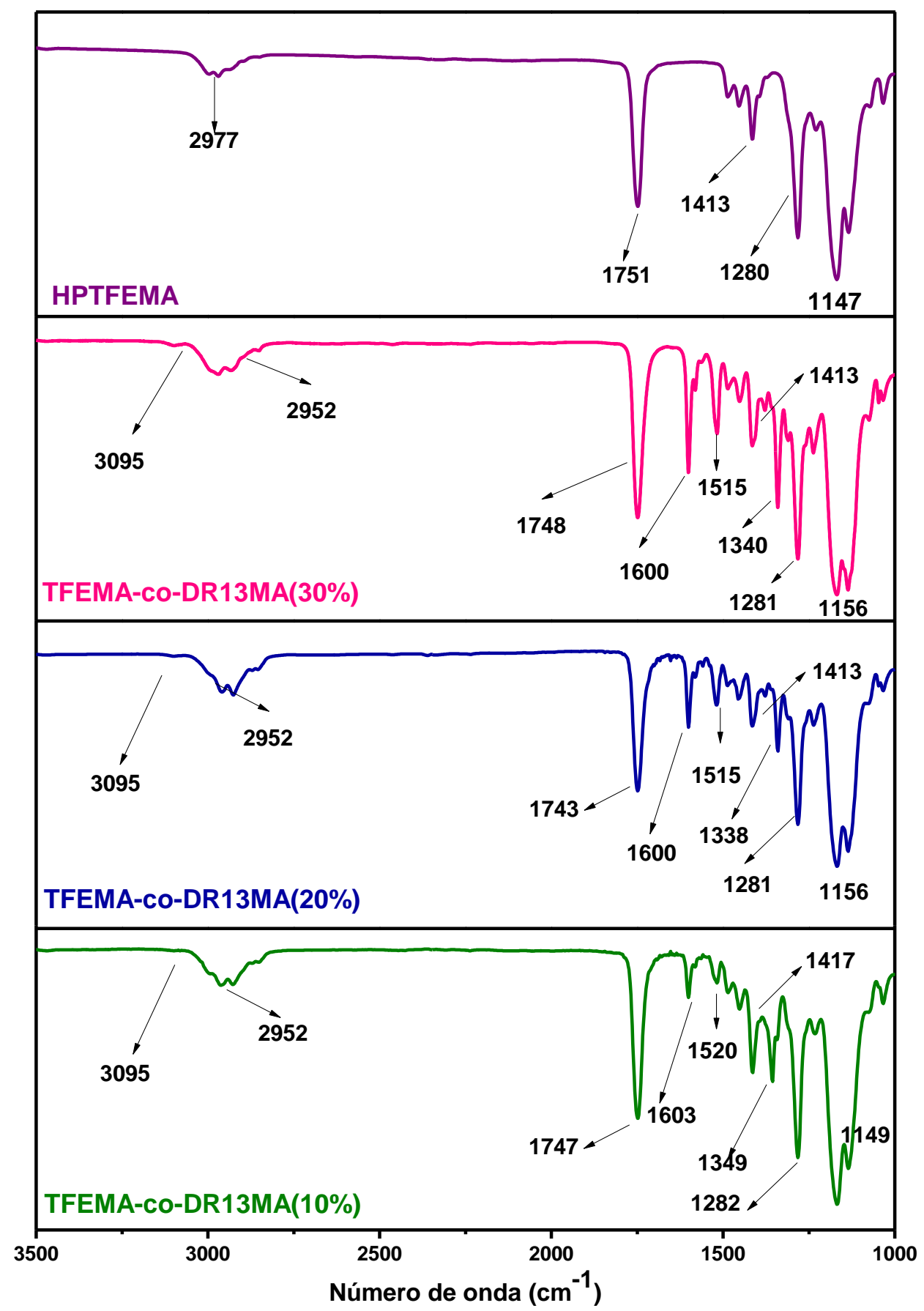

Figura 21-Espectro de Infravermelho do homopolímero HPTFEMA e dos copolímeros TFEMA-coDR13MA

Bandas com números de onda superiores a $3000 \mathrm{~cm}^{-1}$ são atribuídas a deformações axiais de $\mathrm{CH}$ de cadeia aromática. Já números de onda próximos, porém menores de 3000 
$\mathrm{cm}^{-1}$, estão relacionadas a $\mathrm{CH}_{2}$ e $\mathrm{CH}_{3}$ de cadeia alifática. Essa banda contém dois picos, sendo o primeiro (número de onda maior) relacionado à deformação axial assimétrica, em que as duas ligações C-H se estendem enquanto a terceira se contrai, e o segundo está relacionado à deformação axial simétrica, em que as três ligações C-H se estendem e se contraem em fase. Os ésteres possuem duas bandas intensas devidas às deformações axiais dos grupos $\mathrm{C}=\mathrm{O}$ e $\mathrm{C}$ O. A banda em $1600 \mathrm{~cm}^{-1}$ se refere às duplas ligações de anéis aromáticos do mero DR13MA $(\Phi-\mathrm{N}=\mathrm{N}-\Phi)$. Por conterem um grupo nitro-aromático, os copolímeros possuem duas bandas de absorção em torno de 1520 e $1340 \mathrm{~cm}^{-1}$, características das deformações axiais simétricas e assimétricas. Os grupos $\mathrm{CF}_{3}$ e $\mathrm{CF}_{2}$ absorvem fortemente na região de $1350-1120 \mathrm{~cm}^{-1}$ (35).

Tabela 5-Atribuições das principais bandas de FTIR

\begin{tabular}{cc}
\hline Número de onda & Atribuições \\
\hline $3090 \mathrm{~cm}^{-1}$ & Bandas de deformação axila de C-H aromático \\
$2950 \mathrm{~cm}^{-1}$ & Deformações axiais simétrica e assimétricas de CH2 e CH3 alifático \\
$1750 \mathrm{~cm}^{-1}$ & Deformação axial de C=O de éster \\
$1600 \mathrm{~cm}^{-1}$ & Deformação axial assimétrica de C=C de sistemas conjugados \\
$1520 \mathrm{~cm}^{-1}$ & Deformação axial assimétrica de $\mathrm{N}=\mathrm{O}$ ligado ao anel aromático \\
$1410 \mathrm{~cm}^{-1}$ & Deformação angular simétrica no plano de C-H alifático \\
$1340 \mathrm{~cm}^{-1}$ & Deformação axial simétrica de $\mathrm{N}=\mathrm{O}$ ligado ao anel aromático \\
$1280 \mathrm{~cm}^{-1}$ & Deformação axial de C-O de éster \\
$1150 \mathrm{~cm}^{-1}$ & Deformação axial de C-F \\
\hline
\end{tabular}

Com essas análises, infere-se que ambos os monômeros foram incorporados na molécula. Além disso, a ausência da banda do grupo $C=C$, de intensidade fraca em $1640 \mathrm{~cm}^{-1}$, representada no espectro do monômero de DR13MA da figura 22 e atribuída a monômeros vinílicos, confirma a polimerização. Há também um aumento da banda do $\mathrm{N}=\mathrm{O}$ do mero azo com o aumento da sua proporção, confirmando a maior incorporação na molécula. 


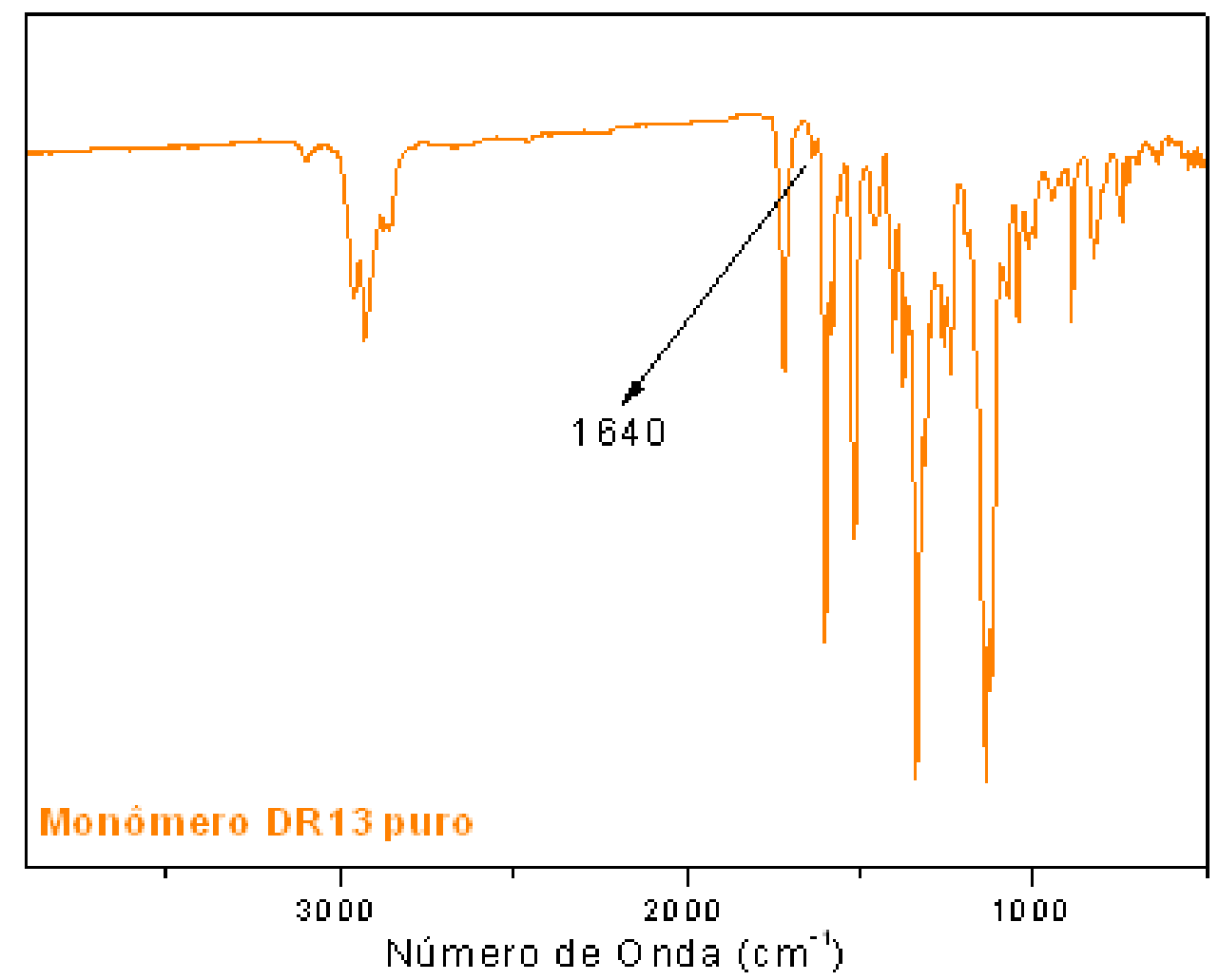

Figura 22-Espectro de FTIR do monômero DR13MA

A figura 23 mostra espectros dos compostos com os meros OFPMA e DR13MA, e do homopolímero HPOFPMA. As bandas são similares às dos compostos TFEMA e suas atribuições estão na tabela 6. Nestes compostos também não se observa a banda dos monômeros correspondente à ligação $\mathrm{C}=\mathrm{C}$, em $1640 \mathrm{~cm}^{-1}$, mostrando que ocorreu a polimerização. Há um aumento das bandas equivalentes à porção do azo mero simultaneamente com a diminuição das bandas correspondentes ao mero hidrofóbico, o que mostra a obtenção de compostos com diferentes concentrações do azo nas cadeias para as duas classes de compostos (TFEMA-co-DR13MA e OFPMA-co-DR13MA). 


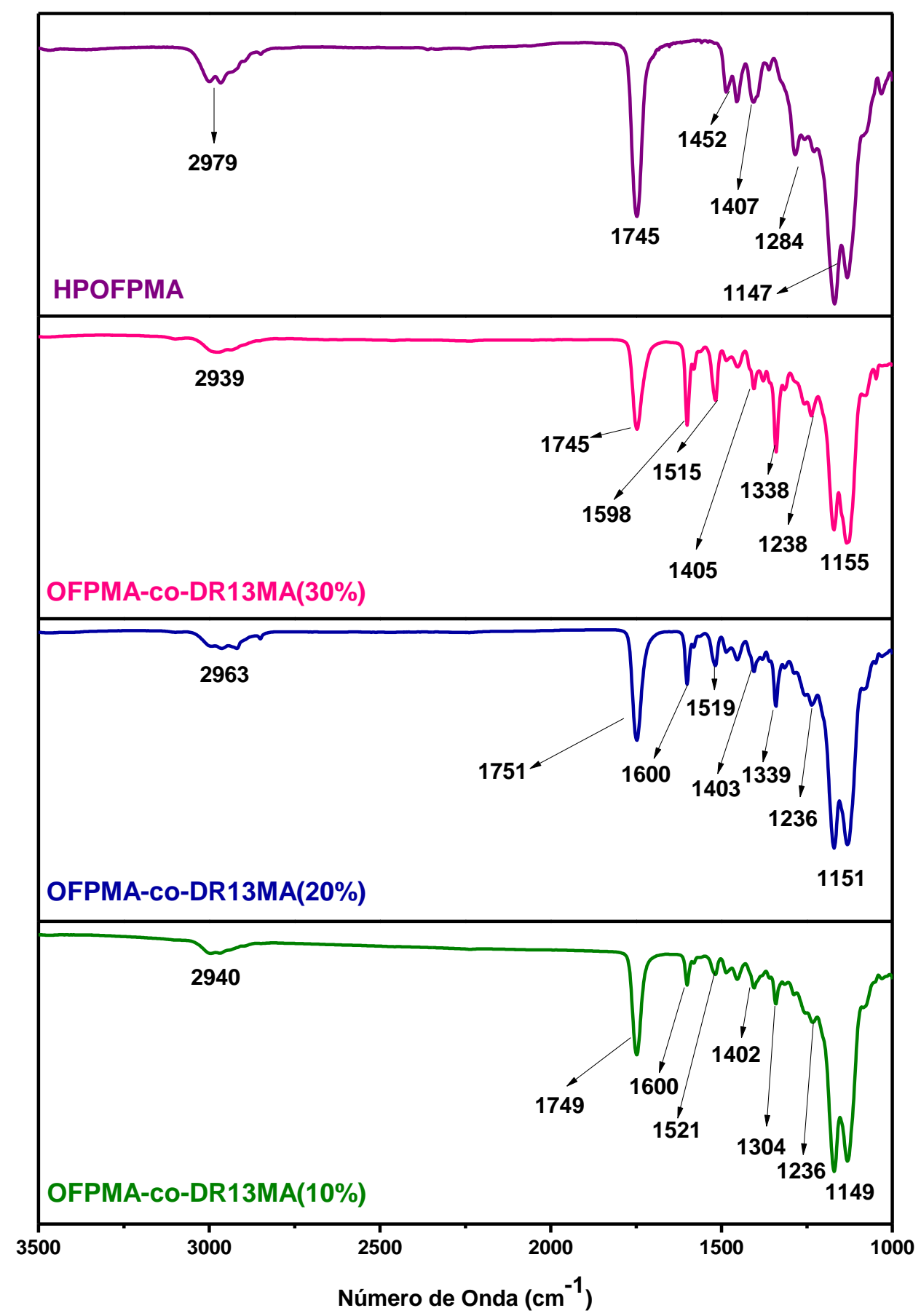

Figura 23-Espectros de Infravermelho do homopolímero HPOFPM e dos copolímeros OFPMA-coDR13MA 
Tabela 6-Atribuições das principais bandas de FTIR

\begin{tabular}{cc}
\hline N$^{\mathbf{0}}$ de onda & Atribuições \\
\hline $2950 \mathrm{~cm}^{-1}$ & Deformações axiais simétrica e assimétricas de CH2 e CH3 alifático \\
$1750 \mathrm{~cm}^{-1}$ & Deformação axial de C=O de éster \\
$1600 \mathrm{~cm}^{-1}$ & Deformação axial assimétrica de C=C de sistemas conjugados \\
$1520 \mathrm{~cm}^{-1}$ & Deformação axial assimétrica de N=O ligado ao anel aromático \\
$1405 \mathrm{~cm}^{-1}$ & Deformação angular simétrica no plano de C-H alifático \\
$1370 \mathrm{~cm}^{-1}$ & Deformação axial simétrica de N=O ligado ao anel aromático \\
$1330 \mathrm{~cm}^{-1}$ & Deformação axial de C-O de éster \\
$1150 \mathrm{~cm}^{-1}$ & Deformação axial de C-F \\
\hline
\end{tabular}

\subsubsection{Espectrometria de ressonância magnética de hidrogênio}

As figuras 24 a 27 mostram espectros de RMN e a identificação dos átomos de hidrogênio dos copolímeros. Os picos entre 6,5 e 8,5 ppm são referentes aos hidrogênios dos anéis aromáticos do grupo azo. Entre 0,5 e 2,5 ppm, os picos representam os $\mathrm{H}$ dos grupos $\mathrm{CH}_{3}$. O estudo de dois picos em especial, destacados na figura 25, permitiu estimar a proporção de cada tipo de mero no copolímero através da análise de hidrogênios em um mero comparados com hidrogênios do outro mero. Neste caso, determinou-se a proporção entre os hidrogênios representados pelos números 5, 6 e 7, que correspondem ao mero azo, como mostra a figura 24, e os hidrogênios com o número 1, que representam os $\mathrm{H}$ do mero fluorado. $\mathrm{O}$ pico maior em aproximadamente $4,3 \mathrm{ppm}$ representa os $\mathrm{H}$ marcados como 1 e os picos ao lado, em aproximadamente 3,6 ppm, representam os $\mathrm{H}$ representados por 5, 6 e 7. A proporção das áreas sob estes dois picos equivale à proporção em mol dos meros azo, que pode ser transformada para porcentagem em massa, cujos valores encontram-se na tabela 7 . 


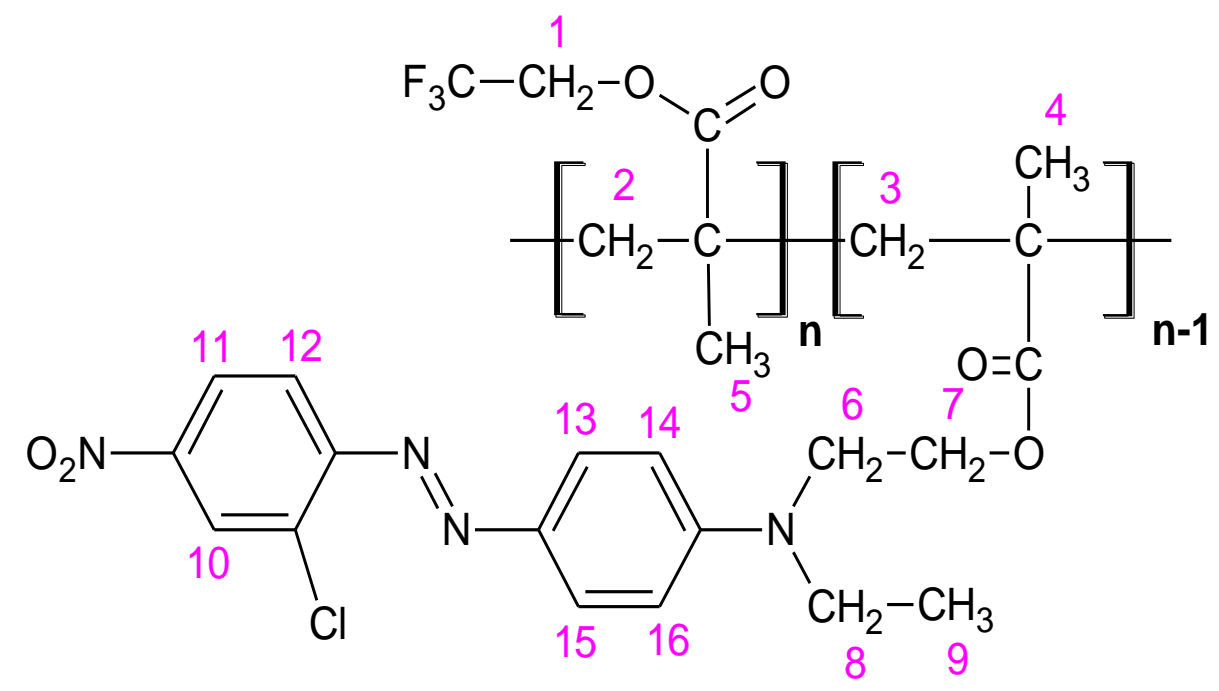

Figura 24-Estrutura dos polímeros TFEMA-co-DR13MA

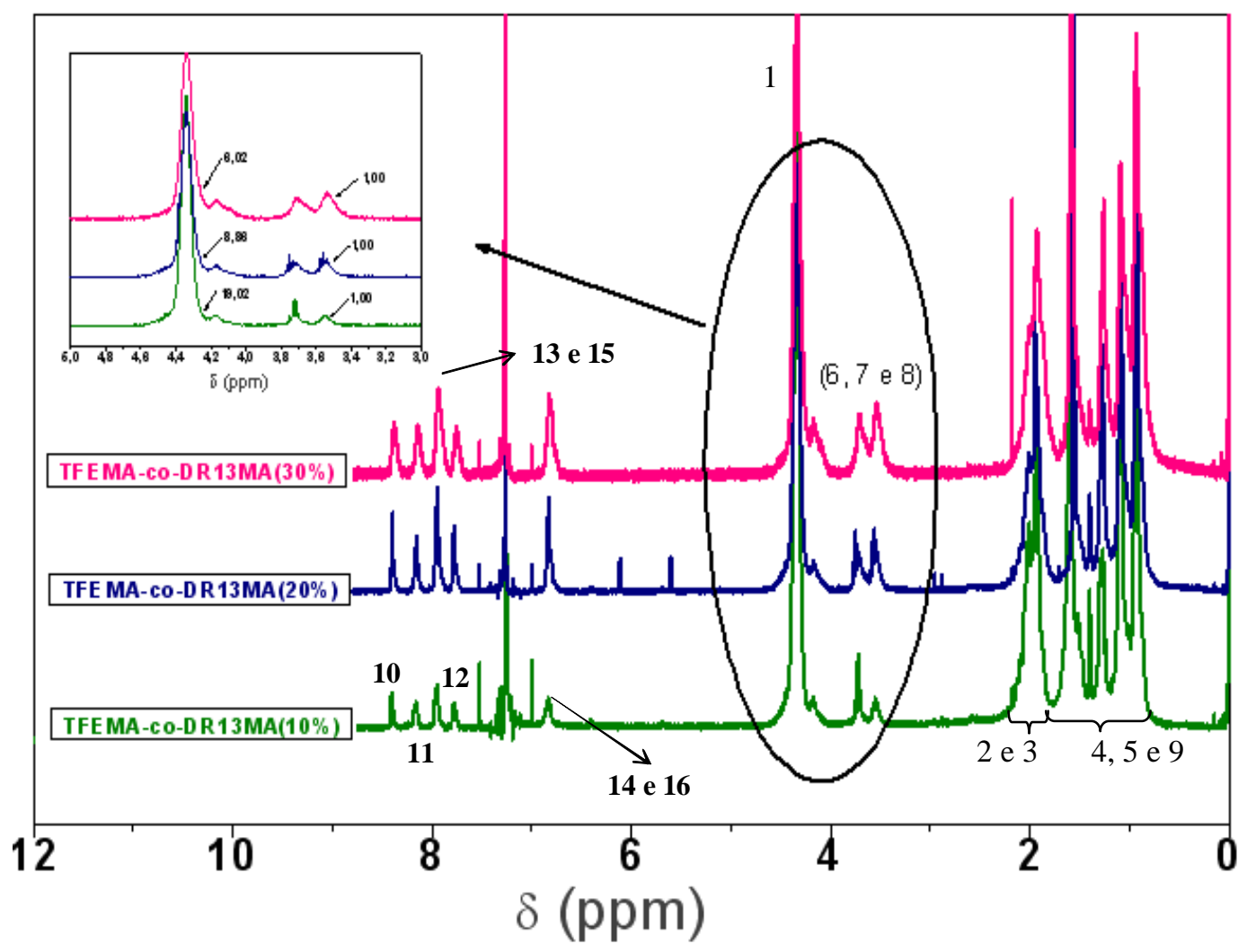

Figura 25-Espectro de $\mathrm{RMN} \mathrm{H}^{-1}$ dos polímeros TFEMA-co-DR13MA 
Tabela 7-Proporção em massa de azo monômero incorporado na molécula determinado por RMN H ${ }^{-1}$

\begin{tabular}{cc}
\hline Polímero & \% de azo calculado \\
\hline TFEMA-co-DR13MA(10\%) & 12 \\
TFEMA-co-DR13MA(20\%) & 24 \\
TFEMA-co-DR13MA(30\%) & 33 \\
\hline
\end{tabular}

Assim como para os TFEMA-co-DR13MA, identificaram-se os hidrogênios da molécula por RMN para os copolímeros OFPMA-co-DR13MA. Os picos de 6,5 a 8,5 ppm são referentes aos hidrogênios dos anéis aromáticos. O triplete em 6 ppm é referente ao $\mathrm{H}$ ligado ao $\mathrm{CF}_{2}$. $\mathrm{O}$ átomo de $\mathrm{F}$ tem spin $1 / 2$ e acopla-se fortemente com os hidrogênios. As regras para o acoplamento com o flúor são as mesmas que as do acoplamento hidrogêniohidrogênio. Em geral, as constantes de acoplamento hidrogênio-flúor são maiores e afetam a uma distância maior. Seu spin, evidentemente, é desdobrado pelos spins do hidrogênio e de outros átomos de flúor e as regras de multiplicidade são as mesmas do átomo de hidrogênio. ${ }^{(36)}$ Entre 0,5 e 2,5 ppm aparecem os $\mathrm{H}$ dos grupos $\mathrm{CH}_{3}$ da molécula. Também foi possível estimar a proporção de cada mero no copolímero. Do mesmo modo, determinou-se a proporção entre os hidrogênios representados pelos números 7,8 e 9, que correspondem ao mero azo, como mostra a figura 26 , e os hidrogênios de número 2 do mero fluorado. Os picos referentes a esses $\mathrm{H}$ estão destacados no espectro da figura 27 , em que o pico maior, em aproximadamente 4,5 ppm, representa os $\mathrm{H} 2$, e os picos ao lado, em aproximadamente 3,5 ppm, representam os H 7, 8 e 9. Os valores, já transformados em porcentagem em massa, estão na tabela 8. 


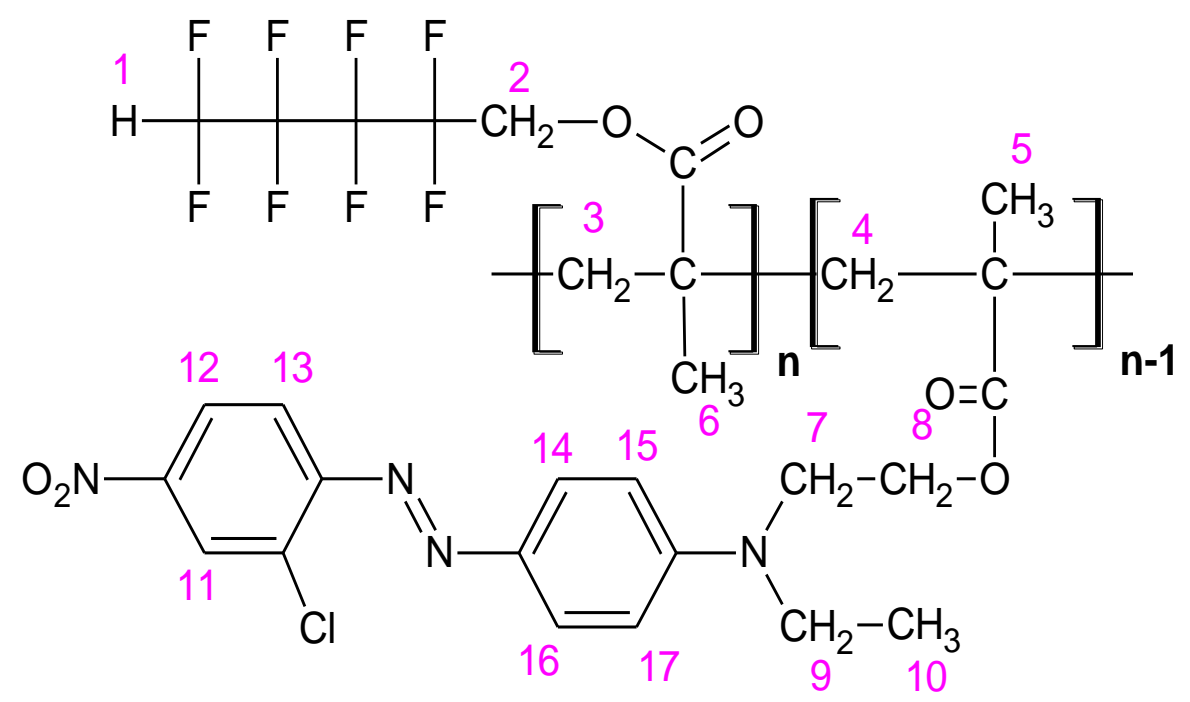

Figura 26-Estrutura dos polímeros OFPMA-co-DR13MA

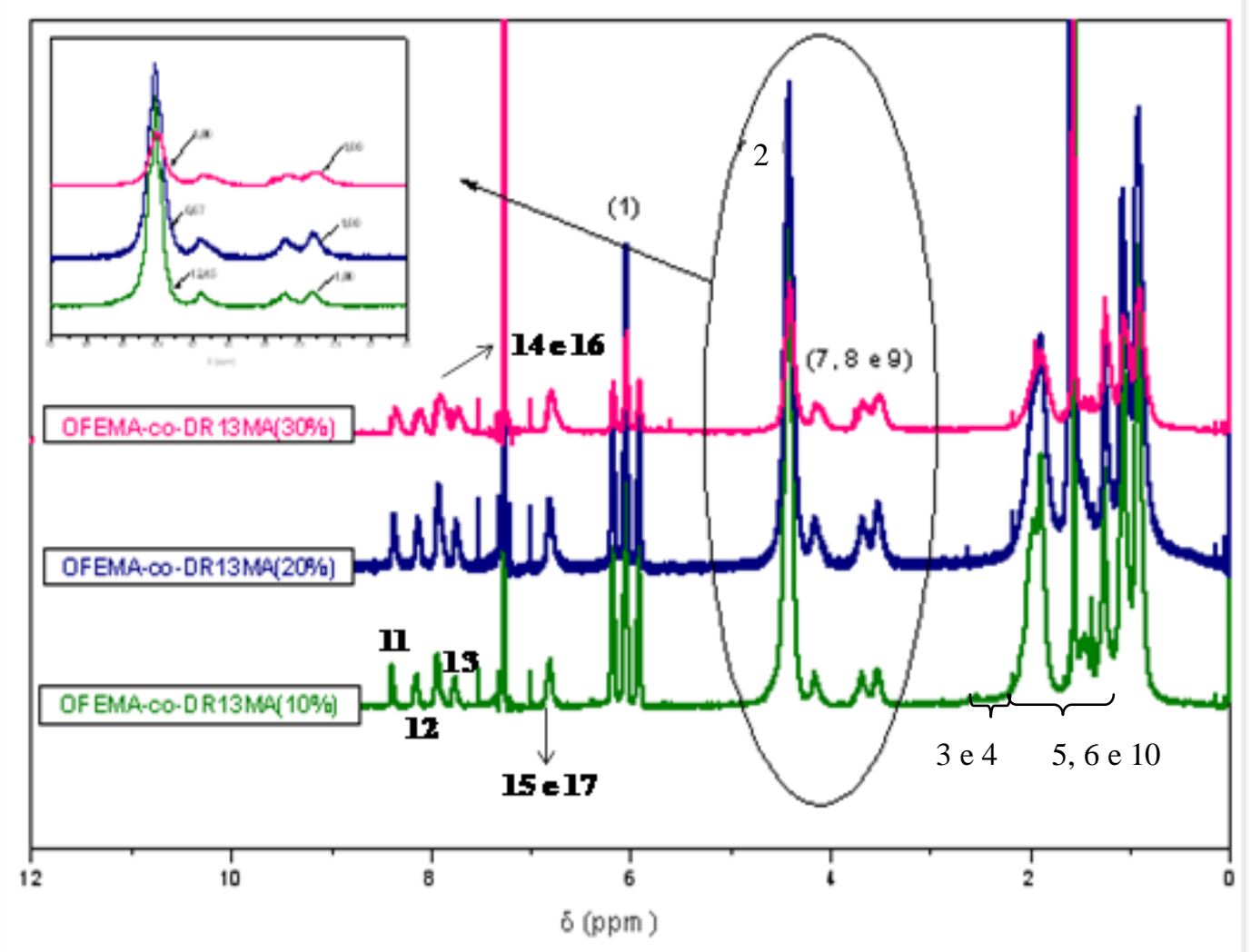

Figura 27-Espectro de $\mathrm{RMN} \mathrm{H}^{-1}$ dos polímeros OFPMA-co-DR13MA 
Tabela 8-Proporção em massa de azo monômero incorporado na molécula determinado por RMN $\mathrm{H}^{-1}$

\begin{tabular}{cc}
\hline Polímero & \% de azo calculado \\
\hline OFPMA-co-DR13MA(10\%) & 11 \\
OFPMA-co-DR13MA(20\%) & 20 \\
OFPMA-co-DR13MA(30\%) & 32 \\
\hline
\end{tabular}

Os valores de proporção de mero azo incorporado nos copolímeros determinados por RMN são próximos aos encontrados por UV-Vis, confirmando que, pelo menos para estas três proporções, a proporção de monômeros utilizada na reação se mantém no produto final, para os dois tipos de copolímeros.

A análise dos espectros de $\mathrm{RMN} \mathrm{H}^{-1}$ dos homopolímeros sintetizados HPTFEMA e HPOFPMA, mostrados na figura 28, indica a presença dos hidrogênios destacados na representação da unidade repetitiva. Essas caracterizações confirmam os resultados anteriores para os copolímeros.
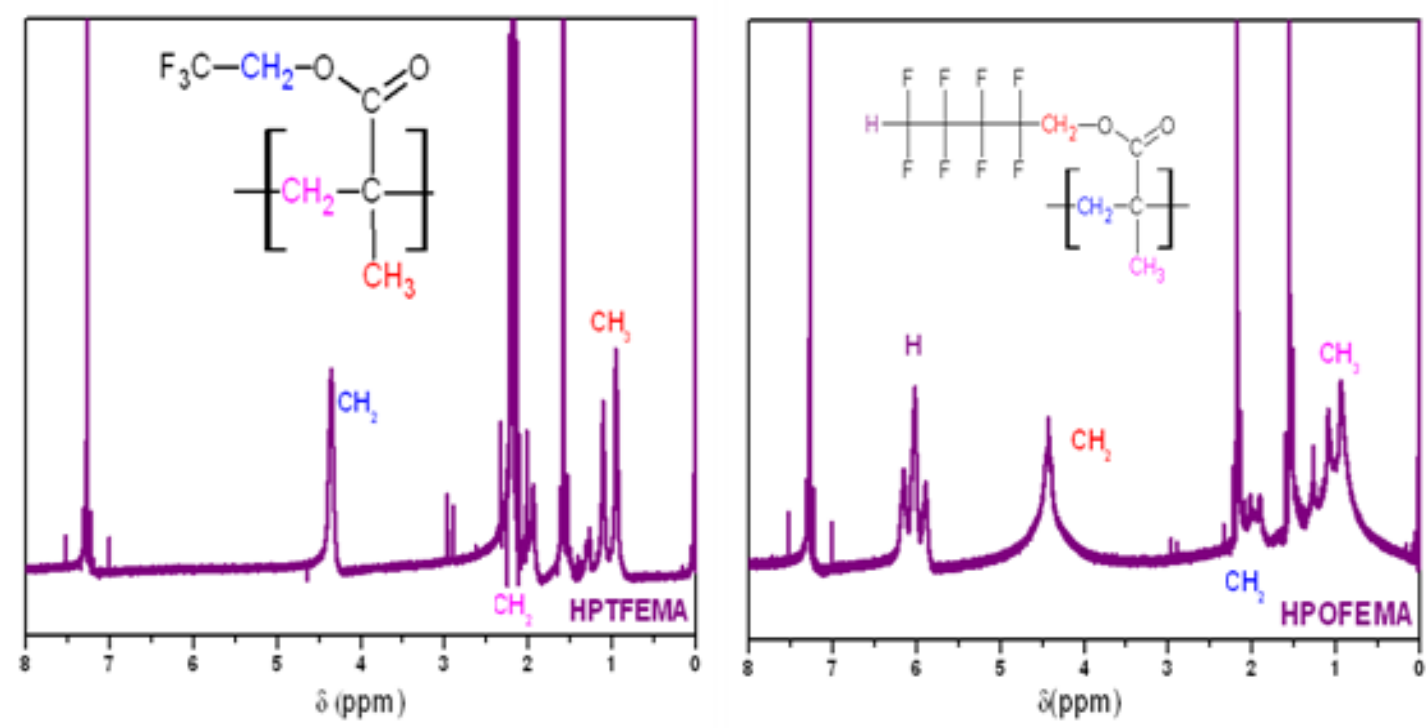

Figura 28-Espectros de RMN dos homopolímeros 


\subsubsection{Análises térmicas}

A chamada Análise Térmica abrange um grupo de técnicas em que uma propriedade física ou química de uma substância é monitorada em função do tempo ou temperatura, enquanto a temperatura da amostra, sob uma atmosfera específica, é submetida a uma variação controlada. As análises térmicas dos polímeros sintetizados neste trabalho foram obtidas com calorimetria exploratória diferencial (DSC) para determinar a temperatura de transição vítrea (Tg) e por análises termogravimétricas (TGA) para verificar a estabilidade térmica dos polímeros. A Tg é o valor médio da faixa de temperatura, durante o aquecimento e resfriamento de um material polimérico, que permite que as cadeias poliméricas da fase amorfa adquiram mobilidade. Abaixo da $\mathrm{Tg}$, o polímero não tem energia interna suficiente para permitir deslocamento de cadeias por mudanças conformacionais. Portanto, quanto mais cristalino o material, mais difícil será observar a banda da transição vítrea. Na curva de DSC, a Tg é caracterizada pela mudança de linha de base devida à mudança no calor específico $(\mathrm{Cp}$, dado em $\left.\mathrm{J} / \mathrm{g}^{\circ} \mathrm{C}\right){ }^{(34)}$.

Termogravimetria é a técnica na qual a mudança da massa de uma substância é medida em função da temperatura que é variada de maneira controlada. Esse método consiste na pirólise do composto em um forno com taxa de aquecimento controlada, em que se mede a perda de massa da amostra com uma balança de precisão. Com esse tipo de análise, pode-se caracterizar a estabilidade térmica e a decomposição dos compostos sob diferentes condições. Para este trabalho, o que mais interessa é o processo de decomposição dos polímeros, caracterizada por duas temperaturas, que são a do início e do fim da decomposição (Ti e Tf respectivamente), além das temperaturas correspondentes a $10 \%$ e $50 \%$ de decomposição.

As figuras 29 e 30 mostram as análises de TGA dos compostos, enquanto as tabelas 9 e 10 fornecem as relações entre Ti, Tf, T10\%, T50\% e porcentagem residual. Os espectros da parte superior das figuras mostram as derivadas dos termogramas da parte inferior, e servem para identificar as temperaturas em que acontecem perdas de massa significativas. A Ti dos copolímeros é igual à Ti do homopolímero hidrofóbico correspondente, que é de cerca de 220 ${ }^{\circ} \mathrm{C}$ para os compostos com o mero TFEMA e $230{ }^{\circ} \mathrm{C}$ para os compostos constituídos do mero OFPMA. Já o homopolímero HPDR13MA apresenta Ti baixa, cerca de $100{ }^{\circ} \mathrm{C}$. As temperaturas correspondentes a 10\% de decomposição do homopolímero HPDR13MA foi a mais baixa $\left(178{ }^{\circ} \mathrm{C}\right)$, e a correspondente ao copolímero TFEMA-co-DR13MA(20\%) foi a mais alta $\left(290^{\circ} \mathrm{C}\right)$ para os compostos contendo o mero TFEMA, e a do copolímero OFPMA- 
coDR13MA $(30 \%)$ foi a mais alta $\left(305^{\circ} \mathrm{C}\right)$ para os derivados do OFPMA. Para a decomposição de $50 \%$ da massa, as temperaturas não variam muito entre sim, sendo todas em torno de $370{ }^{\circ} \mathrm{C}$.

Somente os homopolímeros HPTFEMA e HPOFPMA foram decompostos completamente. O homopolímero HPDR13MA apresentou maior quantidade de resíduo após o processo, que foi de $24,0 \%$, seguido dos copolímeros com maior quantidade de mero azo, o que era já era esperado.
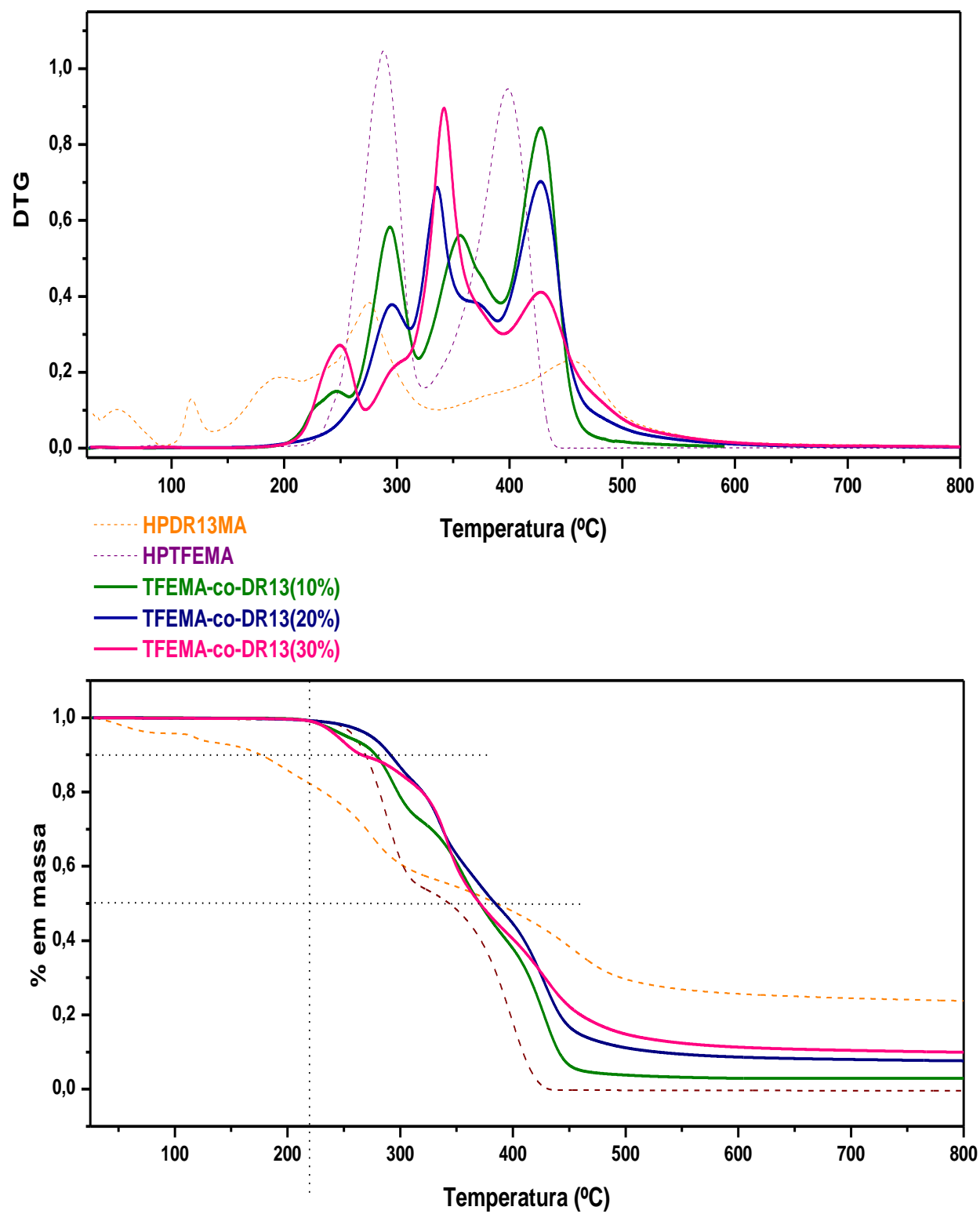

Figura 29-Curvas de DTG e TGA dos copolímeros TFEMA-co-DR13MA e dos homopolímeros HPTFEMA e HPDR13MA 
Tabela 9-Valores de temperatura e \% de resíduo final obtidos por TGA dos homopolímeros HPTFEMA e HPDR13MA e dos copolímeros TFEMA-co-DR13MA.

\begin{tabular}{lccccc}
\hline \multicolumn{1}{c}{ Polímero } & $\begin{array}{c}\text { Ti } \\
\left({ }^{\mathbf{0}} \mathbf{C}\right)\end{array}$ & $\begin{array}{c}\text { T 10\% } \\
\left({ }^{\mathbf{o}} \mathbf{C}\right)\end{array}$ & $\begin{array}{c}\text { T50\% } \\
\left({ }^{\mathbf{0}} \mathbf{C}\right)\end{array}$ & $\begin{array}{c}\text { Tf } \\
\left({ }^{\mathbf{o}} \mathbf{C}\right)\end{array}$ & Resíduo \\
\hline HPTFEMA & 219 & 269 & 344 & 432 & $0,4 \%$ \\
HPDR13MA & 50 & 178 & 386 & 564 & $24 \%$ \\
TFEMA-co-DR13MA(10\%) & 219 & 279 & 370 & 454 & $3 \%$ \\
TFEMA-co-DR13MA(20\%) & 219 & 290 & 386 & 492 & $8 \%$ \\
TFEMA-co-DR13MA(30\%) & 219 & 264 & 370 & 519 & $10 \%$ \\
\hline
\end{tabular}
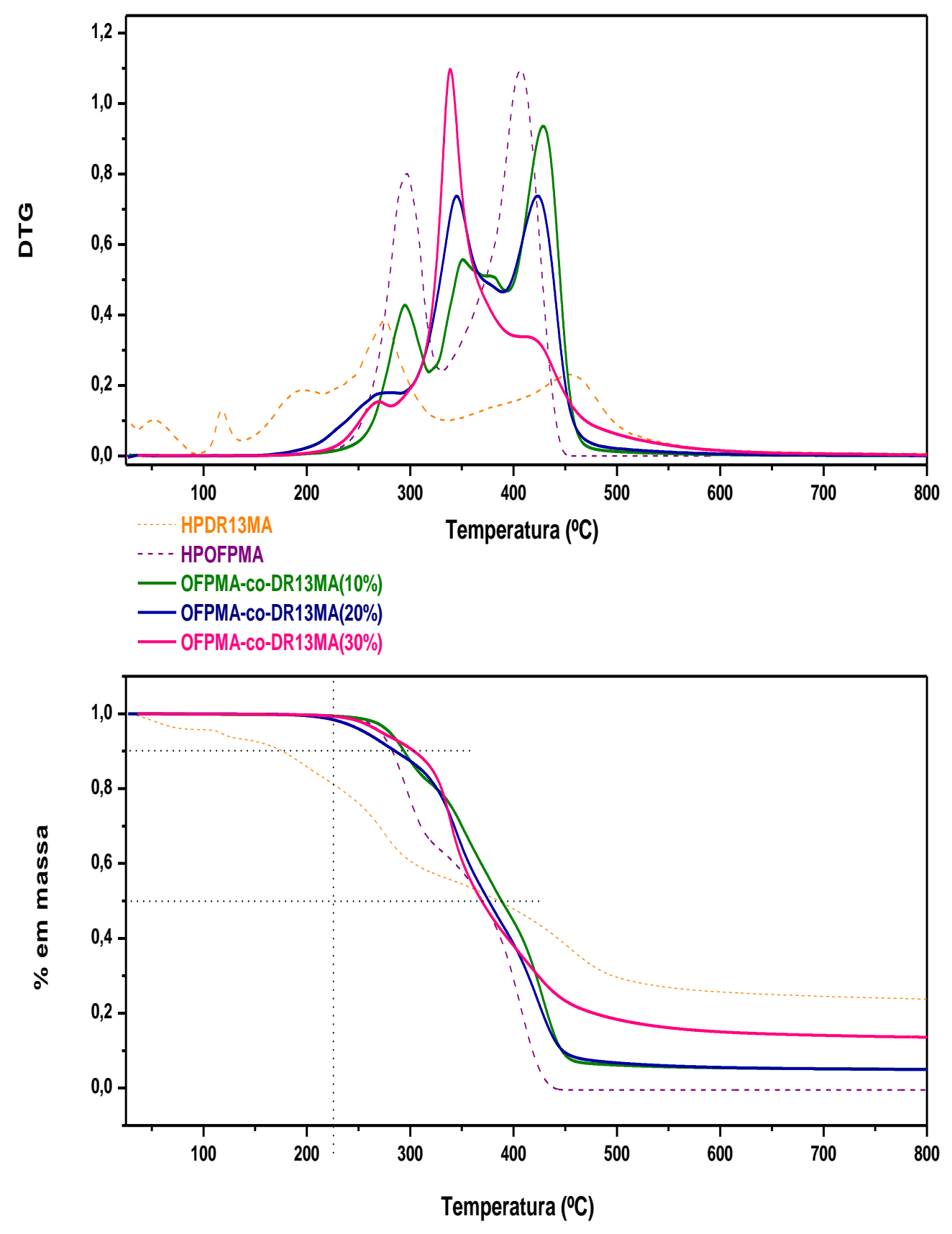
Figura 30-Curvas de DTG e TGA dos copolímeros OFPMA-co-DR13MA e dos homopolímeros HPOFPMA e HPDR13MA

Tabela 10-Valores de temperatura e \% de resíduo final obtidos por TGA dos homopolímeros HPOFPMA e HPDR13MA e dos copolímeros OFPMA-co-DR13MA.

\begin{tabular}{lccccc}
\hline \multicolumn{1}{c}{ Polímero } & $\begin{array}{c}\text { Ti } \\
\left.\mathbf{(}^{\mathbf{0}} \mathbf{C}\right)\end{array}$ & $\begin{array}{c}\text { T 10\% } \\
\left({ }^{\mathbf{0}} \mathbf{C}\right)\end{array}$ & $\begin{array}{c}\text { T50\% } \\
\left({ }^{\mathbf{0}} \mathbf{C}\right)\end{array}$ & $\begin{array}{c}\text { Tf } \\
\left({ }^{\mathbf{o}} \mathbf{C}\right)\end{array}$ & Resíduo \\
\hline HPOFPMA & 227 & 283 & 369 & 446 & $0,5 \%$ \\
HPDR13MA & 50 & 178 & 386 & 564 & $24 \%$ \\
OFPMA-co-DR13MA(10\%) & 227 & 294 & 388 & 462 & $5 \%$ \\
OFPMA-co-DR13MA(20\%) & 227 & 283 & 388 & 462 & $5 \%$ \\
OFPMA-co-DR13MA(30\%) & 227 & 305 & 369 & 501 & $14 \%$ \\
\hline
\end{tabular}

As curvas de DSC estão nas figuras 31 e 32. Para os homopolímeros HPOFPMA e HPDR13 não se observa mudança clara da linha de base que caracterize a transição vítrea. Para o homopolímero HPTFEMA há uma banda em aproximadamente $74{ }^{\circ} \mathrm{C}$. Para os copolímeros derivados do TFEMA a transição vítrea pode ser observada com Tg tomada no ponto médio da transição, de $71{ }^{\circ} \mathrm{C}, 66{ }^{\circ} \mathrm{C}$ e $82{ }^{\circ} \mathrm{C}$ respectivamente para o TFEMA-coDR13MA(10\%), TFEMA-co-DR13MA(20\%) e TFEMA-co-DR13MA(30\%), respectivamente. Para os copolímeros de OFPMA, somente a transição vítrea do OFPMA-coDR13(30\%) pode ser observada em $\mathrm{Tg} 58{ }^{\circ} \mathrm{C}$, valor relativamente mais baixo do que para compostos derivados do TFEMA. 


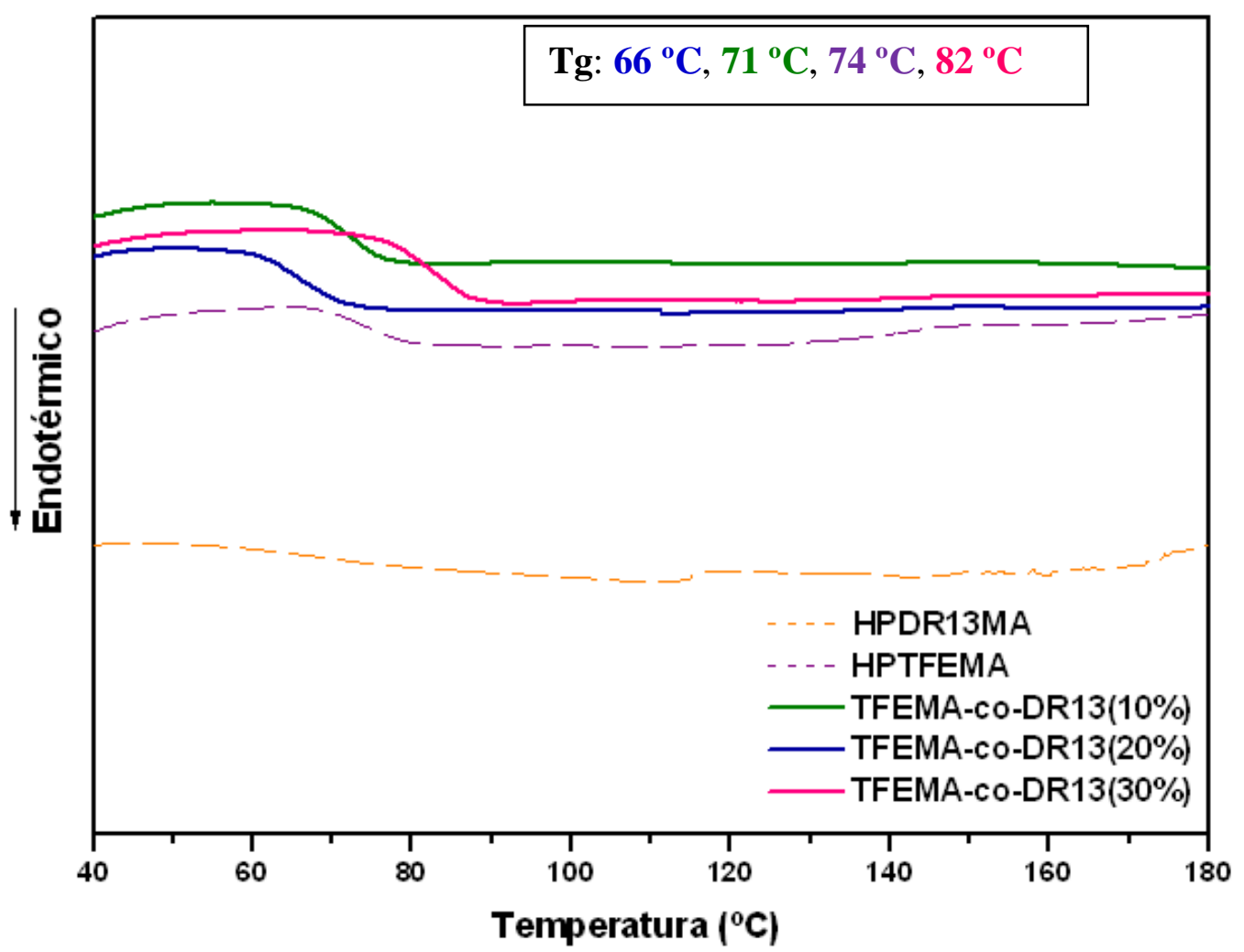

Figura 31-Curvas de DSC dos copolímeros TFEMA-co-DR13MA(10\%), TFEMA-coDR13MA(20\%), TFEMA-co-DR13MA(30\%), e dos homopolímeros HPTFEMA e HPDR13MA. 


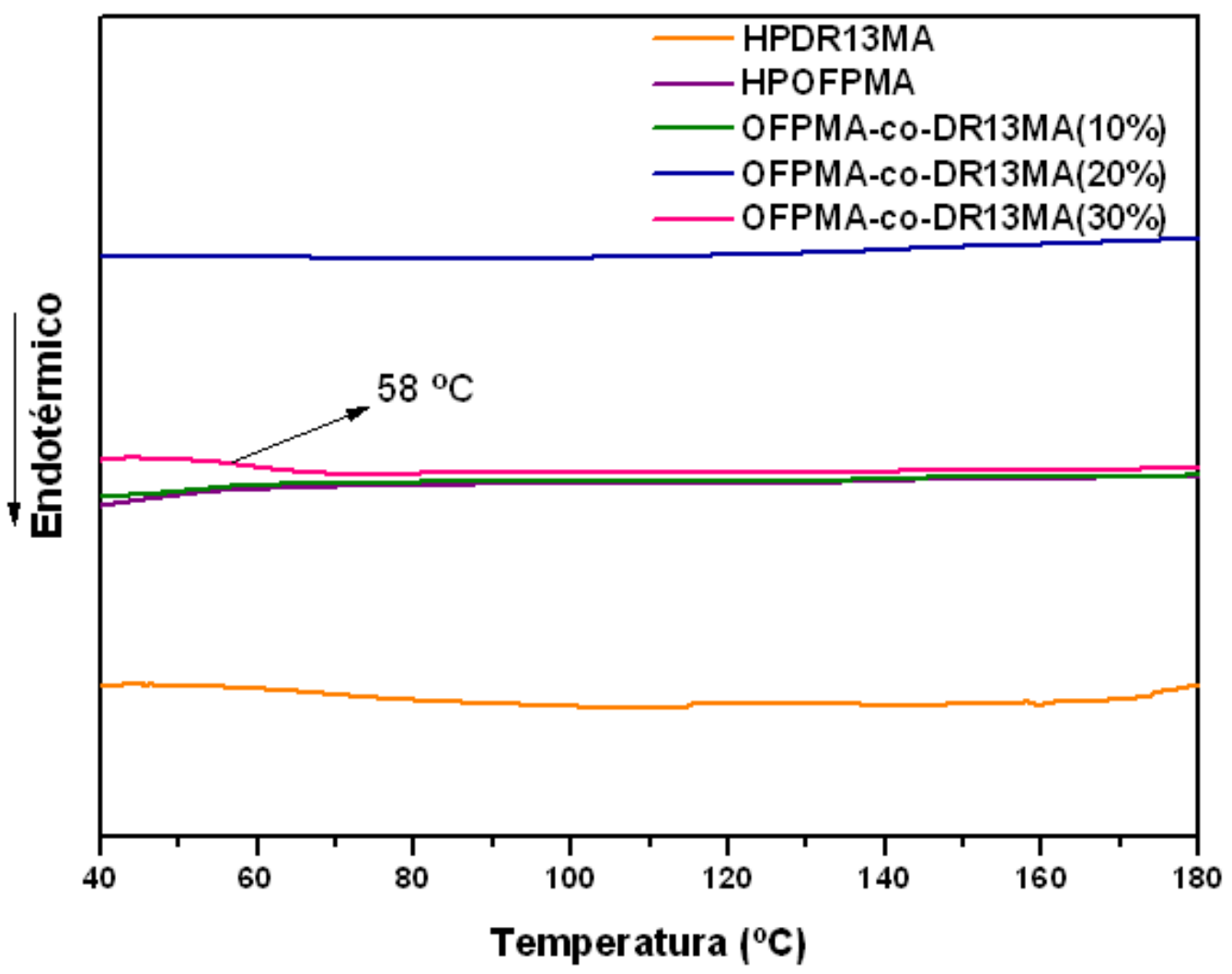

Figura 32-Curvas de DSC dos copolímeros TFEMA-co-DR13MA(10\%), TFEMA-coDR13MA(20\%), TFEMA-co-DR13MA(30\%), e dos homopolímeros HPTFEMA e HPDR13MA

\subsection{Fabricação e caracterização de filmes cast}

Os filmes cast dos copolímeros apresentaram boa homogeneidade, como se pode observar pela foto da figura 33, em que os filmes da parte de cima são os dos copolímeros TFEMA-co-DR13MA com 10, 20 e 30\% de meros azobenzênicos, respectivamente, e os de baixo são dos copolímeros OFPMA-co-DR13MA 20 e 30\% de meros azobenzênicos, respectivamente. Os filmes cast com o copolímero OFPMA-co-DR13MA(10\%) não apresentaram boa homogeneidade, e por isso não foram caracterizados. 


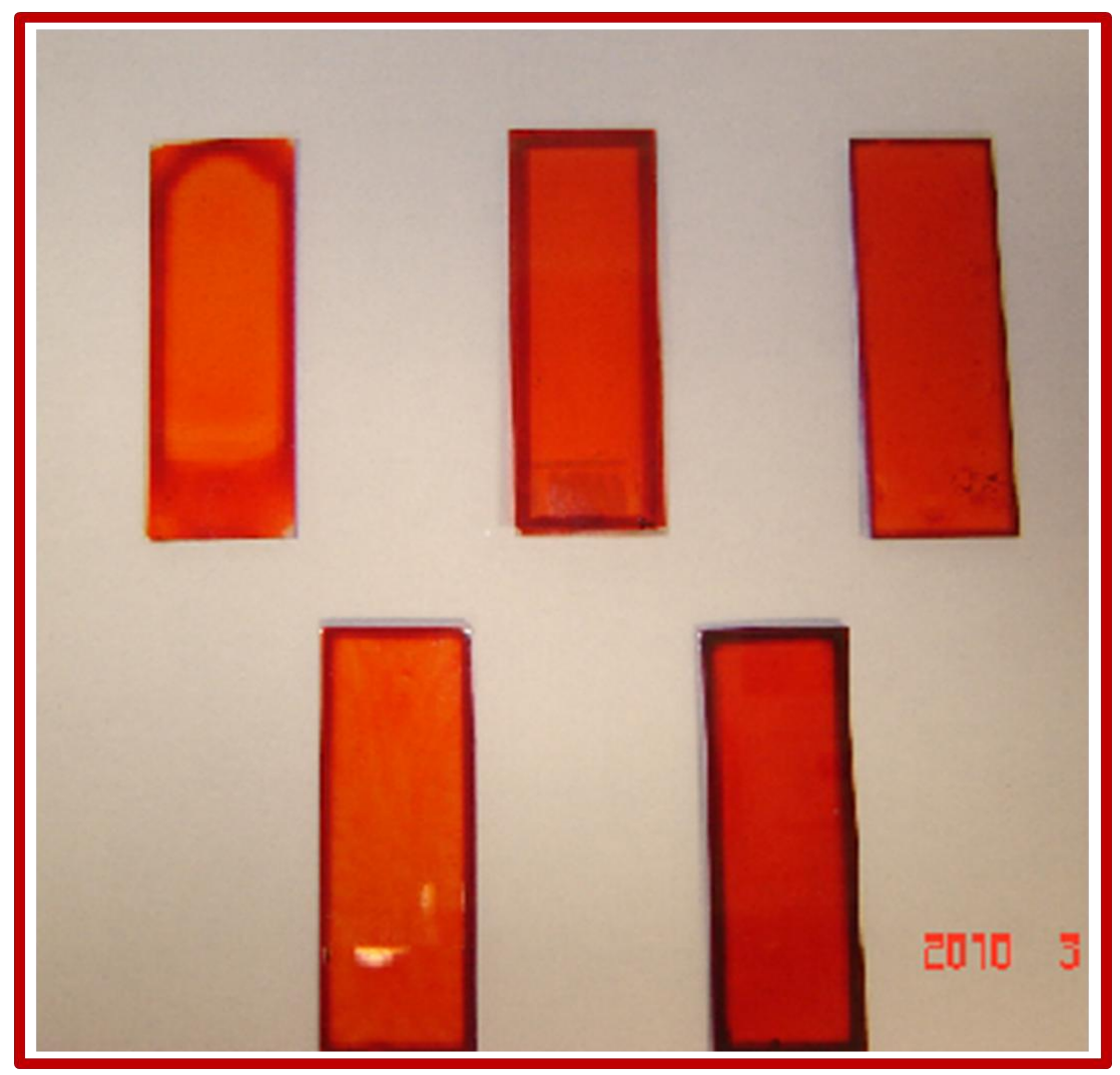

Figura 33-Fotos dos filmes cast dos copolímeros.

Os filmes foram caracterizados por análises de absorção no ultravioleta-visível (UVVis) e através de medidas de ângulo de contato com a água. Os espectros de UV-vis se encontram na figura 34, de onde se nota que o máximo na absorção dos copolímeros é deslocado em relação ao dos espectros dos copolímeros em solução de clorofórmio (que foi de $488 \mathrm{~nm}$ para os copolímeros TFEMA-co-DR13MA(10\%) e OFPMA-co-DR13MA(10\%) e de $484 \mathrm{~nm}$ para os demais compostos). O deslocamento é devido à agregação nos filmes sobre o substrato. 


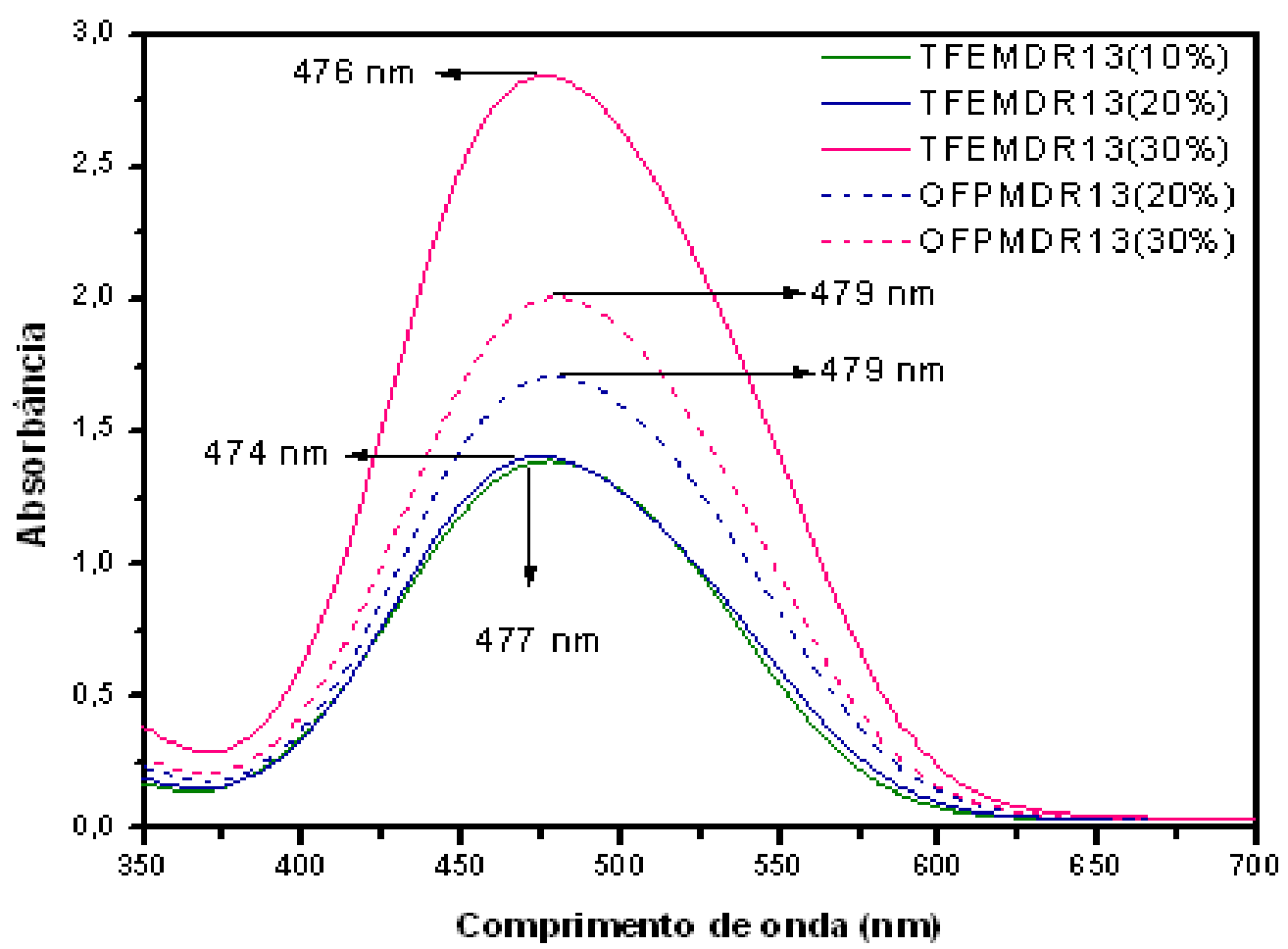

Figura 34-Espectros de UV-vis dos filmes cast.

A tabela 11 mostra os ângulos de contato com a água para os filmes de copolímeros, na qual se observa elevada hidrofobicidade, considerando-se tratar de azo compostos, pois apresentaram ângulos de contato superiores a $90^{\circ}$.

Tabela 11-Ângulo de contato dos filmes cast dos copolímeros

\begin{tabular}{ccc}
\hline Copolímero & $\boldsymbol{\lambda}$ de máxima absorção & Ângulo de contato $\left(^{\mathbf{0}}\right)$ \\
\hline TFEMDR13(10\%) & $477 \mathrm{~nm}$ & $97,0 \pm 0,5$ \\
TFEMDR13(20\%) & $474 \mathrm{~nm}$ & $96,0 \pm 1,0$ \\
TFEMDR13(30\%) & $476 \mathrm{~nm}$ & $95,0 \pm 0,5$ \\
OFPMDR13(20\%) & $479 \mathrm{~nm}$ & $96,0 \pm 1,0$ \\
OFPMDR13(30\%) & $479 \mathrm{~nm}$ & $97,0 \pm 1,0$ \\
\hline
\end{tabular}

Em alguns desses filmes foram realizados testes de formação de grades de relevo, a fim de verificar se a formação das grades levaria a uma maior hidrofobicidade. A figura 34 mostra as grades visualizadas com microscopia ótica com aumento de 100 vezes dos filmes cast dos copolímeros TFEMA-co-DR13MA(30\%) (à direita) e OFPMA-co-DR13MA(30\%) (à 
esquerda). Foi possível inscrever grades, mas os ângulos de contato com a água, medidos sobre as grades, foram de cerca de $95^{\circ}$ para ambos os filmes. Isto indica que essas grades não devem ser suficientemente profundas para causar mudanças significativas na hidrofobicidade da superfície. Para isso, será necessário ajustar vários parâmetros da formação das grades, como espessura dos filmes e potência do laser utilizado. Isso está além do escopo deste trabalho e, portanto, será abordado em trabalhos futuros, para obter superfícies superhidrofóbicas.

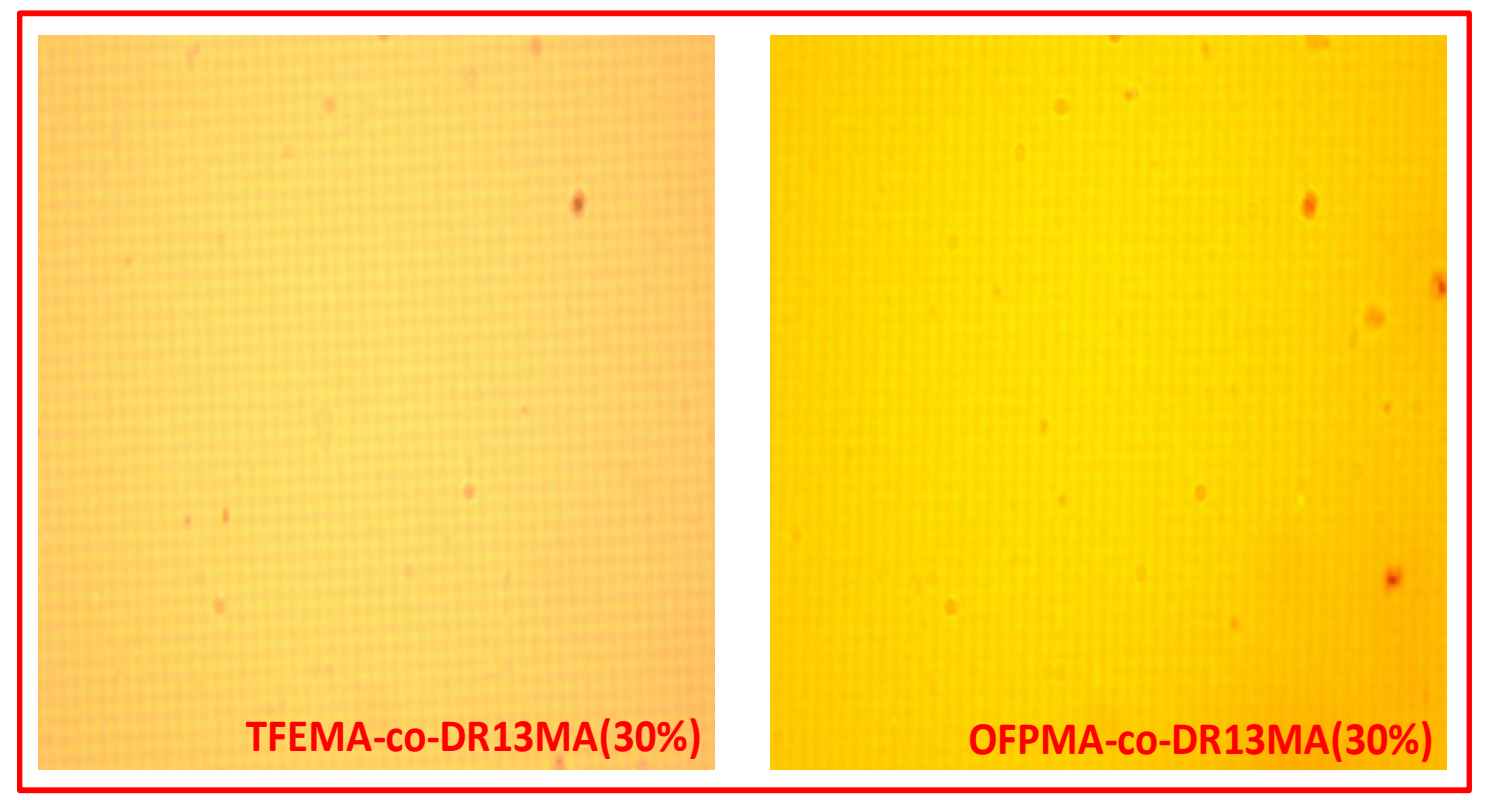

Figura 35-Filmes cast com grades de relevo

\subsection{Filmes de Langmuir e Langmuir-Blodgett (LB)}

O estudo dos filmes de Langmuir dos homopolímeros foi realizado a fim de comparálos com os copolímeros correspondentes.

\subsubsection{Homopolímero HPDR13MA}

O homopolímero HPDR13MA foi sintetizado e caracterizado no grupo de pesquisa em trabalhos anteriores ${ }^{(38)}$. Suas isotermas de pressão e potencial de superfície, mostradas na 
figura 36, foram obtidas para comparar com as isotermas dos copolímeros. No trabalho de Oliveira Jr. et al. ${ }^{(27)}$ o valor de área extrapolada foi $25 \AA^{2}$. A pressão de superfície começa a aumentar em $27 \AA^{2}$ e o colapso ocorre em $13 \AA^{2}$ numa pressão de $44 \mathrm{mN} / \mathrm{m}$. Na figura 36, a área extrapolada é de cerca de $21 \AA^{2}$, portanto, valor similar aos encontrados na literatura. A diferença mais marcante na isoterma de pressão foi a não formação do patamar que aparece nas isotermas dos copolímeros.

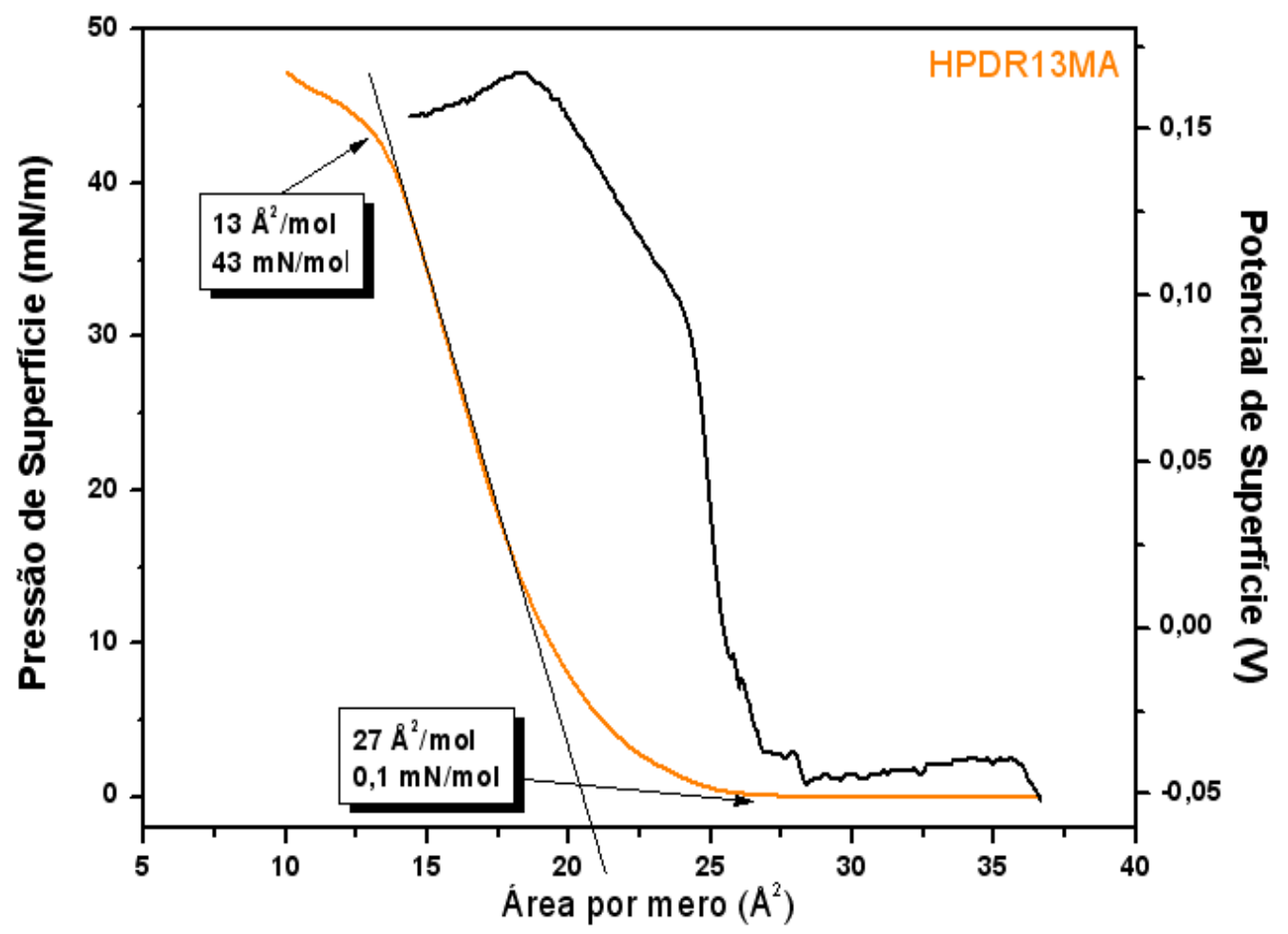

Figura 36-Isoterma de pressão vs. Área por molécula do homopolímero HPDR13MA

As medidas de potencial de superfície mostraram que o potencial no início da compressão era zero e assim permaneceu até se atingir a área por mero de aproximadamente $27 \AA^{2}$. Esses valores continuaram aumentando positivamente até a área por mero de aproximadamente $17 \AA^{2}$. O valor do potencial permanece nulo até valores próximos de área que a pressão começa a subir, chegando a valores de $0,15 \mathrm{~V}$ próximo ao colapso do filme. $\mathrm{O}$ valor nulo para o potencial em grandes áreas denota que não havia muita agregação das moléculas antes da compressão do filme de Langmuir. A subida íngreme no potencial a uma dada área, denominada de área crítica, é típica de filmes de Langmuir, e aparece quando 
domínios de moléculas se juntam a ponto de o potencial de superfície ser detectado pela prova de Kelvin.

O filme de Langmuir pode ser estudado também por microscopia no ângulo de Brewster (BAM) (homenagem ao físico escocês David Brewster) que permite caracterizar a morfologia de um filme em monocamada, a partir do contraste com a subfase, para a qual não há luz de polarização $p$ refletida no ângulo de Brewster. Entretanto, quando uma fase líquido-expandida ou líquido-condensada for formada, ainda que em apenas alguns domínios, seu índice de refração diferente provocará reflexão da luz de polarização $p$. Essa alteração na refletividade gera imagens de alto contraste. Imagens obtidas a diferentes pressões do filme são mostradas na figura 37.

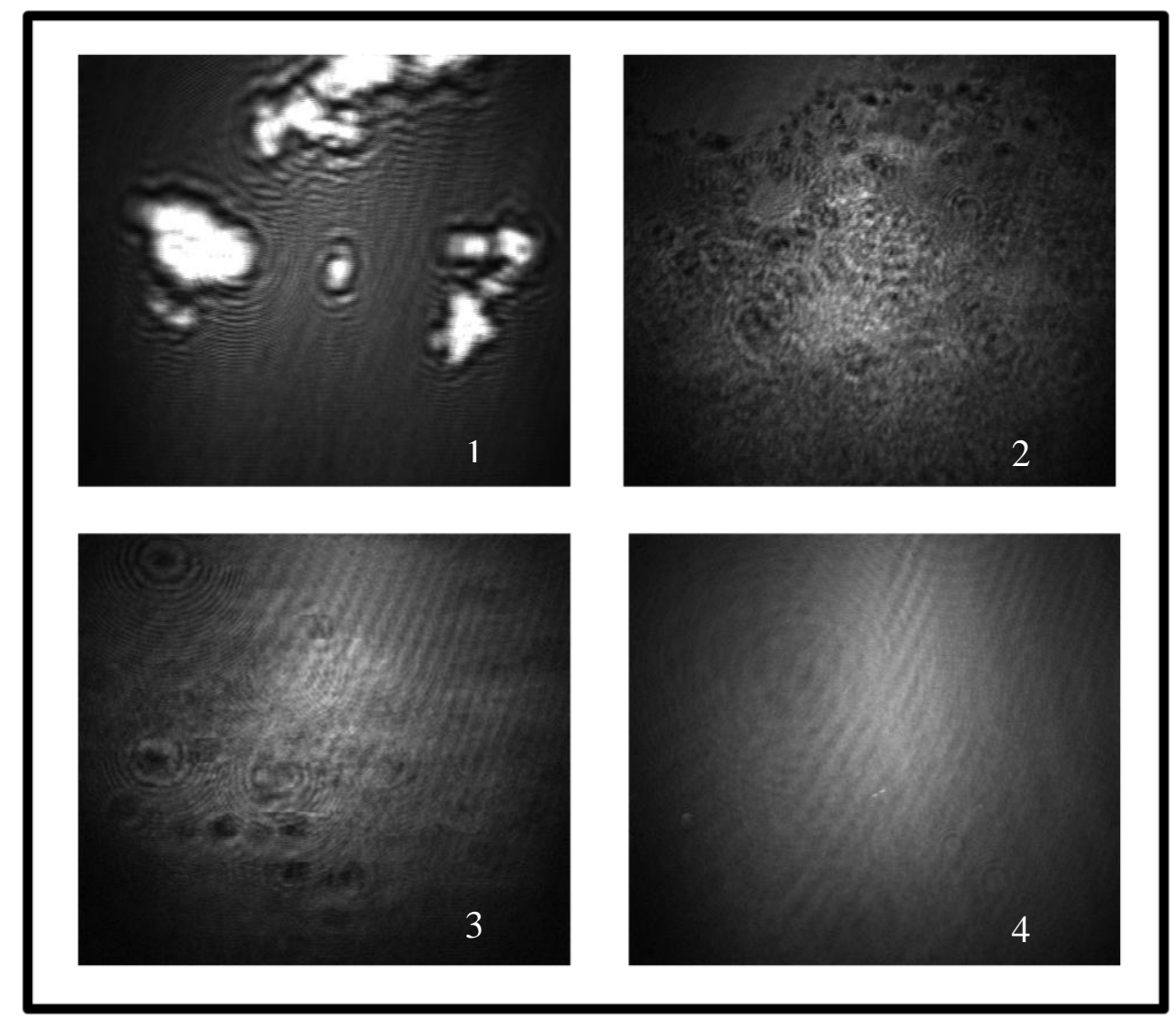

Figura 37-Fotos da superfície do filme de Langmuir do HPDR13MA com o microscópio no ângulo de Brewster

As duas primeiras mostram claramente domínios entre as moléculas, tendo sido obtidas com a monocamada totalmente expandida, ou seja, com pressão zero. Com a compressão pelas barreiras esses domínios vão desaparecendo até não se ver mais nada, como nas duas últimas imagens, indicando que o filme é bastante homogêneo e sem estruturas diferenciadas. Essas imagens estão de acordo com o que foi relatado por dos Santos et al. ${ }^{(39)}$. 


\subsubsection{Homopolímero HPTFEMA}

Os filmes de Langmuir do homopolímero HPTFEMA apresentaram uma região de transição de fase na isoterma de pressão de superfície, indicando possível rearranjo das cadeias poliméricas durante a compressão ou formação de uma bicamada. Esse rearranjo pode levar a diferentes orientações das moléculas dependendo do estágio da compressão. A isoterma do homopolímero HPTFEMA está na figura 38. A área extrapolada (calculada por mero do polímero), obtida pela extrapolação da tangente à parte mais íngreme da isoterma, é $17 \AA^{2}$ antes da "transição" e $9 \AA^{2}$ para a parte mais condensada da isoterma. A pressão deixa de ser nula em $19 \AA^{2}$, e aumenta até atingir um pseudo patamar, em $12 \AA^{2}$, que pode representar uma transição de fase. Com mais compressão, a pressão volta a subir de maneira íngreme, formando um filme bastante condensado. O colapso do filme ocorre em $61 \mathrm{mN} / \mathrm{m}$, com área extrapolada próxima de $5 \AA^{2} /$ mero. Dynarowicz-Łątka et al. ${ }^{(40)}$ encontraram 28 $\AA^{2} /$ molécula para compostos alcanos semifluorados. O baixo valor por mero deste trabalho pode, portanto, significar que o filme de Langmuir não é uma monocamada verdadeira, o que é comum em filmes de polímeros.

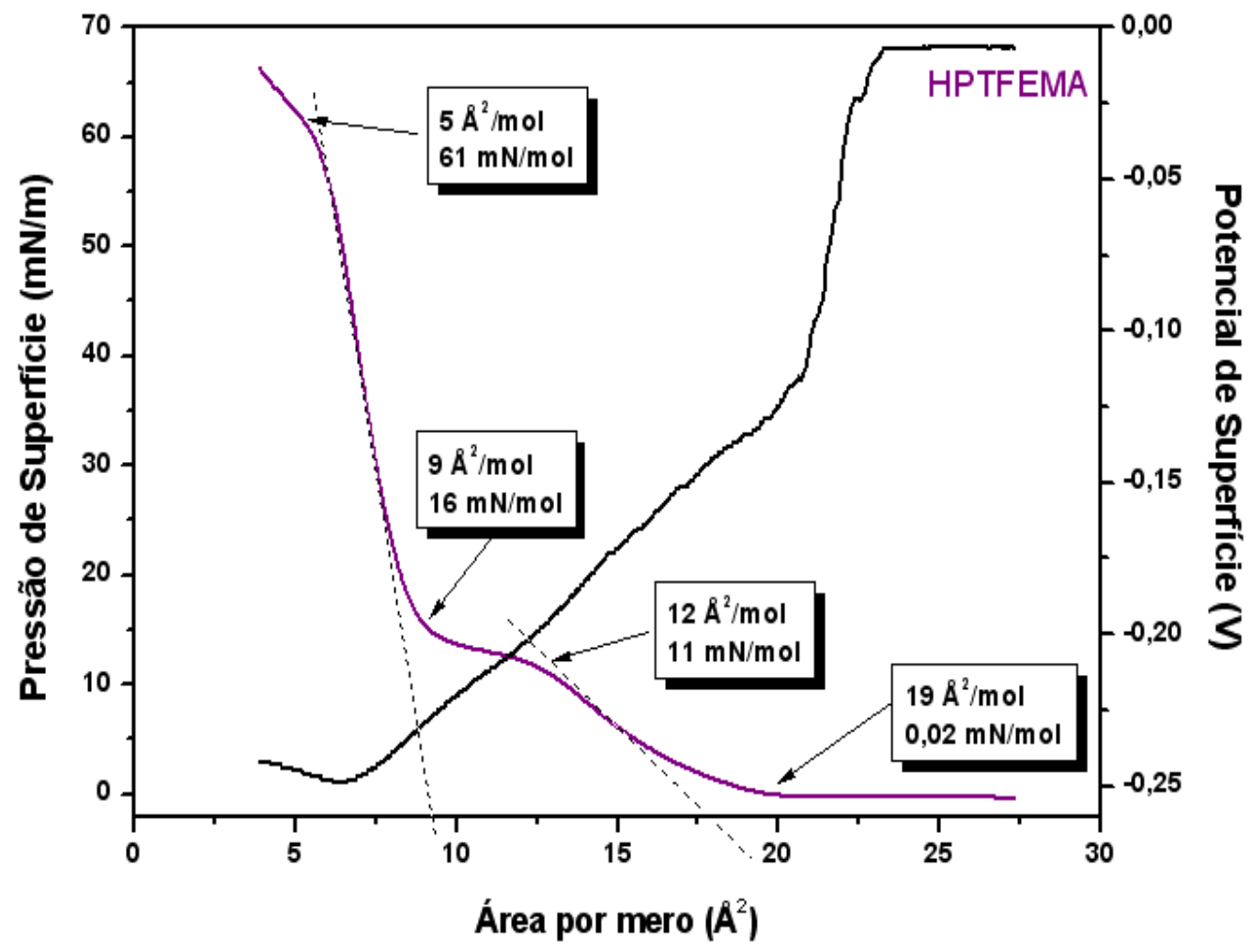

Figura 38-Isoterma de pressão vs. área por mero do homopolímero HPTFEMA 
O potencial para esse homopolímero, diferentemente do HPDR13MA, apresenta valores negativos de potencial, indicando como já era esperado que os átomos de flúor estão orientados para fora da água. A contribuição negativa para o potencial dos momentos de dipolo do grupo C-F predomina, até porque a constante dielétrica na interface filme/ar é a menor delas na equação (5). No início da compressão, o valor do potencial era zero, ou seja, não havia muita agregação, e assim permaneceu até área por mero de $23 \AA^{2}$, que pode ser considerada a área crítica na qual se dá uma queda brusca no potencial. Quando a pressão começa a subir, a curva de potencial tem alteração na sua inclinação, e o potencial passa a decrescer com menor intensidade com a área por mero. O potencial mínimo foi -0,25 V, numa área de $7 \AA^{2}$, próximo ao colapso do filme.

O filme de Langmuir também foi caracterizado por microscopia no ângulo de Brewster (BAM), cujas imagens são mostradas na figura 39. Observam-se pequenos domínios circulares nas duas primeiras imagens, que correspondem a pressões superficiais nulas. Com a compressão, esses domínios vão desaparecendo ( $3^{\mathrm{a}}$ imagem) até o completo desaparecimento ( $4^{\mathrm{a}}$ imagem), mostrando, assim como aconteceu para o HPDR13MA, que o filme é bastante homogêneo e sem estruturas 


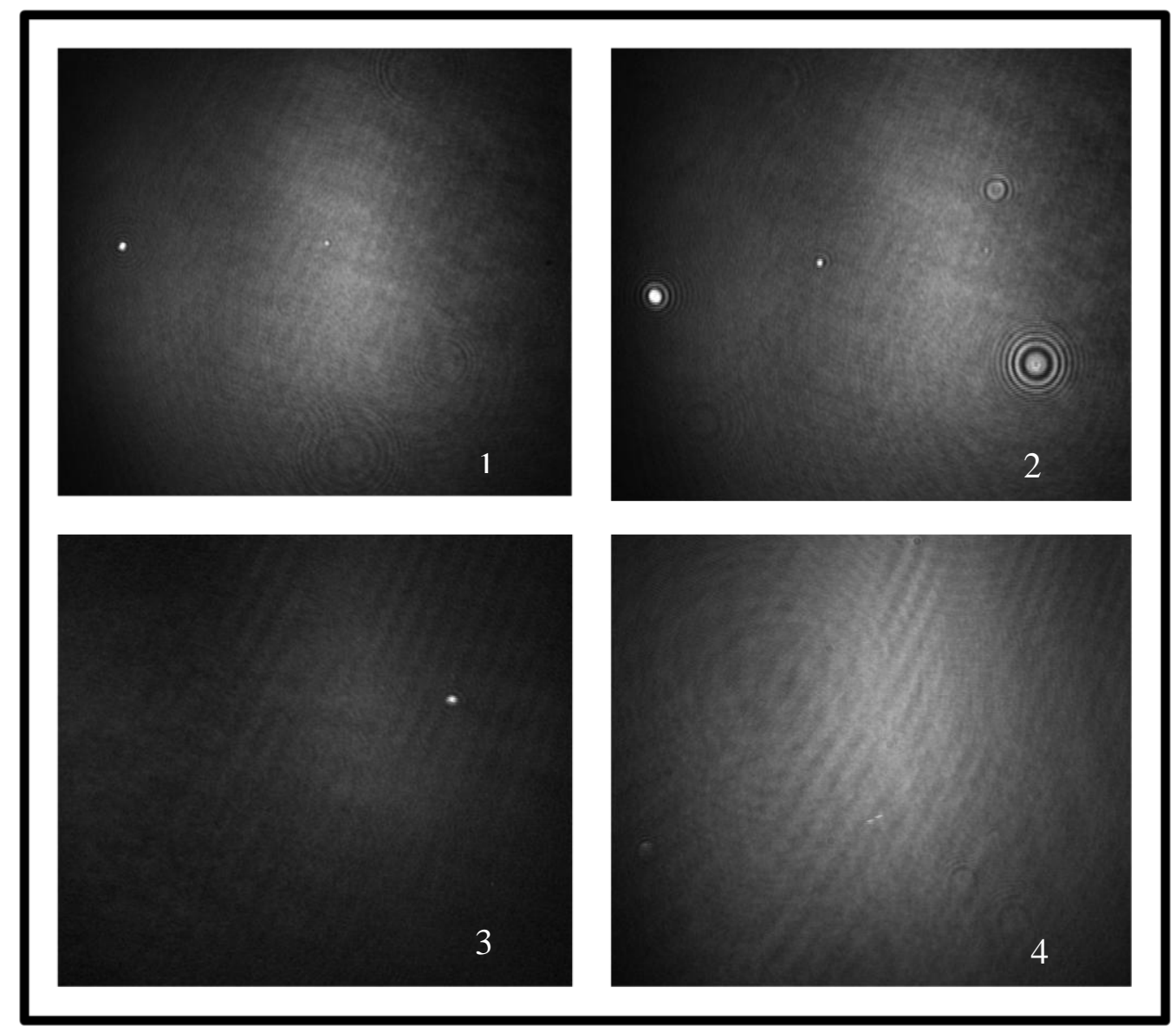

Figura 39-Fotos da superfície do filme de Langmuir do HPTFEMA com o microscópio no ângulo de Brewster

\subsubsection{Homopolímero HPOFPMA}

A isoterma de pressão de superfície dos filmes de Langmuir do homopolímero HPOFPMA, assim como a do homopolímero HPTFEMA, também apresentou uma região com mudança no comportamento da curva, indicando possíveis rearranjos das cadeias durante a compressão ou formação de uma bicamada. A isoterma deste homopolímero é mostrada na figura 40. As áreas extrapoladas são $22 \AA^{2}$ antes da "transição" e $8 \AA^{2}$ para a parte mais condensada da isoterma, valores próximos aos do homopolímero HPTFEMA. Para essa isoterma a compressão não atingiu o colapso, por se tratar de uma monocamada expandida. 


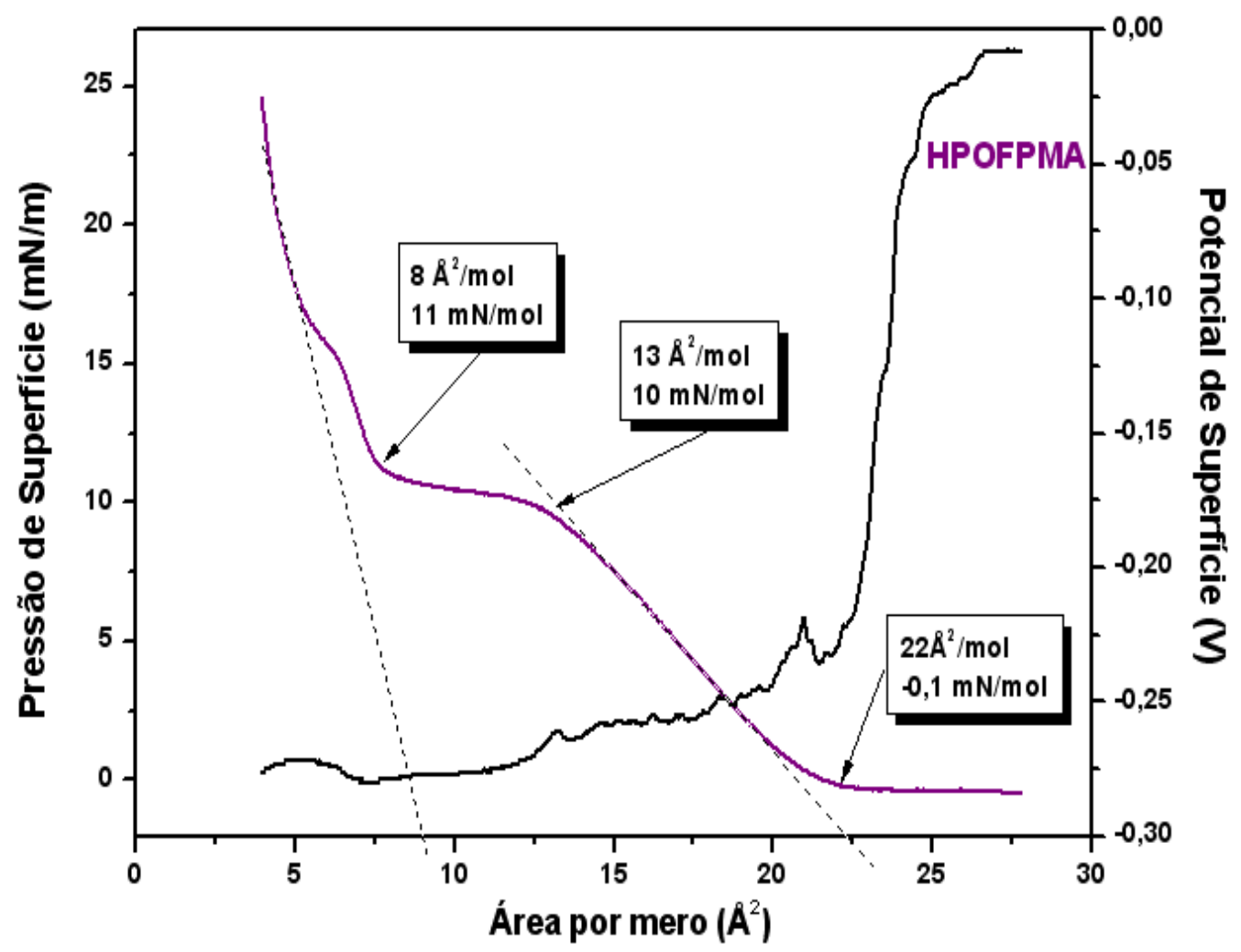

Figura 40-Isoterma de pressão vs. área por molécula do homopolímero HPOFPMA

O potencial de superfície para esse homopolímero apresentou comportamento similar ao do homopolímero HPTFEMA, com valores negativos de potencial, indicando que, assim como acontece para o HPTFEMA, os átomos de flúor estão orientados para fora da superfície. No início da compressão, o valor do potencial era zero e assim permaneceu até a área crítica por mero de $26 \AA^{2}$. Após a queda íngreme, novamente uma alteração na inclinação da curva de potencial aconteceu na área em que a pressão de superfície começou a subir. Embora não se possa precisar a origem dessa alteração, o mais provável é uma reorganização molecular. $\mathrm{O}$ potencial para o estado condensado foi $-0,30 \mathrm{~V}$, numa área de $5 \AA^{2}$ por mero.

Assim como para os compostos já descritos, o filme de Langmuir do HPOFPMA foi caracterizado por microscopia no ângulo de Brewster (BAM), cujas imagens estão na figura 41. O comportamento é o mesmo para o HPTFEMA, com pequenos domínios circulares em pressão nula (1 e 2) e o desaparecimento dos mesmos com o aumento da compressão (imagens 3 e 4 ). 

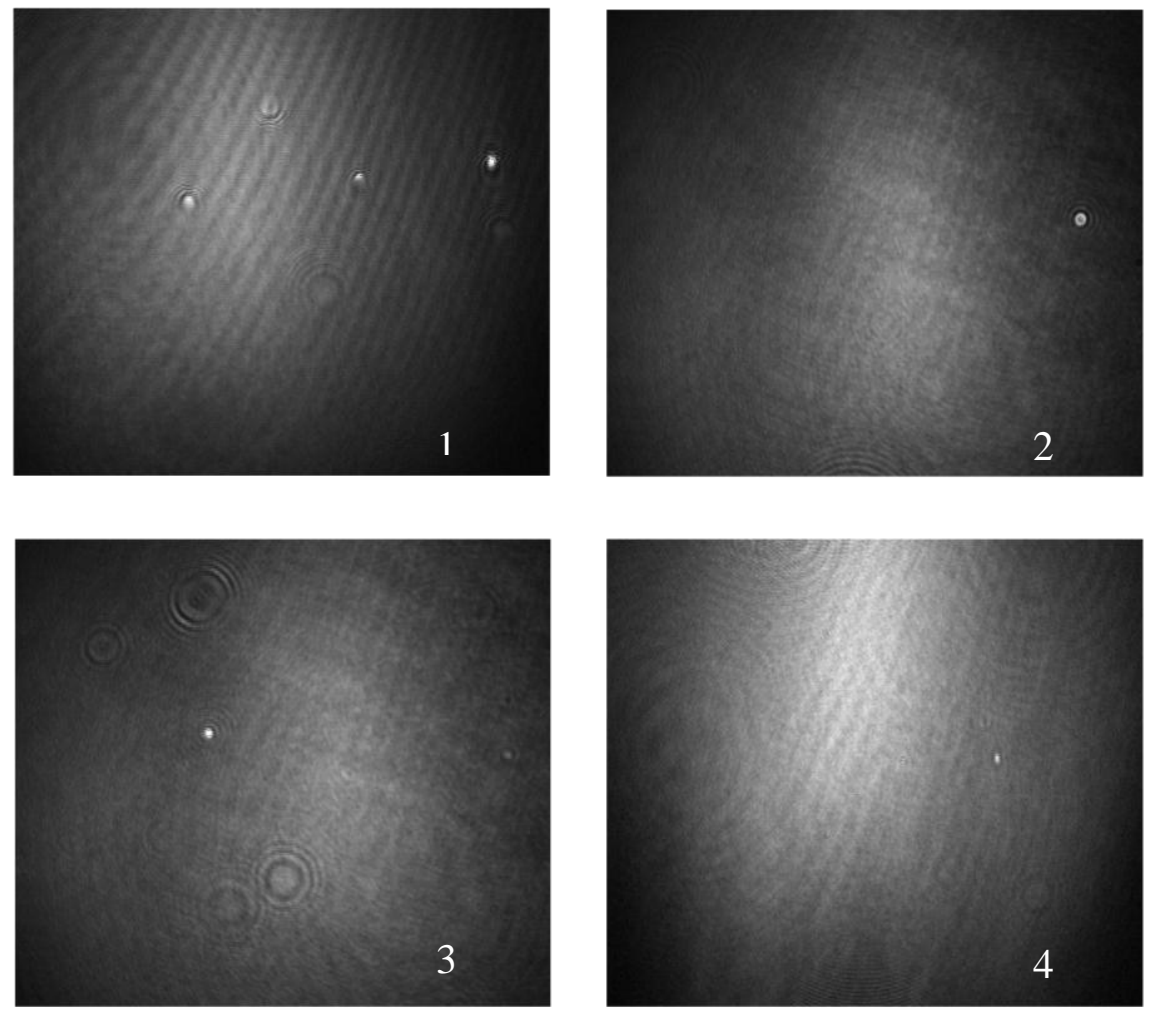

Figura 41-Fotos da superfície do filme de Langmuir do HPOFPMA com o microscópio no ângulo de Brewster

\subsubsection{Copolímero TFEMA-co-DR13MA(10\%)}

Como esperado por esse polímero ter uma pequena quantidade de mero azo-substituído, a isoterma de pressão na figura 42 para o copolímero TFEMA-co-DR13MA(10\%) apresentou características muito parecidas com a curva do HPTFEMA. Foram obtidos valores próximos de pressão e área a cada mudança do comportamento da curva. Apenas a área extrapolada a partir da primeira "transição" foi pouco maior, $28 \AA^{2}$. 


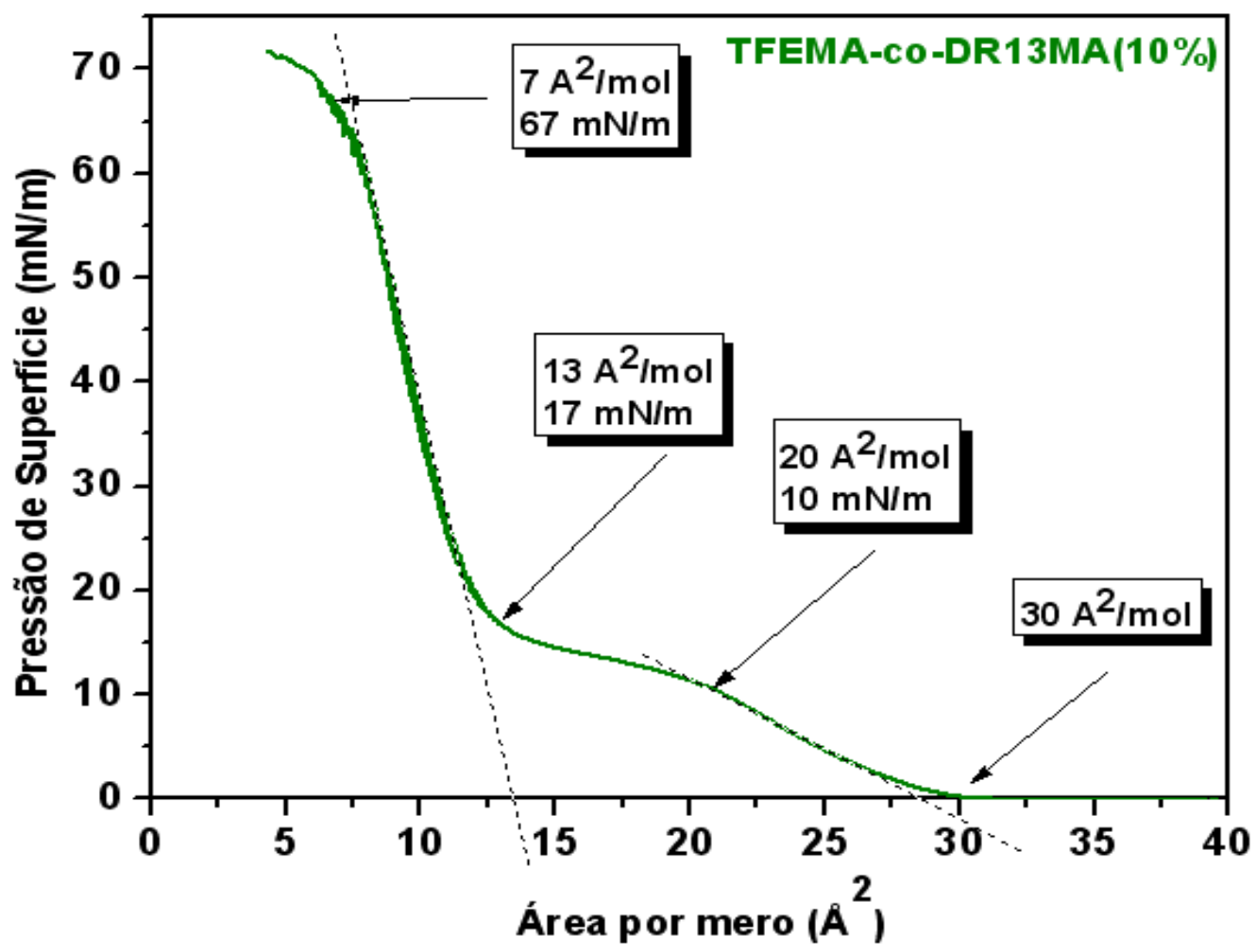

Figura 42-Isoterma de pressão vs. área por molécula do copolímero TFEMA-co-DR13MA(10\%)

Como esse composto apresentou estabilidade do filme de Langmuir, foi possível depositar filmes LB. Foi feito somente um filme LB na pressão de $30 \mathrm{mN} / \mathrm{m}$, com 70 camadas em substrato de vidro hidrofóbico. O estudo detalhado da deposição dos filmes LB dos copolímeros foi realizado somente para o composto TFEMA-co-DR13MA(20\%), que será descrito adiante.

\subsubsection{Copolímero TFEMA-co-DR13MA(20\%)}

O copolímero com $20 \%$ de mero azo-substituído também apresentou comportamento similar ao do homopolímero TFEMA, com uma região de possível rearranjo molecular, porém em valores menores de pressão e área por mero, como mostra a figura 43. A área extrapolada a partir da primeira "transição" foi $27 \AA^{2}$ e depois da transição, nas fases mais condensadas, $12 \AA^{2}$. 


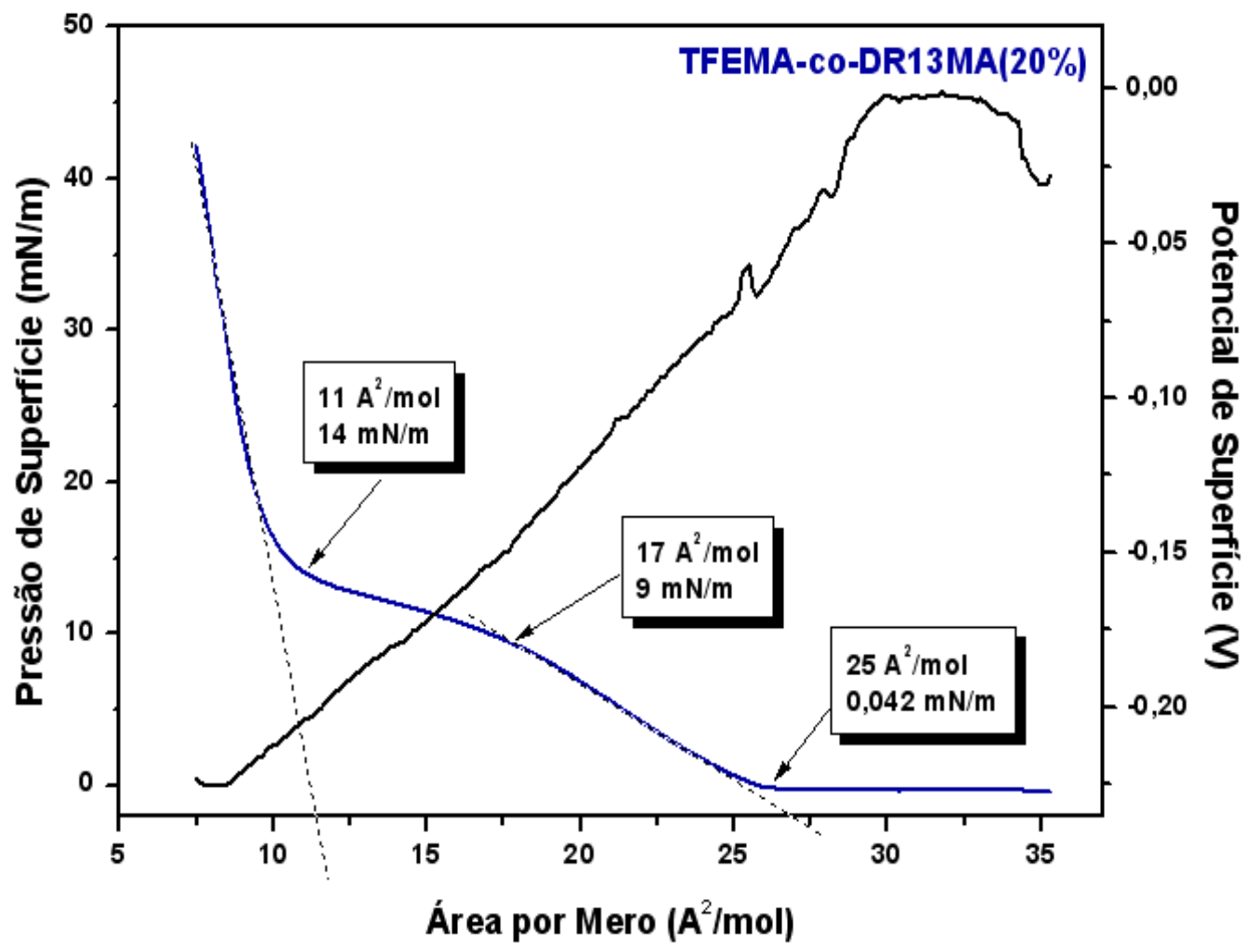

Figura 43-Isoterma de pressão vs. Área por molécula do copolímero TFEMA-co-DR13MA(20\%)

O potencial de superfície deste composto tem características parecidas com as do homopolímero HPTFEMA, como valores negativos, indicando, da mesma forma, que os átomos de flúor estão orientados perpendicularmente para fora da água. No início da compressão, o valor do potencial era zero e assim permaneceu até área por mero de aproximadamente $30 \AA^{2}$, valor mais alto do que o apresentado para o HPTFEMA, e apresentou valores cada vez mais negativos ao ser comprimido até $7 \AA^{2}$, chegando a um potencial de aproximadamente $-0,22 \mathrm{~V}$, pouco menor do que o observado para o homopolímero fluorado correspondente, que foi de aproximadamente -0,25 V.

Por apresentar porcentagem intermediária de azo substituinte, esse composto foi escolhido para estudar a possível orientação e rearranjo molecular nas diferentes regiões da isoterma. Primeiramente estudou-se a estabilidade do filme em três pressões, 5, 10 e 30 $\mathrm{mN} / \mathrm{m}$. Como o filme era estável em todas essas pressões, foi possível depositar filmes Langmuir-Blodgett (LB). O filme pôde, também, ser estudado por microscopia no ângulo de Brewster (BAM). As imagens a diferentes pressões aparecem na figura 44, mostrando domínios somente antes de a pressão de superfície começar a subir, ou seja, em pressões menores que $1 \mathrm{mN} / \mathrm{m}$. Com a compressão, esses domínios se juntam para formar um filme 
contínuo, típico de filmes líquidos. À medida que se aumenta a pressão, a refletividade aumenta, o que pode ser indicativo de um filme mais espesso. É possível que isso se deva à formação de filmes não monomoleculares.

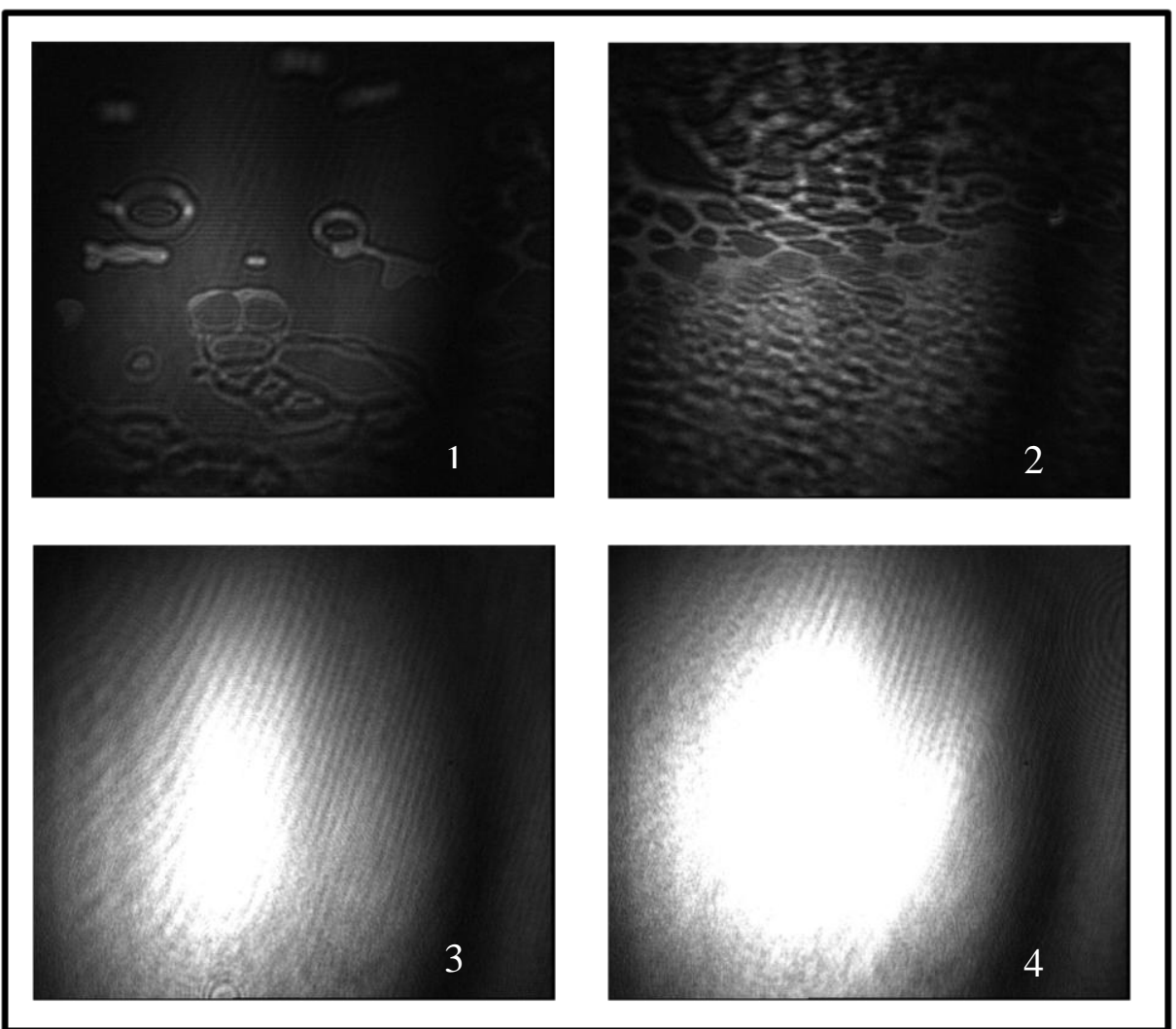

Figura 44-Fotos da superfície do filme de Langmuir com microscópio no ângulo de Brewster

Filmes LB do copolímero TFEMA-co-DR13MA(20\%) foram depositados em lâminas de vidro hidrofóbico, em silício e em vidro recoberto com ouro. Mencione-se que não foi possível depositar filmes sobre vidro hidrofílico. Os filmes foram sempre do tipo Y, com imersão na imersão e retirada do substrato, sendo que a primeira camada era sempre depositada na imersão. Por isso, todos os filmes estudados têm número par de camadas. As diferentes pressões e número de camadas depositadas estão na tabela 11. Os filmes sobre ouro e silício foram estudados por espectroscopia na região do infravermelho, nos modos de reflexão e transmissão, respectivamente, com o objetivo de inferir a possível organização das moléculas no filme a partir da comparação entre os espectros nos dois modos, que são sensíveis a momentos de dipolo na direção perpendicular (por reflexão) e no plano do substrato (por transmissão). Além disso, pode ser possível verificar se há reorganização molecular nas regiões de mudança de comportamento da isoterma de pressão. 
Tabela 12-Relação dos filmes LB para o composto TFEMA-co-DR13MA(20\%)

\begin{tabular}{ccc}
\hline Pressão $(\mathbf{M n} / \mathbf{m})$ & Tipo de Lâmina & Número de camadas \\
\hline 5 & Ouro & 30 \\
5 & Silício & 30 \\
5 & Vidro hidrofóbico & 30 \\
5 & Vidro hidrofóbico & 50 \\
5 & Vidro hidrofóbico & 70 \\
10 & Ouro & 30 \\
10 & Silício & 30 \\
10 & Vidro hidrofóbico & 30 \\
10 & Vidro hidrofóbico & 50 \\
10 & Vidro hidrofóbico & 70 \\
30 & Ouro & 30 \\
30 & Silício & 30 \\
30 & Vidro hidrofóbico & 10 \\
30 & Vidro hidrofóbico & 30 \\
30 & Vidro hidrofóbico & 50 \\
30 & Vidro hidrofóbico & 70 \\
\hline & & \\
\hline & & \\
\hline
\end{tabular}

A figura 45 mostra os espectros de FTIR por transmissão em diferentes pressões. Podese observar 4 bandas bem intensas, correspondentes aos $\mathrm{CH}$ alifático e aromáticos próximos a $3000 \mathrm{~cm}^{-1}$, aos grupamentos $\mathrm{C}=\mathrm{O}$ e C-O de éster em 1750 e $1280 \mathrm{~cm}^{-1}$ respectivamente e em $1165 \mathrm{~cm}^{-1}$ correspondente às ligações C-F. A intensidade relativa das bandas varia ligeiramente, sendo que para pressões mais baixas de 5 e $10 \mathrm{mN} / \mathrm{m}$ observa-se a mesma proporção entre as bandas de $\mathrm{C}=\mathrm{O}$ e de $\mathrm{C}-\mathrm{O}$, porém a banda referente ao $\mathrm{C}-\mathrm{F}$ é pouco mais intensa na pressão de $10 \mathrm{mN} / \mathrm{m}$ do que para $5 \mathrm{mN} / \mathrm{m}$. Na pressão de $30 \mathrm{mN} / \mathrm{m}$, as bandas de $\mathrm{C}=\mathrm{O}$ e $\mathrm{C}-\mathrm{O}$ apresentaram a mesma intensidade, porém a de $\mathrm{C}-\mathrm{O}$ foi menor que para pressões mais baixas, e a banda correspondente ao C-F foi a menos intensa do que as observadas em pressões menores. 

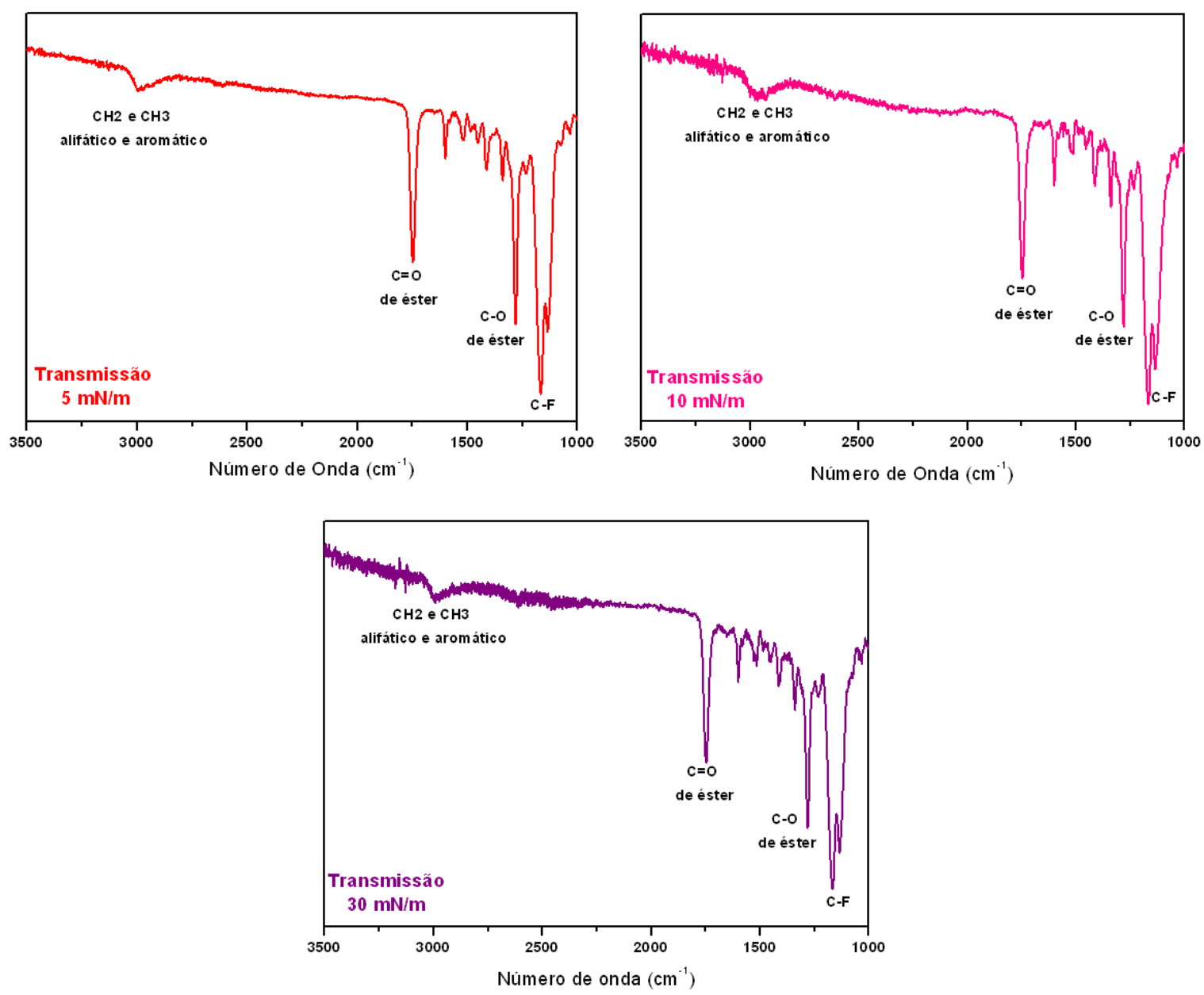

Figura 45-Espectro de Infravermelho por transmissão dos filmes LB do copolímero TFEMA-coDR13MA(20\%)

A figura 46 mostra os espectros de FTIR por reflexão do copolímero em 3 pressões, assim como foi feito para o modo de transmissão. Neste caso só se observam 3 bandas mais intensas, atribuídas aos grupos C=O e C-O de éster e C-F, em 1750, 1290 e $1186 \mathrm{~cm}^{-1}$, respectivamente. A intensidade relativa entre as bandas mostra diminuição dos picos de $\mathrm{C}-\mathrm{O}$ e C-F na pressão de $10 \mathrm{mN} / \mathrm{m}$ e aumento das mesmas para $30 \mathrm{mN} / \mathrm{m}$. 

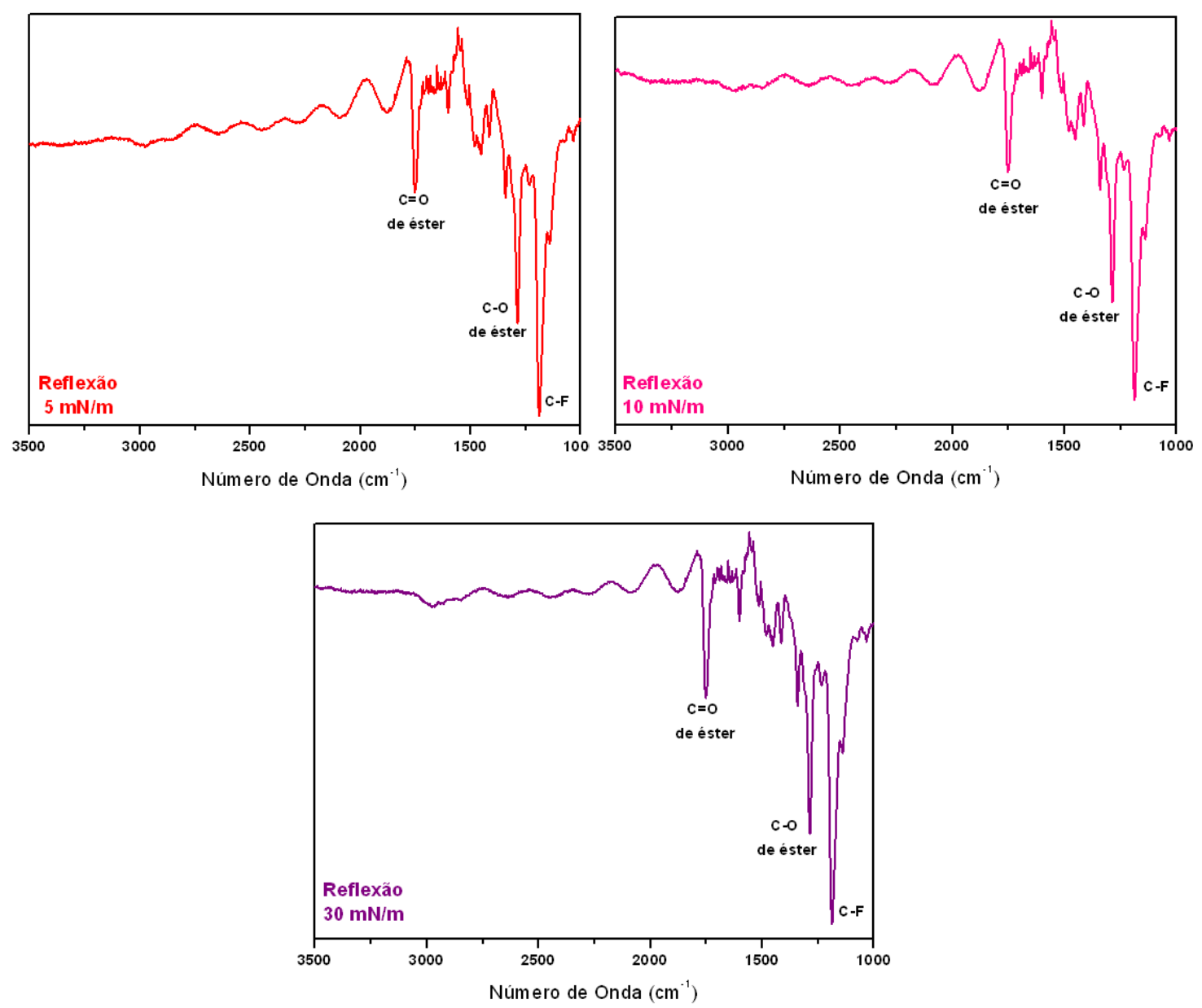

Figura 46-Espectro de Infravermelho por reflexão dos filmes LB do copolímero TFEMA-coDR13MA(20\%)

A deposição dos filmes sobre substrato hidrofóbico começou com o substrato fora da água, fazendo com que a primeira camada depositada apresentasse a cauda hidrofóbica da molécula voltada para o substrato, como mostrado na figura 47. A deposição é do tipo Y, ou seja, ocorre de forma que as camadas se organizem com a estrutura cauda/cauda, cabeça/cabeça, e com número de camada par. Foram feitas tentativas de deposição em substrato hidrofílico, porém não foi possível obter bons filmes. Essa configuração dos filmes de Langmuir-Blodgett (LB) confirma que os átomos de flúor estão orientados para fora da superfície aquosa como inferido das medidas de potencial de superfície. Essa conformação também é responsável pela hidrofobicidade dos filmes, pois, como se obtém um número par de camadas, a cauda hidrofóbica fica na camada mais externa do filme. 


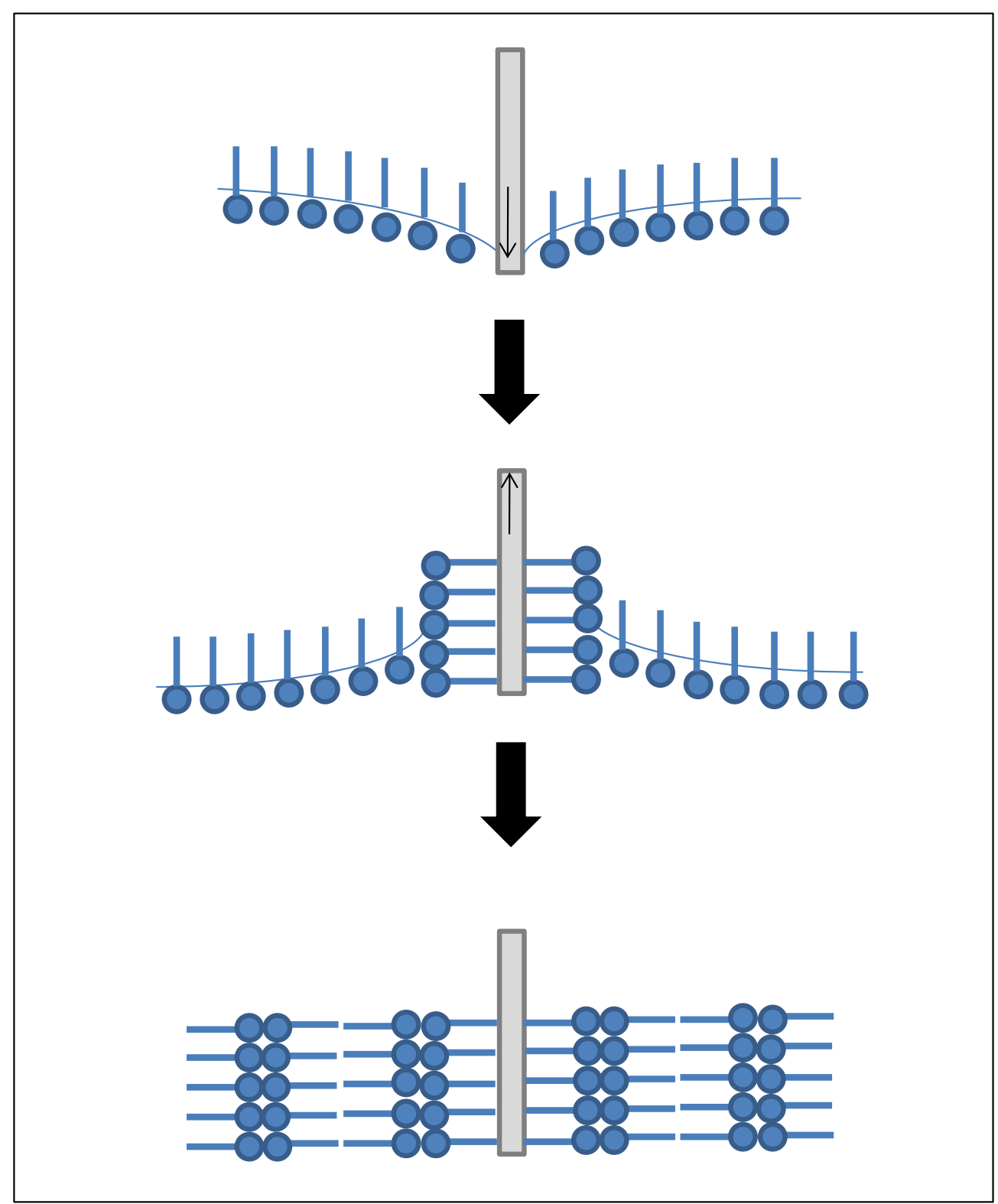

Figura 47-Esquema do tipo de deposição realizada nos copolímeros

Os filmes LB em lâmina de vidro hidrofóbico com diferentes camadas foram estudados por espectroscopia na região do ultravioleta, para avaliar a homogeneidade do crescimento. Os espectros da figura 48 mostram absorção crescente com o número de camadas. Observa-se crescimento aproximadamente linear até cerca de 50 camadas, principalmente na pressão de $10 \mathrm{mN} / \mathrm{m}$, e um desvio da linearidade para um número maior de camadas. 

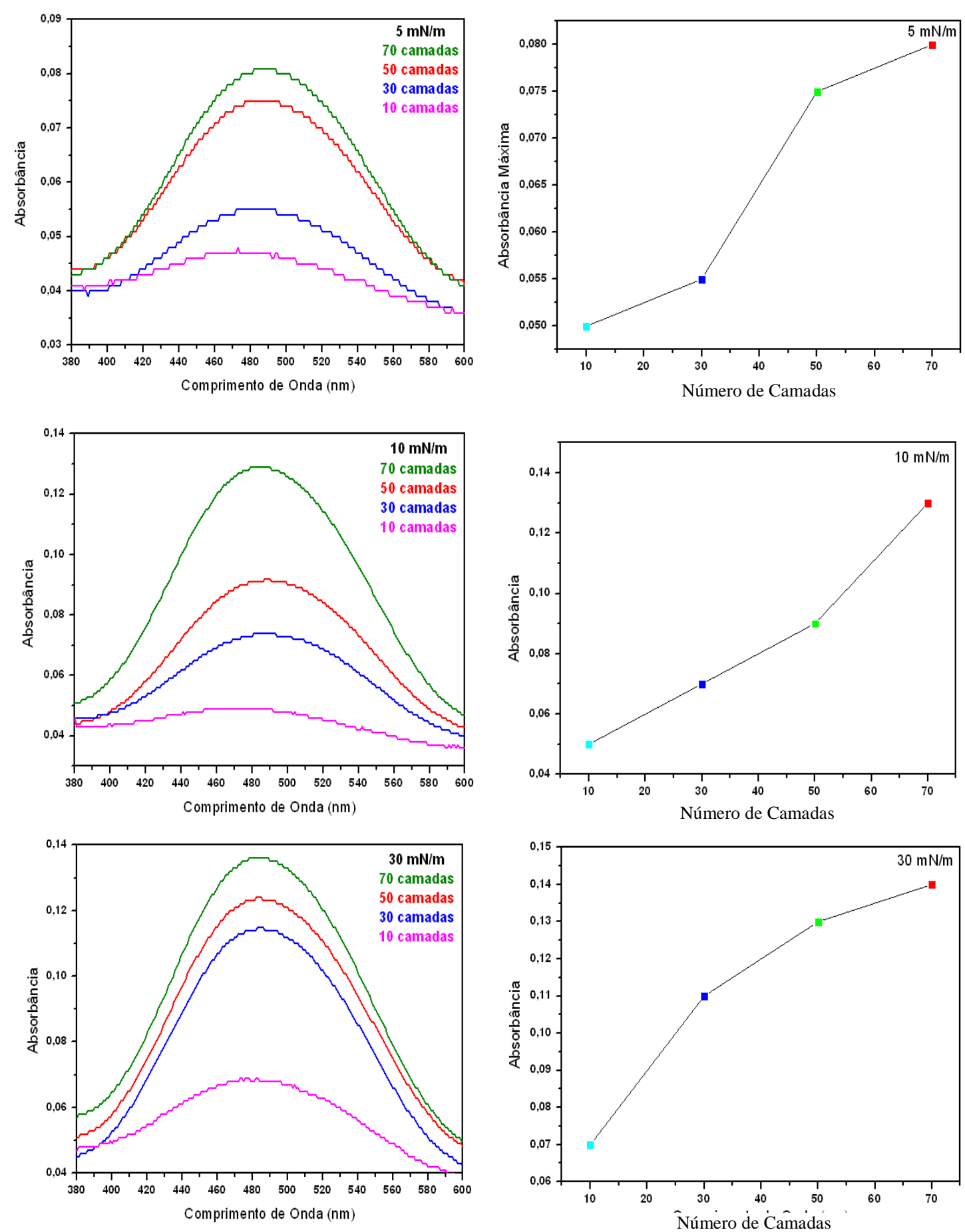

Figura 48-Espectros de UV-Vis dos filmes LB e suas respectivas curvas de absorbância por número de camada do copolímero TEMDR13(20\%)

O ângulo de contato com a água para os filmes LB é apresentado na tabela 13. Ângulos maiores foram medidos para os filmes depositados em pressões de 5 e $30 \mathrm{mN} / \mathrm{m}$. Porém, esses valores não são muito diferentes dos ângulos para os filmes cast, indicando que uma possível organização do filme não influiu consideravelmente na hidrofobicidade. Como se espera que 
filmes LB mais espessos (ou seja, com maior número de camadas) sejam menos ordenados, medimos o ângulo de contato de um filme com somente 10 camadas para a pressão de 30 $\mathrm{mN} / \mathrm{m}$. O valor medido foi $88^{\circ}$, ou seja, não há mudança significativa com o número de camadas para os filmes depositados nesta pressão. Já para a pressão de $10 \mathrm{mN} / \mathrm{m}$, o ângulo decresce linearmente com o aumento do número de camadas, como pode ser visto na figura 49. Isso implica que o filme deve ficar menos organizado, e com menor número de átomos de flúor na superfície, quando a espessura aumenta para deposições em que o empacotamento das moléculas na interface ar/água não era tão condensado.

Tabela 13-Ângulos de contato dos filmes LB em vidro do copolímero TFEMA-co-DR13MA(20\%)

\begin{tabular}{ccc}
\hline Pressão $(\mathbf{m N} / \mathbf{m})$ & Número de Camadas & Ângulo de contato $\left.\mathbf{~}^{\mathbf{0}}\right)$ \\
\hline 5 & 10 & $92,0 \pm 1,0$ \\
5 & 30 & $95,0 \pm 0,5$ \\
5 & 50 & $85,0 \pm 1,0$ \\
5 & 70 & $91,0 \pm 1,0$ \\
10 & 10 & $97,0 \pm 1,0$ \\
10 & 30 & $93,0 \pm 0,5$ \\
10 & 50 & $87,0 \pm 0,5$ \\
10 & 70 & $80,0 \pm 1,0$ \\
30 & 10 & $90,0 \pm 1,0$ \\
30 & 30 & $89,0 \pm 0,5$ \\
30 & 50 & $83,0 \pm 1,0$ \\
30 & 70 & $94,0 \pm 1,0$ \\
\hline
\end{tabular}




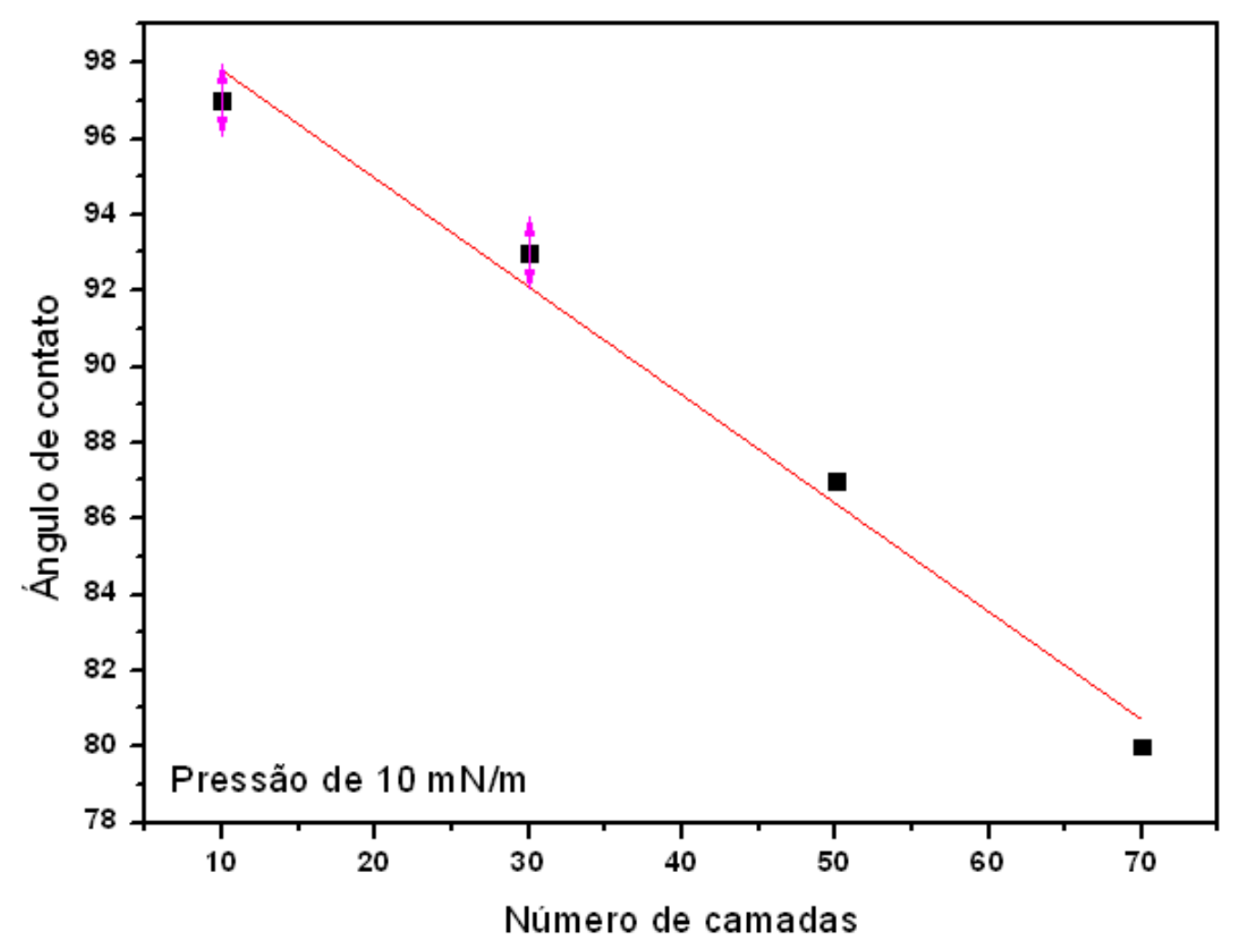

Figura 49-Dependência linear do ângulo de contato com o número de camadas

\subsubsection{Copolímero TFEM-co-DR13(30\%)}

A isoterma do copolímero TEFMA-co-DR13MA(30\%) da figura 50 tem transição de fase menos definida do que nos outros copolímeros. Isso era esperado porque com maior quantidade de mero azo-substituído o comportamento do filme é mais parecido com o HPDR13, onde não há mudança nítida de comportamento. As áreas extrapoladas são respectivamente 21 e $34 \AA^{2}$. A pressão de superfície do filme começa a subir em $34 \AA^{2} / \mathrm{mol}$. Em $20 \AA^{2} / \mathrm{mol}$ com uma pressão de $14 \mathrm{mN} / \mathrm{m}$ ocorre mudança sutil no comportamento da isoterma, bem menor do que para os outros copolímeros. O colapso acontece em $12 \AA^{2} / \mathrm{mol}$ numa pressão de $60 \mathrm{mN} / \mathrm{m}$. 


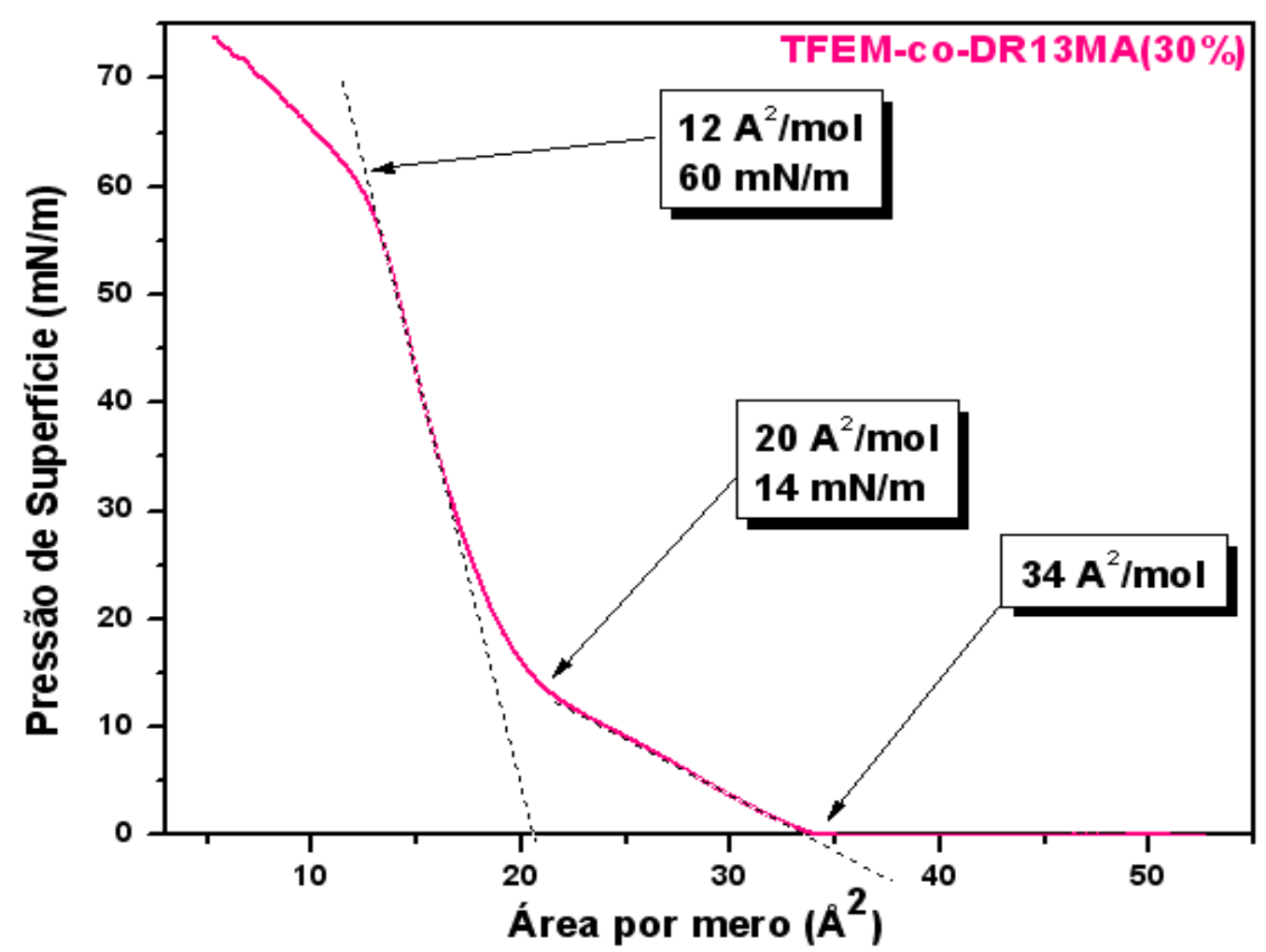

Figura 50-Isoterma de pressão vs. área por molécula do copolímero TFEMA-co-DR13MA(30\%)

A estabilidade do composto foi estudada somente na pressão de $30 \mathrm{mN} / \mathrm{m}$, e em seguida foi possível depositar um filme LB com 70 camadas. Foi feito somente um filme pelo mesmo motivo discutido para o TFEMA-co-DR13MA(10\%). O ângulo de contato foi $90^{\circ}$, próximo ao encontrado para filmes LB dos outros copolímeros e também para os filmes cast.

\subsubsection{Copolímero OFPMA-co-DR13MA(10\%)}

Assim como para o copolímero TFEMA-co-DR13MA(10\%), era de se esperar que a isoterma de pressão de superfície do OFPMA-co-DR13MA(10\%) apresentasse características muito parecidas com a curva do HPTOFPMA. Porém, neste caso a isoterma é mais expandida, sendo que o copolímero apresenta valores muito maiores de área por molécula na extrapolação da primeira curva, que é de cerca de $50 \AA^{2}$, e também da segunda que é $17 \AA^{2}$. A sua isoterma é mostrada na figura 51. 


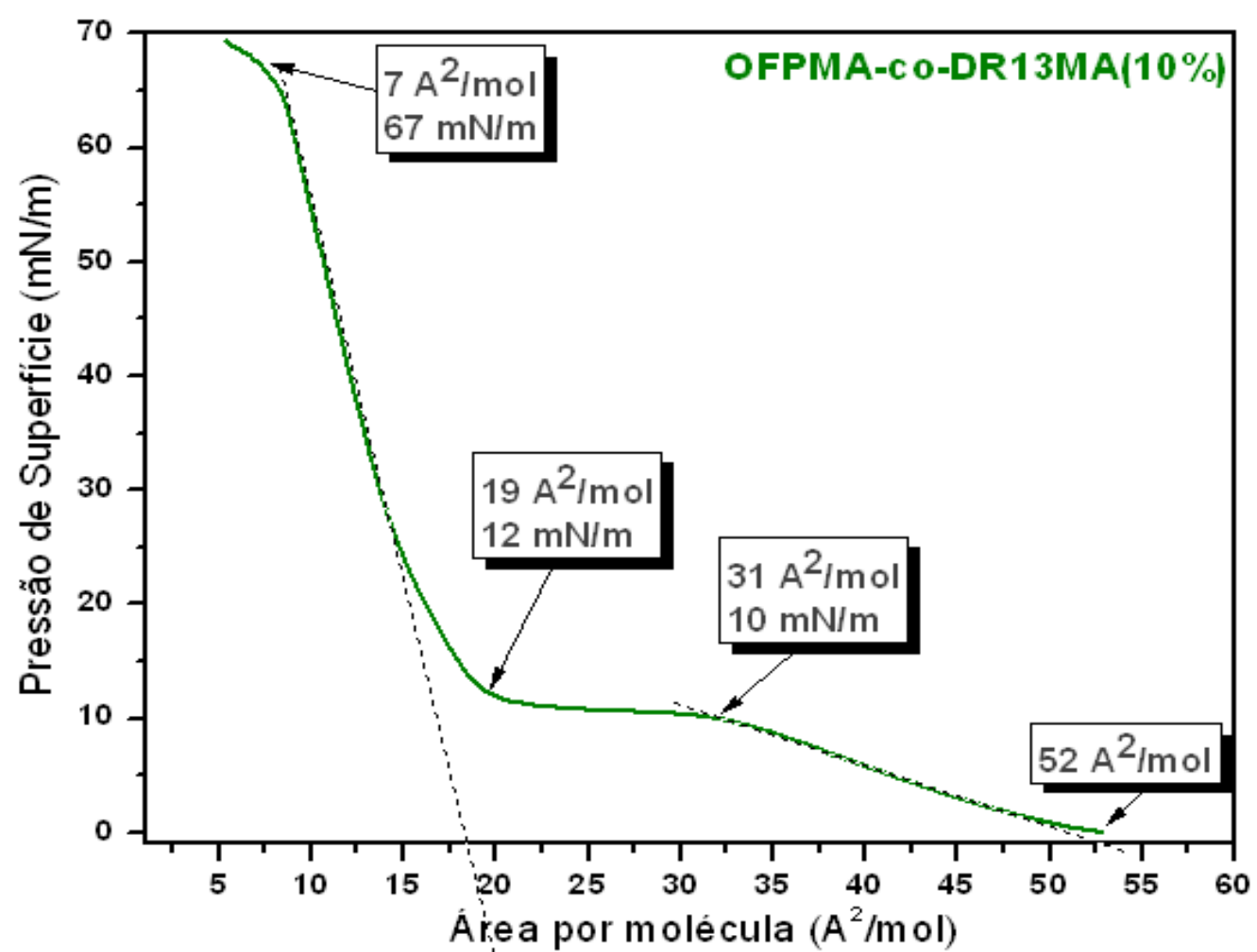

Figura 51-Isoterma de pressão vs. área por molécula do copolímero OFPMA-co-DR13MA(10\%)

Este polímero também apresentou estabilidade do filme de Langmuir, e por isso foi possível depositar filmes LB. Fabricou-se um filme LB na pressão de $30 \mathrm{mN} / \mathrm{m}$ com 70 camadas sobre vidro hidrofóbico. O estudo detalhado desses materiais foi realizado somente para o composto OFPMA-co-DR13MA(20\%), que será descrito adiante.

\subsubsection{Copolímero OFPMA-co-DR13MA(20\%)}

O copolímero OFPMA-co-DR13MA(20\%) foi escolhido dentre os compostos contendo o monômero fluorado OFPMA pelo mesmo motivo que o TFEMA-co-DR13MA, ou seja, por possuir a proporção intermediária de mero azo substituinte dentre os demais. A isoterma do OFPMA-co-DR13MA(20\%) também apresentou comportamento similar ao do homopolímero HPOFPMA (figura 52), porém com somente uma região de possível rearranjo molecular e não duas como o homopolímero. A área extrapolada a partir da primeira "transição" da isoterma foi $40 \AA^{2}$, bem maior do que para o homopolímero que foi de $22 \AA^{2}$. O mesmo 
acontece para a extrapolação na região depois da transição, que para o copolímero foi de 20 $\AA^{2}$ e para o homopolímero foi de $7 \AA^{2}$.

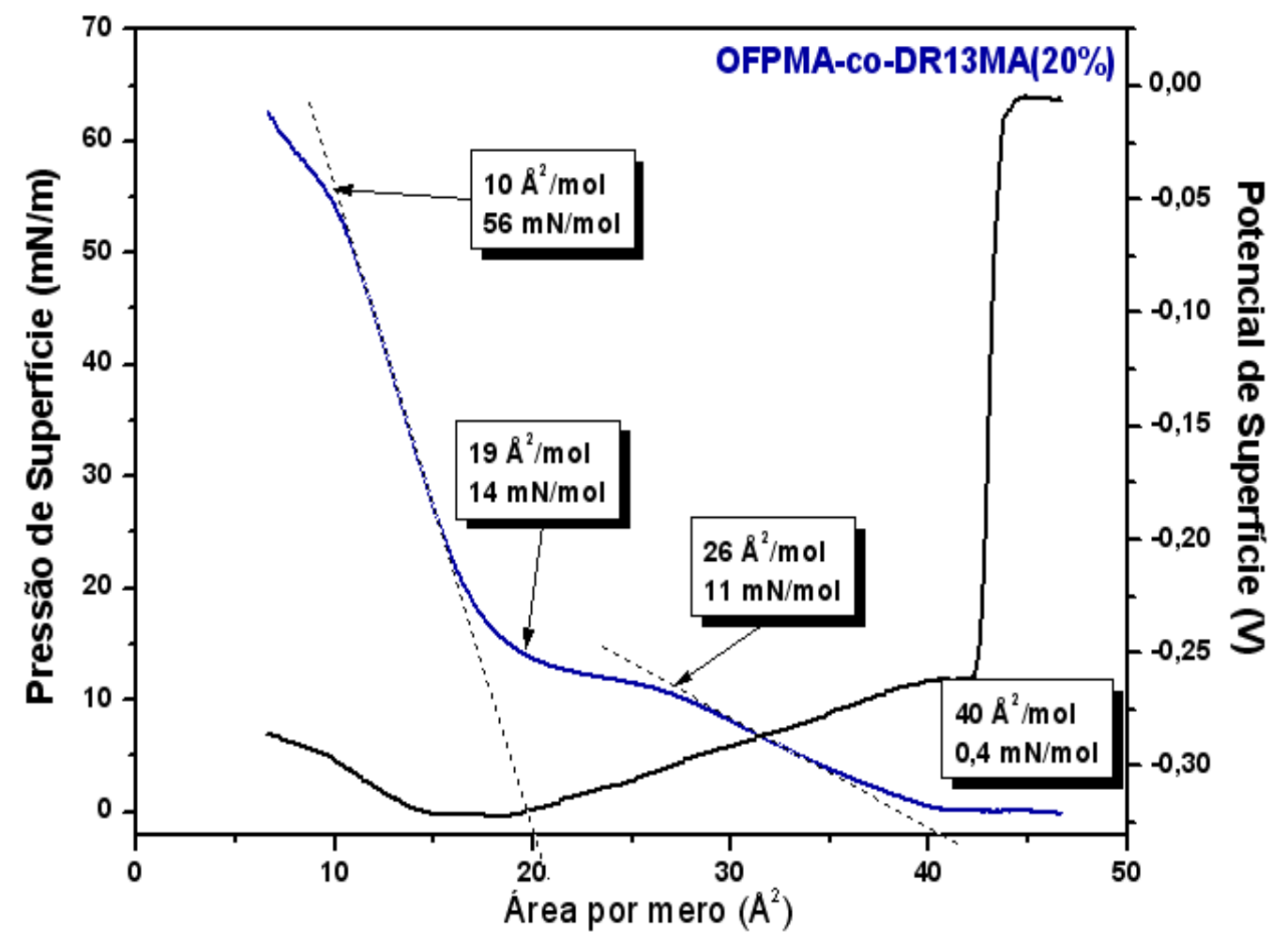

Figura 52-Isoterma de pressão vs. área por molécula do copolímero OFPMA-co-DR13MA(20\%)

O potencial de superfície deste composto apresenta características parecidas com as do homopolímero HPOFPMA, com valores negativos, indicando a orientação dos átomos de flúor para fora da água. No início da compressão, o valor do potencial era zero, denotando ausência de agregados. Na área crítica de $45 \AA^{2}$ houve um decréscimo brusco do potencial e à medida que a pressão começou a subir o decréscimo foi menos intenso.

As imagens de BAM do filme de Langmuir do TFEMA-co-DR13MA(20\%) são mostradas na figura 53, sendo semelhantes às obtidas para o homopolímero HPOFMA, diferentemente do que ocorre para o copolímero TFEMA-co-DR13MA. Aqui também se observam pequenos domínios circulares que vão sumindo com a compressão do filme. 


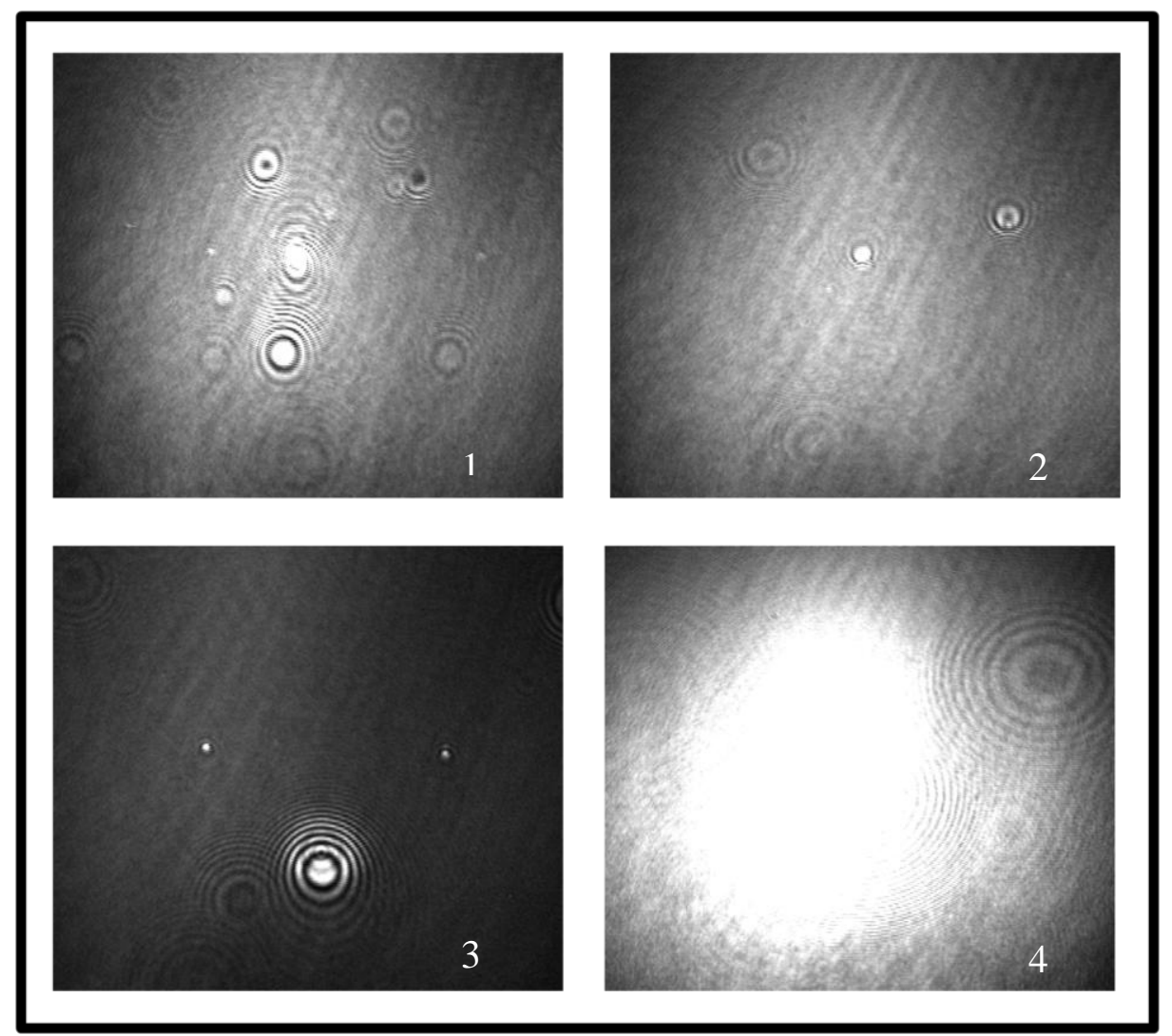

Figura 53-Fotos da superfície do filme de Langmuir do TFEMA-co-DR13MA(20\%) com o microscópio no ângulo de Brewster

Para a deposição dos filmes em substratos, primeiramente estudou-se a estabilidade da monocamada em três pressões, 5,10 e $30 \mathrm{mN} / \mathrm{m}$, e como o filme apresentou-se estável foi possível fabricar filmes LB sobre lâminas de vidro hidrofóbico, em silício e em ouro. As diferentes pressões e número de camadas são os mesmos que para o copolímero TFEMA-coDR13MA(20\%) da tabela 10. Os filmes em ouro e em silício foram estudados por FTIR, nos modos de reflexão e transmissão, respectivamente. Só foi possível depositar em lâmina de silício na pressão de $5 \mathrm{mN} / \mathrm{m}$ para esse composto. O espectro da figura 54 mostra o FTIR no modo de transmissão. O composto não apresentou boa afinidade com o silício, e mesmo tendo depositado na pressão de $5 \mathrm{mN} / \mathrm{m}$, esse filme foi muito fino dificulta o estudo detalhado das principais bandas, sendo observadas somente duas, as correspondentes aos grupamentos $\mathrm{C}=\mathrm{O}$ de éster e C-F. 


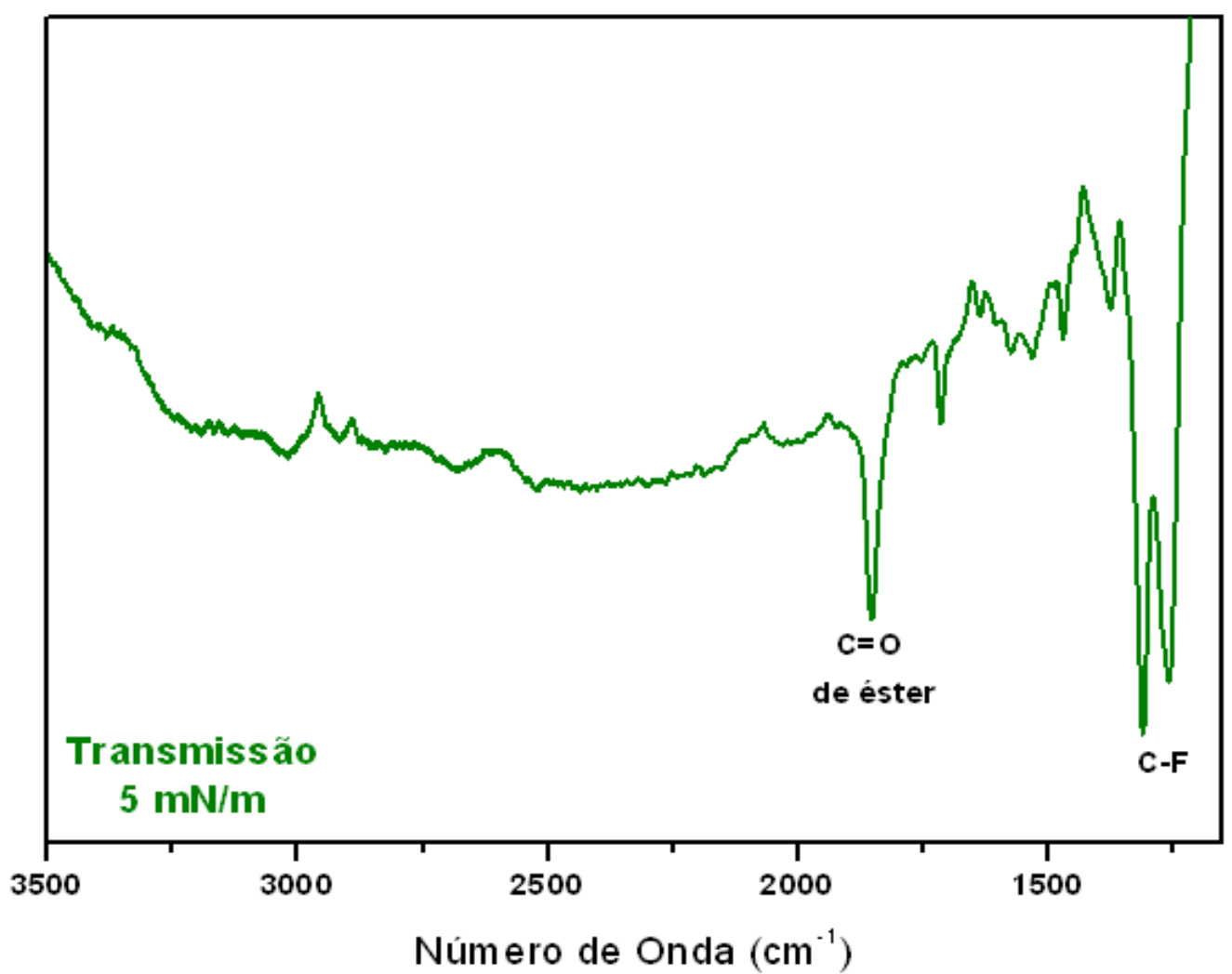

Figura 54-Espectro de Infravermelho por transmissão dos filmes LB do copolímero OFPMA-coDR13MA(20\%)

A figura 55 mostra os espectros de FTIR pelo modo de reflexão dos filmes LB depositados em ouro. Foi possível depositar nas três pressões desejadas, porém o filme também ficou fino, sendo difícil a análise de todas as bandas. Pode-se observar 2 bandas intensas, assim como no modo de transmissão, atribuídas aos grupos $\mathrm{C}=\mathrm{O}$ de éster e $\mathrm{C}-\mathrm{F}$. A proporção relativa entre os picos é maior para o filme depositado na pressão de $12 \mathrm{mN} / \mathrm{m}$, analogamente ao copolímero TFEMA-co-DR13MA. 

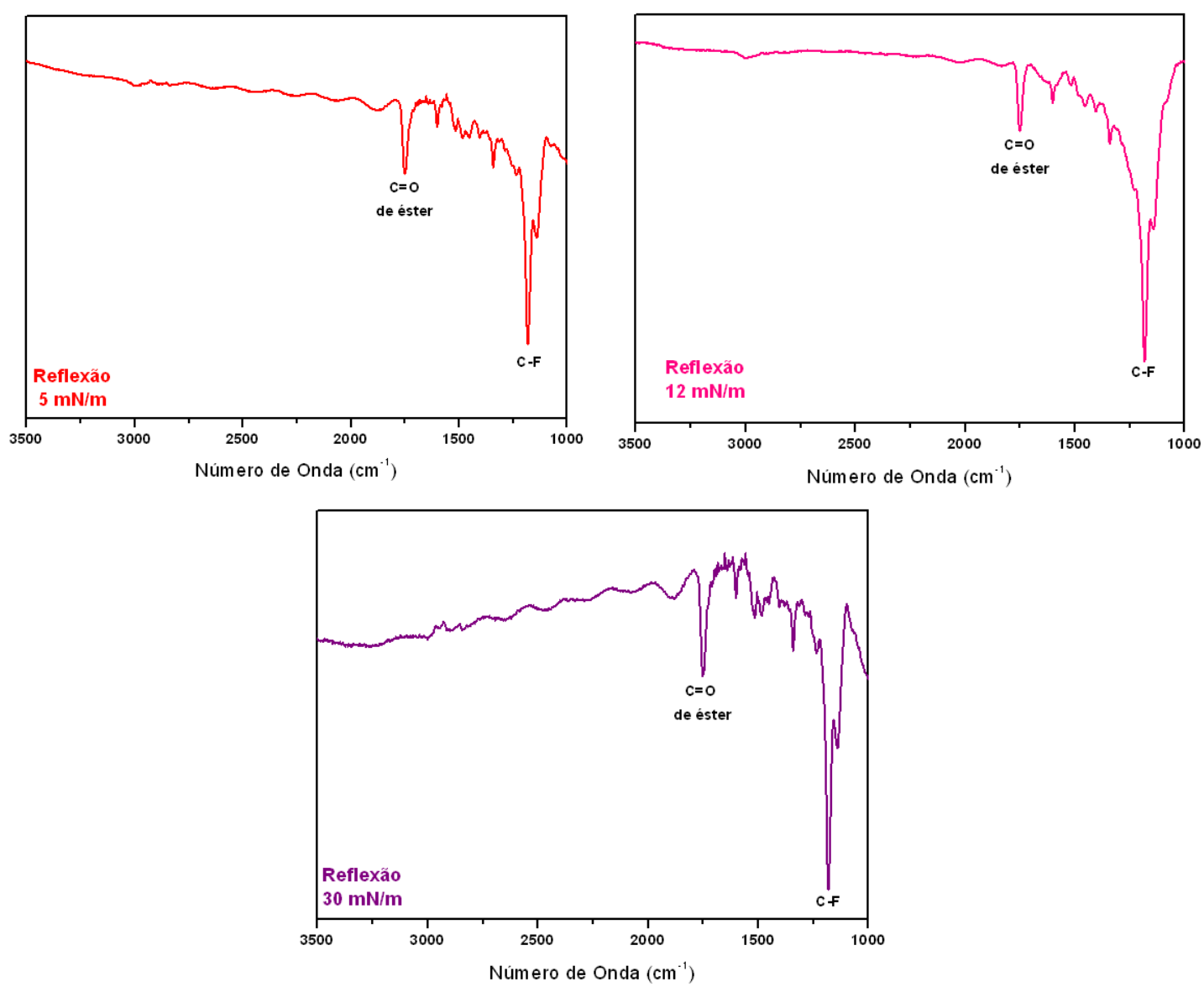

Figura 55-Espectros de Infravermelho no modo de reflexão dos filmes LB, depositados em ouro, do copolímero OFPMA-co-DR13MA(20\%)

O crescimento dos filmes LB em lâmina de vidro hidrofóbico também foi estudado por espectroscopia na região do UV-vis., com os espectros mostrados na figura 56. Para as pressões mais baixas, o comportamento é mais linear do que para a pressão de $30 \mathrm{mN} / \mathrm{m}$, mostrando processo de deposição homogêneo até um maior número de camadas. 

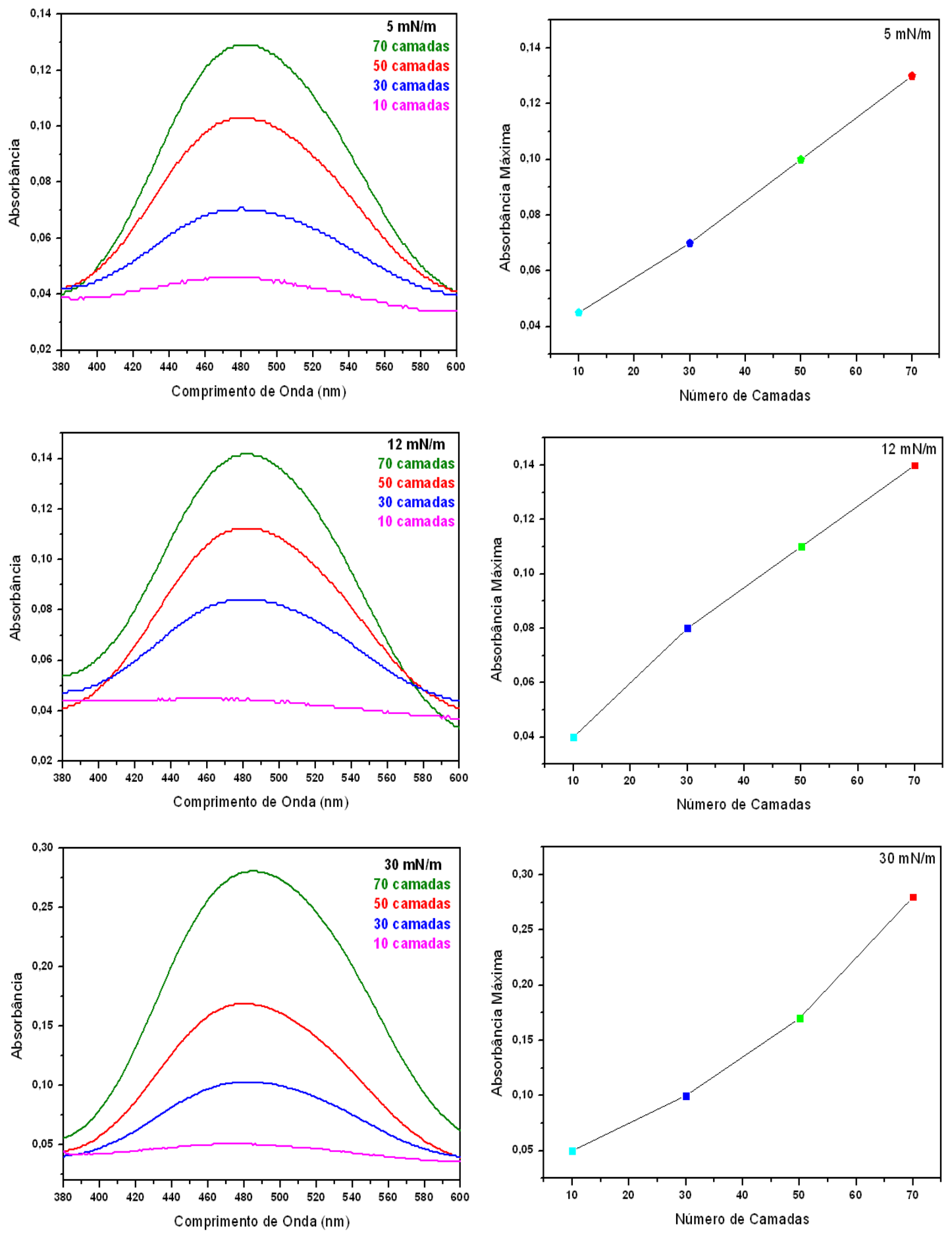

Figura 56-Espectros de UV-Vis dos Filmes LB e suas respectivas curvas de absorbância por número de camada do copolímero OFPMA-co-DR13MA(20\%)

Os ângulos de contato com a água para esses filmes LB, mostrados na tabela 14, não apresentam grandes variações com a pressão ou o número de camadas, ao contrário do que se observou para os filmes LB do copolímero TFEMA-co-DR13MA(20\%). E esses valores são 
menores do que os dos filmes cast para este composto $\left(96^{\circ}\right)$, o que indica que provavelmente não há uma organização do filme ou esta não influiu na hidrofobicidade.

Tabela 14-Ângulos de contato dos filmes LB em vidro do copolímero OFPMA-co-DR13MA(20\%)

\begin{tabular}{ccc}
\hline Pressão $(\mathbf{M n} / \mathbf{m})$ & Número de Camadas & Ângulo de contato $\left(^{\mathbf{0}}\right)$ \\
\hline 5 & 30 & $92,0 \pm 1,0$ \\
5 & 50 & $92,0 \pm 0,5$ \\
5 & 70 & $93,0 \pm 0,5$ \\
10 & 30 & $94,0 \pm 0,5$ \\
10 & 50 & $94,0 \pm 1,0$ \\
10 & 70 & $92,0 \pm 1,0$ \\
30 & 30 & $94,0 \pm 0,5$ \\
30 & 50 & $94,0 \pm 0,5$ \\
30 & 70 & $94,0 \pm 0,5$ \\
\hline
\end{tabular}

\subsubsection{Copolímero OFPMA-co-DR13MA(30\%)}

$\mathrm{Na}$ isoterma do copolímero OFPMA-co-DR13MA(30\%) da figura 57 praticamente não se observa a "transição" dos demais copolímeros. Isso se deve ao fato de este composto ter maior quantidade de mero azo-substituído. Assim, seu comportamento é mais parecido com o HPDR13, onde não há mudança nítida de comportamento. As áreas extrapoladas são respectivamente 55 e $30 \AA^{2}$. A pressão de superfície do filme começa a subir em $55 \AA^{2} / \mathrm{mol}$. Em $29 \AA^{2} / \mathrm{mol}$ com uma pressão de $15 \mathrm{mN} / \mathrm{m}$ ocorre pequena mudança no comportamento da curva. O colapso ocorre em $16 \mathrm{~A}^{2} / \mathrm{mol}$ numa pressão de $57 \mathrm{mN} / \mathrm{m}$. 


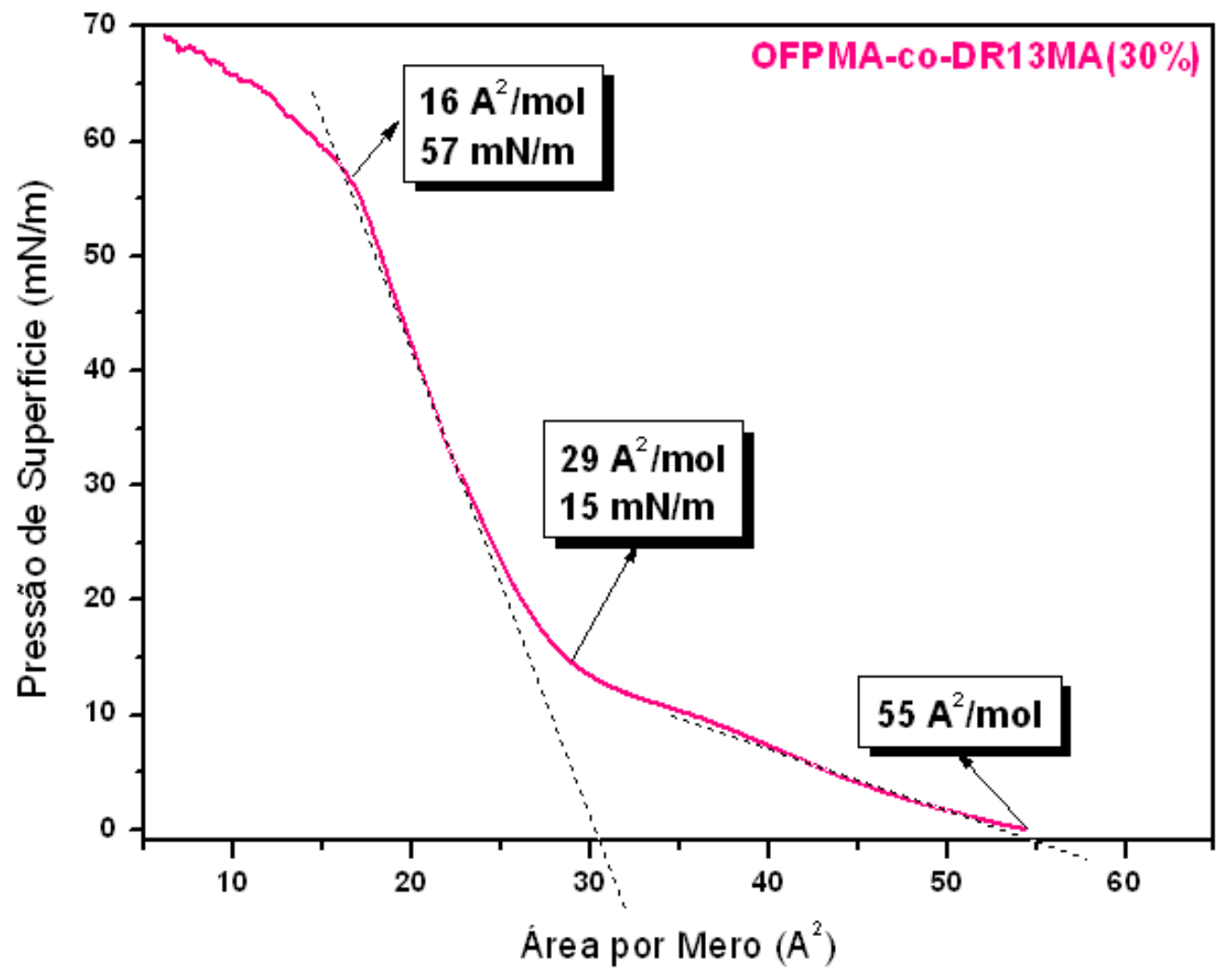

Figura 57-Isoterma de pressão vs. área por molécula do copolímero OFPMA-co-DR13MA(30\%)

A estabilidade do composto foi estudada somente na pressão de $30 \mathrm{mN} / \mathrm{m}$, e um filme LB com 70 camadas foi depositado. O ângulo de contato foi de $92^{\circ}$, valor próximo aos dos filmes LB dos outros copolímeros e também para os filmes cast. 


\section{Conclusões e perspectivas}

Os polímeros sintetizados tiveram um crescimento satisfatório, apresentando moléculas com massa molar da ordem de $10^{4} \mathrm{~g} / \mathrm{mol}$, como indicaram as análises por cromatografia por exclusão de tamanho. Estas também mostraram uma polidispersividade relativamente pequena para uma polimerização pelo método convencional. As estruturas pretendidas para os copolímeros foram confirmadas com medidas de RMN e espectroscopia no infravermelho, inclusive com concordância quantitativa nos métodos de RMN e absorção no UV-Vis. Os filmes produzidos com os copolímeros, quer seja pela técnica de casting como por LB, são hidrofóbicos, como se esperava. Entretanto, uma possível organização dos filmes LB não afetou a hidrofobicidade dos filmes nas condições de deposição estudadas.

Um resultado promissor foi a estabilidade dos filmes de Langmuir para várias concentrações relativas dos monômeros nos copolímeros. Isso permitiu a transferência de dezenas de camadas para um mesmo substrato, formando filmes LB bastante espessos. Porém, essa espessura não foi suficiente para a inscrição de grades de relevo com profundidade apreciável, e um trabalho de otimização de condições será necessário no futuro.

As isotermas de pressão de superfície para os filmes de copolímeros apresentaram perfil intermediário entre aqueles obtidos com os filmes de homopolímeros, como também se esperava. Há casos em que aparece uma transição de fase durante a compressão, e isso poderá ser estudado em detalhe em trabalhos futuros com medidas de espectroscopia no infravermelho in situ, na interface ar/água, empregando-se o equipamento de PM-IRRAS (polarization-modulated infrared reflection absorption spectroscopy). Com esta técnica, será possível verificar se há reorganização das moléculas na transição de fase, além da interação entre os meros no nível molecular.

Os testes de formação de grades de relevo para os filmes cast mostraram que é possível a inscrição. Neste trabalho, não foi possível otimizar as condições de fabricação de grades para obter superfícies superhidrofóbicas, o que será alvo de projetos futuros. 


\section{Referências}

1 MUELLER, A. Fluorinated hyperbranched polymers. Michigan: Departament of Chemistry; Central Michigan University Mount Pleasant, 2006. Sigma-Aldrish 2006.

2 KUMAR, G. S. Azo functional polymers: functional group approach in macromolecular design. Pennsylvania: Thecnomic Publishing Company, 1992

3 TABAK, D. The cis-trans isomerization in solutions of polyamides containing azobenzene residues in chain backbone. Buffalo: Polytechnic Institute of Brooklyn University of Bufallo, 1975.

4 NATANSHON, A.; ROCHON, P.; GOSSELIN, J.; XIE, S. Azo polymers for reversible optical storage 1. Poly[4'-[[2-(acryloyloxy)ethyl]ethylamino]-4-nitroazobenzene]. Macromolecules, v. 3, n. 4, p. $207-213,1996$

5 ZOLLINGER, H. Color chemistry. 2.ed. New York: VCH, 1991.

6 BONI, L. D. Não linearidades ópticas em azocompostos. 2004. Tese (Doutorado em Física). Instituto de física de São Carlos, Universidade de São Paulo, São Carlos, 2004.

7 KIM, D. Y.; TRIPATHY, S. K.; LI, L.; KUMAR, J. Laser-induced holographic surfacerelief gratings on nonlinear optical polymer films. Applied Physics Letters, v. 66 n. 10 , p. 1166-1168, 1995.

8 MENDONÇA, C. R. et al. Optically induced birrefringence and surface relief gratings in composite Langmuir-Blodgett (LB) films of poly[4'-[[2-(methacryloyloxy)ethyl]ethylamino]2-chloro-4-nitroazobenzene]HPDR13) and cadmium stearate. Macromolecules, v. 32, n. 5 . p. 1493-1499, 1999.

9 HE, J. A. et al. Surface relief gratings from electrostatically layered azo dye films. Applied Physics Letters, v. 76, n. 22 ,p. 3233-3235. 2000.

10 BIAN, S.; HE, J.A.; LI, L.; KUMAR, J.; TRIPATHY, S. K. Large photoinduced birefringence in azo dye/polyon films assembled by electrostatic sequential adsorption. Advanced Materials, v. 12, n. 16 ,p. 1202-1205, 2000.

11 LEE, S. K. et al. Azo polymer multilayer films by electrostatic self-assembly and layer-bylayer post azo functionalization. Macromolecules, v. 33, n. 17 ,p. 6534-6540, 2000. 
$12 \mathrm{Kim}, \mathrm{D}$. Y. et al. Polarized laser induced holographic surface relief gratings on polymer films. Macromolecules, v.28, n. 26, p. 8835-8839. 1995.

13 BARRETT, C. J.; NATANSOHN, A. L.; ROCHON, P. L. Mechanism of optically inscribed highefficiency diffraction gratings in azo polymer films. Journal Physical Chemistry. v.100, n. 21, p.8836-8842,1996.

14 OLIVEIRA JUNIOR, O. N.; KUMAR, J.; LI, L.; TRIPATHY S.K.; Surface-relief gratings on azobenzene-containing films. In: SEKKAT, Z.; KNOLL, W.; Photoreactive organic thin films. Califórnia: Elsevier Science, 2002. p. 429-486.

15 BALL, P. Shark skin and other solutions. Nature, v. 400, n. 5744, p. 507-508, 1999.

16 FENG, L. et al. Super-hydrophobic surfaces: from natural to artificial. Advanced Materials, v. 14, n. 24,p. 1857, 2002.

17 ZHU, L.; FENG, Y.; YE, X.; ZHOU, Z. Tuning wettability and getting superhydrophobic surface by controlling surface roughness with well-designed microstructures. Sensors and Actuators A, v.130-131, p.595-600,2006.

18 GUITIÁN, R. Evolução dos conceitos de polímero e de polimerização. Plástico moderno, v. 246, n. 246, p. 28-32, 1994.

19 PAVINATTO, F. J. Filmes de langmuir e langmuir-blodgett (lb) de azopolímeros com controle do tamanho da cadeia e posição dos cromóforos. 108 p. 2006. Dissertação (Mestrado) - Instituto de física de São Carlos, Universidade de São Paulo, São Carlos, 2006.

20 ALLINGER, N. L. Química orgânica. 2.ed. Rio de Janeiro: Ed. LTC,1976. p.610-617

21 BLODGETT, K. B. Films built by depositing successive monomolecular layers on a solid surface. Journal of the American Chemical Society, v. 57, n. 1007,p. 1007, 1935.

22 PETTY, C. Langmuir-Blodgett films. Cambridge: Cambridge University, 1996.

23 ADAMSON, A. W. Physical chemistry of surfaces. New York: Wiley \& Sons, 1976.

24 SHAW, D.J. Introduction to colloid and surface chemistry. 3.ed. London: Ed. Butterworth \& Co,1980. 
25 GARBASSI, F.; MORRA, M.; OCCHIELlO, E. Polymer surfaces from physics to technology. 3.ed. New York: Ed. Wiley, 1998.

26 YOUnG, T. An essay on the cohesion of fluids. Philosophical Transactions, v. 95, n. 1805 , p. $65-87,1805$.

27 OLIVEIRA JUNIOR, O.N.; TAYLOR, D.M.; MORGAN, H. Modelling the surface potential-area dependence of a stearic acid monolayer. Thin Solid Films, v. 210-211, v. 7678, 2002.

28 DEMCHAK, R. J.; FORT JUNIOR, T. J. Surface dipole moments of close-packed unionized monolayers at the air-water interface. Journal of Colloid and Interface Science, v. 46, n. 2,p. 191-202, 1974.

29 OLIVEIRA JUNIOR, O.N. et al.; Estimation of Group Dipole Moments from Surface Potential Measurements on Langmuir Monolayers. Journal Chemical Society, v. 85, n. 4, p. 1009-1018, 1989.

30 TAYLOR, D.M.; OLIVEIRA JUNIOR, O.N.; MORGAN, H. Models for Interpreting Surface Potential Measurements and Their Application to Phospholipid Monolayers. Journal of Colloid and Interface Science, v. 139, n.2, 508-518, 1990

31 VOGEL, V.; MOBIUS, D.; Local Surface Potentials and Electric Dipole Moments of Lipid Monolayers: Contributions of the Water/Lipid and the Lipid/Air Interfaces. Journal of Colloid and Interface Science, v. 126, n. 2, 408-420, 1988.

32 FERREIRA. M. Técnicas de caracterização para investigar interações no nível molecular em filmes de Langmuir e Langmuir-blodgett (LB). Química Nova, v. 28,n. 3, p. 502-510, 2005.

33 SKVARLA, J. Hydrophobic interaction between macroscopic and microscopic surfaces. Unification using surface thermodynamics. Advances in Colloid and Interface Science, v. 91, n. 3, p. 335-339, 2001.

34 KUMAR, J.et al.; Gradient force: the mechanism for surface relief grating formation in azobenzene functionalized polymers. Applied Physics Letters, v. 72, n.17, p.2096, 1998.

35 VISWANATHAN, N. K.et al. Surface relief structures on azo polymer films. Journal of Materials Chemistry, v. 9, n.9, p.194,1999. 
36 SILVERSTEIN, R. M.; WEBSTER, F. X. Identificação espectrométrica de compostos orgânicos. 6.ed. Rio de Janeiro: p. 429-486Ed. LTC, 2006. p.67-135.

37 CANEVAROLO JUNIOR, S. V. Técnicas de caracterização de polímeros. São Paulo: Coordenação Editorial, 2003.p.209-263.

38 SANFELICE, R.C.; OLIVEIRA JUNIOR, O.N. Confecção de filmes Langmuir Blodgett (LB) de homopolímeros e copolímeros em bloco contendo azocorantes. São Carlos: IFSC/USP. 2008. Relatório de Iniciação Científica - Processo nº 2007/55066-5.

39 DOS SANTOS JUNIOR. D. S.et al;. In situ UV-vis absorbance measurements for Langmuir films of poly[4'-[[2-(methacryloyloxy)-ethyl]ethylamino]-2-chloro-4nitroazobenzene] (HPDR13) azopolymer. Journal of Colloid and Interface Science, v. 276, n. 1, p. 138-142, 2004.

40 BRONIATOWSKI, M.; DYNAROWICZ-LATKA, P. Semifluorinated alkanes - primitive surfactants of fascinating properties. Advances in Colloid and Interface Science, v.138, n. 2, p.63-83, 2008. 